University of Rhode Island

DigitalCommons@URI

Open Access Master's Theses

1983

\title{
Oilspill Hindcast Simulation of the IXTOC 1 Gulf of Mexico Spill
}

Eric L. Anderson

University of Rhode Island

Follow this and additional works at: https://digitalcommons.uri.edu/theses

\section{Recommended Citation}

Anderson, Eric L., "Oilspill Hindcast Simulation of the IXTOC 1 Gulf of Mexico Spill" (1983). Open Access Master's Theses. Paper 1168.

https://digitalcommons.uri.edu/theses/1168

This Thesis is brought to you for free and open access by DigitalCommons@URI. It has been accepted for inclusion in Open Access Master's Theses by an authorized administrator of DigitalCommons@URI. For more information, please contact digitalcommons-group@uri.edu. 


\section{OILSPILL HINDCAST SIMULATION \\ OF THE IXTOC 1 GULF OF MEXICO SPILL}

BY

ERIC L. ANDERSON

A THESIS SUBMITTED IN PARTIAL FULF ILLMENT OF THE REQUIREMENTS FOR THE DEGREE OF

MASTER OF SCIENCE

IN

OCEAN ENGINEERING

UNIVERSITY OF RHODE ISLAND

1983 
Title Abstract

IXTOC 1 OILSPILL

SIMULATION HINDCAST 


\section{MASTER OF SCIENCE THESIS}

OF

ERIC L. ANDERSON

APPROVED :

\section{Thesis Committee}

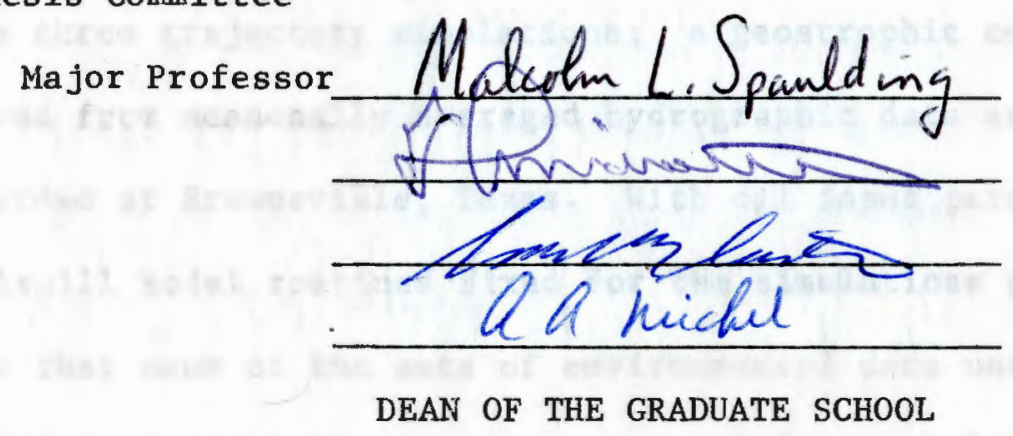

UNIVERSITY OF RHODE ISLAND

1983 
Abstract

An oil spill model developed at the University of Rhode Island was used to hindcast the Ixtoc 1 ofl well blowout using three pairs of wind and current field inputs. The sensitivity of the model trajectory predictions to these environmental inputs is discussed and comparisons made to overflight field data collected by the United States Coast Guard and National Oceanic and Atmospher1c Administration. 011 mass balance model predictions and fleld data derived mass balance estimates are compared for sea surface, water column, and atmospheric partitions. Surface oll trajectory and subsurface elevated hydrocarbon water masses are mapped using the best of the three trajectory simulations: a geostrophlc current field derived from seasonally averaged hydrographic data and a wind record recorded at Brownsville, Texas. With oil 1nput parameters and the URI Oilspill Model routines fixed for the simulations presented, it is shown that none of the sets of environmental data used have adequate scales of resolution to drive the model in a ballistic simulation and achieve trajectory estimates which match the observed trajectories of Ixtoc oil. Model mass balance estimates for ofl in several enviromental partitions fall reasonably within the bounds of field-data-derived mass balance estimates. 
Acknowledgements

I would like to express my, gratitude to Malcolm Spaulding for his steacy guidance and Inspiration, to Cynthia Anderson for her support and understanding through the many evening and weekend separations, to Messrs Isaji, Reed, and Swanson for their technical and emotional support, and to Ter1 Highling for her willing typing assistance throughout the course of the work. To Saul Salla and Randy watts, thanks for their careful reading and useful comments on the drafts, and to Dr. Grose for his willing and prompt delivery of a current field used in the simulations. 
Table of Contents

Page

Abstract...............................

Acknowledgement........................

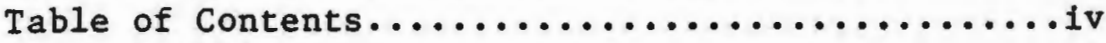

List of Tables..........................

List of Figures.......................

INTRODUCTION :

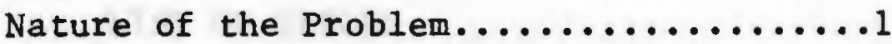

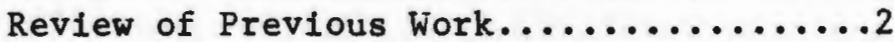

Synopsis of Hindcast Effort..........6

CHAPTER 1: DESCRIPTION OF THE IXTOC 1 SPILL

Drilling and Blowout.............8

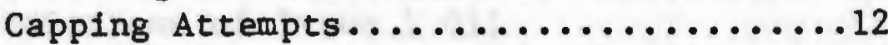

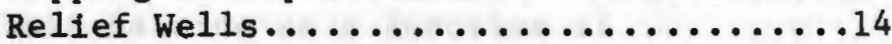

Sea Surface Recovery...............14

CHAPTER 2: URI OILSPILL FATES MODEL DESCRIPTION

Context: URI/OSFM Versus Other

Current1y Exist1ng Models............16

Major Routine Descriptions...........17

CHAPTER 3: URI/OSEM INPUT DATA DESCRIPTION

Environmental Data...............26

Spil1 Parameters..................28

CHAPTER 4: IXTOC 1 HINDCAST INPUT DATA DESCRIPTION

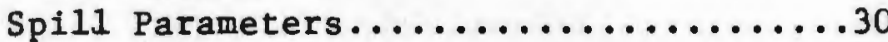

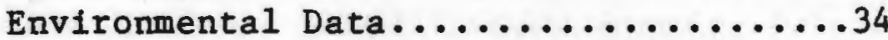

CHAPTER 5: RESULTS OF MODEL SIMULATIONS

Surface Trajectory...............73

Mass Balance Predictions...........96

ChAPTER 6: CONCLUSIONS.................111

LITERATURE CITED............................ 


\section{LIST OF TABLES}

1 Input Data for the URI/OSFM Describing

the Ixtoc 1 spill..........................

2 URI/OSFM Predictions of Ixtoc $10 i 1$

Spill Mass Balance as a Function of

Time................................

3 Estimates of Ixtoc 1 Spilled 011 Mass Balance

on September 19, 1979; Based on Observations..103 


\section{LIST OF FIGURES}

1. TIme L1ne of Ixtoc 1 Events............9

2. URI/OSFM Program Flow Chart............18

3. Ixtoc 1011 Mass Spilled vs T1me.........33

4. Ixtoc 1 Environmental Dataset Integration

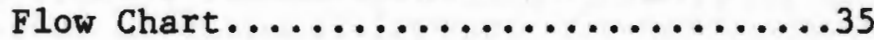

5A-D. Four Seasonal PEG Wind Fields...........38

6A-D. Four Seasonal Dynalysis Wind Fields.......44

7. Brownsville NCC Wind Data St1ck Plot.....48

8A-D. Four Seasonal PEG-Ekman Current Flelds....56

9A-D. Four Seasonal Dynalysis Current Fields....60

10A-D. Four Seasonal Geostrophic Plus Coastal

Current Fields.....................64

11A-C. 90 Day Predicted Trajectorles for Each of the Three Simulations Using Current Advection Only........75

12A-C. 90 Day Predicted Trajectories for Each of the Three Simulations Using Wind Advection Only..........78

13A-C. 90 Day Predicted Trajectorles for Each of the Three Simulations Using Wind and Current Advect1on......82

14A-H. Overlays of OSFM Trajectory Predictions with Overflight Fleld Observations of

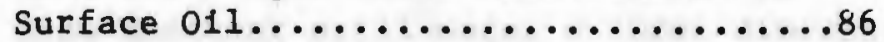

15. Ixtoc 1 Sp1lled 011 Mass Balance,

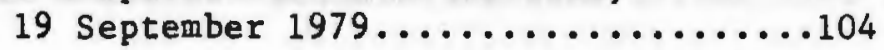

16A-E. Ixtoc 1 Surface Trajectory and $50 \mathrm{ppb}$ Subsurface Water Contour Plots.......106 
INTRODUCTION

\section{Neture of the Problem:}

An oilspill hindcast is a comparison of the results of a particular oilspill model simulation with field data collected during and after some spill event. The model simulation hindcast uses the Inception of the spill as time zero, and proceeds forward in time making predictions about the fate of the spilled oil. These model predictions are compared with field measurements of the state variables predicted by the model simulation. The hindcast shows the strengths and weaknesses of model formulation and implementation, and is a critical step in the efforts to improve our capability to. predict the fate of spilled oil in the marine environment (Stolzenbach et al., 1977; Raytheon, 1982).

Few spills have been studied extensively enough to warrant their use in hindcast studies. The URI 011spill Model (Cornillon and Spaulding, 1978a, b; Cornillon et al., 1979) has previously been used to hindcast the Argo Merchant spill using a three dimensional numerical hydrodynamic model to estimate the wind-driven flow field in the area of the spill (Spaulding et al., 1982a). The Ixtoc 1 spill was selected as the next intensive hindcast effort because it was a reasonably well studied spill; it would test the oflspill model's use in a new geographical area; and an extensive three 
dimensional numerical model for the Gulf of Mexico (Blumberg and Mellor, 1981) had recently been completed. It was hoped that the flow field generated by this hydrodynamic model would give the basis for an accurate prediction of the surface trajectory of oil from the Ixtoc 1 blowout. Application of the URI 01lspill Model to a completely new geographic area would give experience in the data collection effort needed to apply the model to new environments. The URI 01lspill Model has been used extensively in the Georges Bank Gulf of Maine region (Cornilion and Spaulding, 1978a, b; Cornilion et al., 1979; Spaulding et al., 1982a, b) and it was felt important to extend the geographic extent of its application.

In addition, the URI 0ilspill Model's capability to give mass balance estimates for atmospheric, water surface, water column (subsurface), and beached oil; and to give a prediction of the temporal and spatial extent of elevated subsurface hydrocarbon levels would contribute to the understanding of these as yet unreported simulation estimates.

\section{Review of Previous Work:}

Two previous ollspill hindcasting efforts of the Ixtoc 1 blowout have been reported. Grose, et al (1982) at the Environmental Data and Information Service (EDIS), National Oceanic and Atmospheric Administration (NOAA) reported on a surface trajectory hindcast of the Ixtoc 1 spill as part of the verification of the environmental 
variable fields (wind and current) for a regional strategic assessment model of chronic hydrocarbon input into the Gulf of Mexico area. The model implemented uses a "transport matrix," which is a statistical representation of the probability of transport of sea surface ofl from one cell of the model grid to any other within each time step of the simulation. Monthly transport matrices were developed based on climatological estimates of mean monthly wind roses (eight directions) and seasonally-hydrographic-forced current estimates. The reported hindcast of the Ixtoc 1 spill gives good agreement with the observed limits and sea surface concentrations of Ixtoc 1 ofl for July of 1979 (two months after the start of the spill), concentrating the oil in the Southwestern Gulf area within a rough triangle formed by the southwestern Gulf coast and a line drawn from Brownsville, Texas south and east to the intersection of the Mexican coastline with the 92 longitude (W) meridian (Grose et al., 1982). Grose has kindly supplied the current field used for the EDIS model for this study.

Galt (1981) headed the most intensive of the modeling efforts concurrent with the spill. Sources of information on the current field in the western Gulf of Mexico cited by Galt include: Nowlin and McLellan (1972), dynamic topography; Bureau of Land Management (BLM) studies of the offshore Texas region, including the results of a number of current studies that used drift cards and current meters as well as hydrographic data; current studies and numerical modeling work done at NOAA/Atlantic Oceanographic and Meteorological 
Laboratory (AOML); a paper by W. Sturges and J. P. Blaha (1976), bypothesizing that the strength of the Mexican Coastal Current is related to the large-scale curl of the wind stress over the Gulf of Mexico (see Discussion section under Chapter 4, Currents); and a Master's thesis by A. M. V. de la Cerda (1975). De la Cerda derived surfaces of constant thermosteric anomaly (Montgomery, 1954; Montgomery and Wooster, 1954) using a number of hydrographic data sets in the southwestern area of the Gulf, giving crucial information on the Campeche gyre and other permanent and non-permanent cyclonic and anticyclonic features of the region.

Because of the massive amounts of oil released from the blowout and the possibility of Impacts on United States waters, considerable field observational resources were made available to the modeling group. GOES, TIROS, and ERTS satellite imagery were compared with model predictions of surface extent of oil transport within the first few weeks of the spill. Lower altitude aircraft overflights began on 3 July (Galt, 1981), leading to further flights by the State of Texas, Department of Transportation, the U. S. Coast Guard, and the National Atmospheric and Space Administration (NASA).

Surface ship data collection to quantify the strength and extent of the Mexican Coastal Current began in mid-July (Galt, 1981). A number of cross-shelf expendable bathythermograph (XBT) transects were carried out which delineated the axis of the Mexican Coastal Current and a smaller cyclonic feature off Tampico, Mexico. To define local small scale current features, helicopter-deployed 
Richardson current probes and radio frequency drogues and satellite-tracked drogues were deployed (Galt, 1981).

All of these field data were used to calibrate a two-component current modeling system consisting of a regional geometry first order geostrophic plus Ekman dynamics solution superposed with a streamline analysis (Galt, 1980) generating a mass-conserving flow field (Galt, 1981). The combination of the intensive collection of field data and multiple model simulations represents the work of a large group of investigators and support personnel with a considerable operational budget .

It is not reasonable to expect, given the inputs to the Galt (1981) modeling effort, that a better job of trajectory modeling on the Ixtoc 1 spill will be done in the foreseeable future. The discussion of the Grose et al (1982) and the Galt (1981) papers shows something of the diversity of approach and levels of resource expenditure that may be represented under the label of an "oilspill modeling study." In particular, it should be emphasized that the Grose et al model is a climatological, ballistic trajectory model, while the Galt modeling effort included near-real-time data updating feedback and time-specific environmental data input. In a ballistic model projection no updating procedure corrects model predictions during the course of the simulation using information external to the model input parameters. Ballistic modeling approximations with climatologically derived environmental data input can result in useful predictions over the short term to the extent that variations 
In oceanographic and atmospheric energy inputs are dominated by slowly evolving processes of annual repeatability. Errors of prediction are cumulative in a modeling system, and without some feedback of updated information, any ballistic projection is likely to suffer an increasing propagation of error as a simulation progresses.

\section{3ynopsis of Hindcast Effort:}

Three major elements make up an oilspill simulation effort: a) the definition of the oll spill parameters such as fractionation and spill rate; b) the underlying physics and numerical implementation describing the fate and distribution of the oil (oilspill model); and c) the source and methodology for specifying the environmental driving forces for the model simulation. The major question to be asked is: "Which among these three sets of elements is limiting in the prediction?" The work described here focuses on the use of existing environmental data inputs for the Ixtoc hindcast simulation. Two relatively simplistic environmental wind and current datasets are contrasted with a reasonably advanced "state-of-the-art" three-ditiensional time-dependent hydrodynamic model as inputs for hindcasting of the Ixtoc spill. The one set of wind and current information which most closely matches the observed trajectories and shoreline beaching of Ixtoc oil is subsequently used to give oil mass balance estimates for environmental partitions. In addition to the 
major emphasis on comparison of different environmental inputs, some observations on the relative strengths and weaknesses of model formulation are made. 
CHAPTER 1

The Ixtoc 1 Spill, Description.

Drilling and Blowout:

Figure 1 gives an overview of the Ixtoc 1 spill with events pertinent to the discussion below. Drilling on the IXTOC 1 , located approximately $80 \mathrm{~km} \mathrm{NNW}$ of Ciudad del Carmen (19 $24 \mathrm{~N}$; $9219 \mathrm{~W}$ ) in the Bahia de Campeche, began shortly after 1 December 1978, (0il Spill Intelligence Report (OSIR), 1980a). Geophysical studies in the area, the Southwest Gulf of Mexico had indicated large hydrocarbon reserves. Petroleos Mexicanos (PEMEX), Mexico's largest enterprise and largest employer, controlled the active drilling in the 8000 square kilometer area, and had plans in 1979 to complete the installation of ten stationary drilling platforms, six production platforms, and one connecting platform. On 3 June at 0330 the well had an uncontrolled oil and gas blowout. The SEDCO 135 semi-submersible platform, under contract to Perforaciones Marinas del Golfo S.A. of Mexico City and leased to PEMEX, was drilling in about 50 meters of water. This was the first well drilled into this particular geological structure. Drilling had been completed down to the top of a suspected productive stratum at about 3500 meters. Production well casing was extended and cemented at that depth, and the well extended another $30 \mathrm{~m}$ when drilling fluid circulation was completely lost. Drilling fluid is pumped down the center of the 
figure 1 (1)

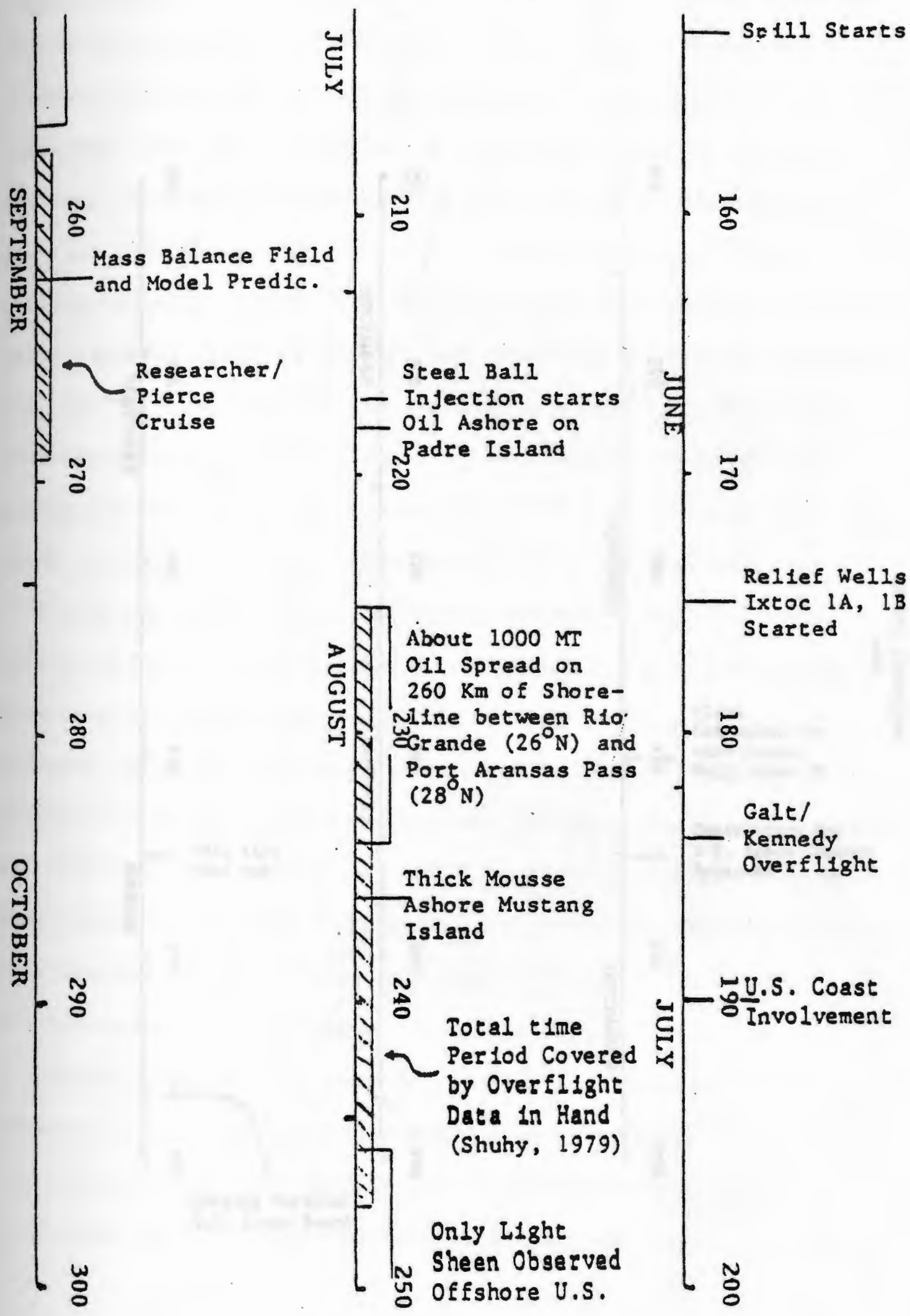




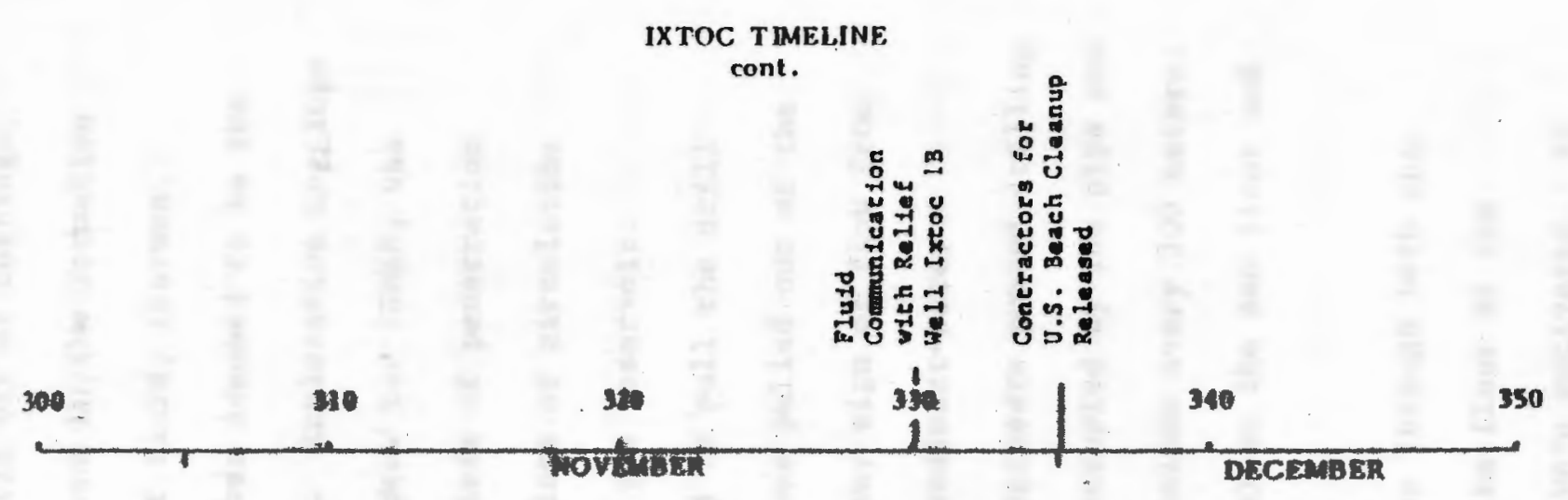

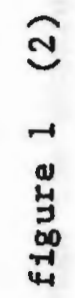

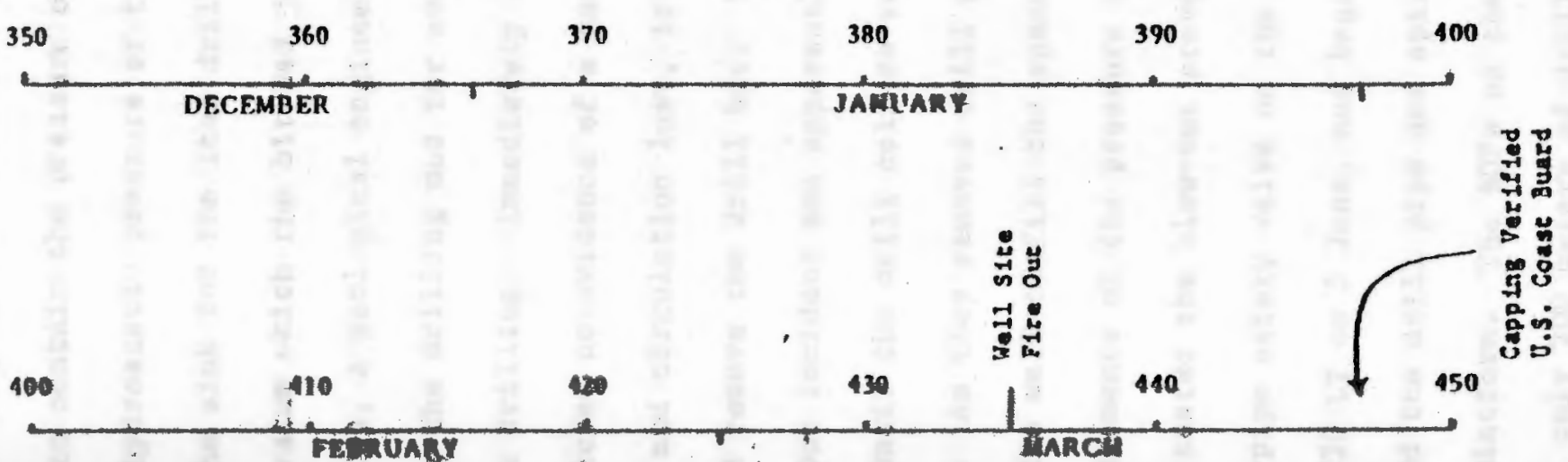


dr111 string, returning through the annulus formed by the outside of the drill string and the rock and/or well casing which forms the conduit for eventual ofl and gas production. The mud serves two purposes: one, to lubricate and clean the drill bit of cuttings; and two, to contain the pressure of hydrocarbons in the formation with the hydrostatic pressure of the column of fluid, (Garmon, 1980).] The sink for the lost drilling fluid was assumed to be the porous stratum which the bit had just entered. Exploration Loggings S.A. (EXLOG), a geological engineering contractor for PEMEX, was monitoring the drilling mud for every five meters of penetration during the drilling. Immediately before the loss of circulation EXIOG detected no evidence of a nearby ofl or gas reservoir. With mud c1rculation lost, it was decided to pull the drill string and remove the drill bit. The string was pulled out of the hole without incident and apparently without any sign of flow from the well unt1l the drill collars reached the sediment-water interface. As they removed drill pipe, the engineers pumped drilling mud into the well to fill the space formerly occupied by the pipe and took measurements of the pressure in the mud column every 300 meters. They also tested the blow-out preventers (BOPs) on the sea floor and the drill-pipe safety valve on the platform.

At 0230 LT on 3 June, mud began flowing up through both the annulus and the drill pipe and spilling onto the floor of the drilling platform. The BOPs on the sea floor were activated. At this time, only 200 meters of drill pipe remained in the well, and 
the pipe section with the drill collars was at the level of the BOP stack. The drill collars support the bit, and are of smaller diameter and heavier wall thickness than the rest of the drill pipe. Three mechanisms for flow stoppage existed in the BOP, the first two of which were not effective because they were designed to be actuated with the smaller diameter, thinner walled drill pipe in the BOP stack. The first, pipe rams, could not seal on the large diameter, and the second, shear rams, could not shear the drill collars. The third hydraulically operated annular BCP successfully sealed the annulus, but could do nothing to stop the flow through the drill string because of jammed threads on a safety valve adapter above the drilling floor. Oil and gas began to gush from the drill pipe to a helght of 30 meters above the drilling platform floor and ignited upon contact with operating pump motors. All PEMEX, SEDCO, and PERMARGO personnel abandoned the rig in lifeboats. No significant Injuries resulted, but the resulting fire melted the drilling tower and destroyed most of the equipment and machinery on the SEDCO 135 . An official report by Oscar F. Sanche, the Attorney General of Mexico, concluded that no act or omission by drilling crews caused the blow-out.

\section{Capping Attempts:}

An unsuccessful capping attempt was made on 24 June, when the well casing reportedly burst after the $B C P$ was closed at the sea floor. The well fire was reported to be brighter and the spill rate 
greater after the capping attempt. PEMEX attempted to slow the flow of oil at the well head on 5 August by injecting a mixture of barite and cement, along with a daily amount of up to 8000 steel and lead balls weighing approximately $1.6 \mathrm{~kg}$ each. By early August, 30,000 balls had reportedly been injected, and while many of the balls were expelled from the wellhead through the BOP stack, many remained suspended in the fluid column. PEMEX estimated the flow to have been decreased from 30,000 barrels per day to 15,000 . PEMEX reportedly had injected more than 100,000 balls by mid-August, reducing the flow to approximately 10,000 barrels. Continued injection of balls through mid-November resulted in a PEMEX flow estimate of 4,000 barrels per day. U.S. observers disputed this estimate. Jerome M1lgram of the Massachusetts Institute of Technology visited the well site in October and estimated as much as 50,000 barrels per day may have been spilling.

PEMEX contracted Brown and Root, Inc. of Houston to construct an Inverted steel cone six meters high and twelve meters in diameter at the base designed to be lowered over the wellhead and divert the flow of oil through a 30-inch pipe to a drilling platform. The 310 metric ton (112 MT submerged) cone, nicknamed "Sombrero," was designed to handle up to 30,000 barrels per day. After one aborted attempt at Installation in mid-September, the Sombrero was centered over the BOP stack on 15 October, but falled to operate successfully. Rough seas hampered the maintenance of a pipeline connection to barges and the oll/water ratio was too low for effective extraction of the oil. 
Also, much of the escaping oil was not contained by the Sombrero. Gas conveyed to the surface was flared, and dispersants were injected into the Sombrero piping system before the oil-water mixture was returned to the Bahia de Campeche. A PEMEX attempt in November to establish a subsea pipeline between the Sombrero and an onshore refinery was unsuccessful (OSIR, 1980a).

\section{Rellef Wells}

In mid-June PEMEX began drilling IXTOC $1 \mathrm{~A}$ and IXTOC 1B, both directional relief wells. Fluid communication between the IXTOC IB and the IXTOC 1 wells was established in late November, but capping was not successful until 27 March 1980 .

\section{Sea Surface 011 Recovery}

Equipment from several manufacturers was exercised at the spill area, and at different times throughout the clean up operations was hindered by: 1) breakdown or improper deployment, 2) shifting plume trajectory, 3) oil sucked into working vessels' cooling systems, 4) suspension of activities for the safety of diving operations, 5) high winds and seas, and 6) low oil/water recovery ratios (OSIR, 1980a). PEMEX sald on 2 October that it had recovered 6 million gallons of an estimated 103 million gallons of spilled oil.

Spi11 cleanup contractors reported to 011 Spil1 Intelligence Report (OSIR, 1980a) personnel that PEMEX did not supply sufficient support equipment, did not purchase or borrow enough cleanup 
equipment, and did not permit the contractors to deploy the equipment in optimal fashion. None of the recovery systems deployed at the well site recovered wore than $14 \%$ of the emulsion intercepted by the booms deployed around each system, according to an estimate by Research Consultants, Inc. of Framingham, Massachusetts (ibid). 
CHAPTER 2

URI 011 Spill Fates Model Description

\section{ext: URI O11spill Model versus other}

\section{rrently Existing Models:}

The URI O1lspill Model (Cornillon and Spaulding 1978a, b, Cornillon et al., 1979) is one of the most advanced of the oilspill models now in use. It is notable for its modular construction and high level of within-code documentation. Particular attention has been pald to the bookkeeping tasks of dimensional units, variations in the grid spacing and angles of inclination, and usable printed, plotted, and machine-readable simulation output.

Huang and Monastero (1982) in their Review of the State-of-the-Art of 011 Spill Simulation Models state that "the URI/Georges Bank model is 1deally suited for environmental impact assessment purposes." The background work for the Huang and Monastero report appears to have been reasonably exhaust1ve, with more than one thousand references complled initially through computer literature searches and consultations with recognized experts in the oll spill modeling field. Thirty-five models were complled from this reference base, representing all those models developed expressly for use in oil spill simulation. The interested reader is referred to this report for further model comparisons on an 
algortthm-by-algorithm basis.

\section{lor Routine Descriptions:}

The URI/OSFM formulation and development have been presented and documented adequately elsewhere (Cornillon and Spaulding, 1978; Corntlion et al., 1979; Reed et al., 1979; Reed, 1980). A brief description of the major routines follows.

Figure 2 gives a schematic overview of the model logic. In operation, the model first initializes the bathymetry and land data, then for each time step inputs the environmental information (wind, current, and temperature fields) that are to be updated, and the spill descriptive data (spill volume, location, time of inception, density, interfacial tension, kinematic viscosity, total mass, and mass fraction in each of eight fractions). The oil mass input into the model system is treated as a series of discrete sub-spills, or spillets. Virtually all of the processes'within the model treat each of the spillets individually for each time step. For each of the steps, a spatial average of the wind, current, and temperature fields Is computed over the area of the spillet, and the surface routines are implemented: spreading across the water surface by a balance of gravity, viscous, and surface tension forces; evaporation into the air column; advection across the water surface by wind and currents; and entrainment into the water column. Once the surface routines are completed the subsurface routines then diffuse and advect the 


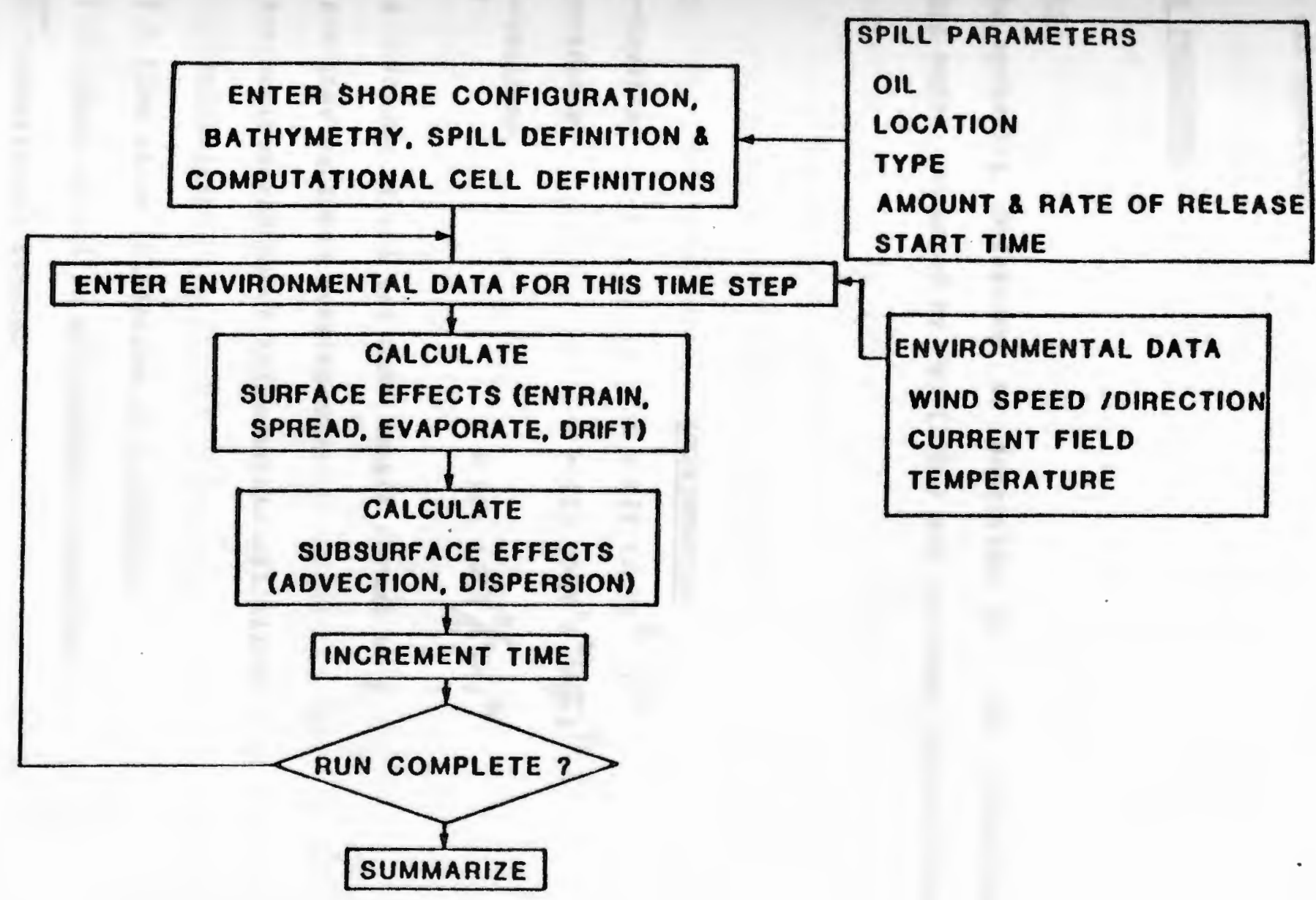


ontrained oil within the water column. Following are descriptions of each of the algorithms describing the surface and subsurface behavior of the oil spillets.

\section{GURFACE PROCESSES}

Spreading

The spreading mechanism is described by the three-regime spreading model proposed by Fay (1971) and is shown in the following table.

\section{Stage}

Gravity-inertia

Gravity-viscous

Surface-tension-

Viscous
Axisymmetric

$$
\begin{aligned}
& r=K 21\left(\Delta g t^{2}\right)^{1 / 4} \\
& r=K 2 v\left(\Delta g v^{2} t^{3 / 2} / \sqrt{\mu}\right)^{1 / 6} \\
& r=K 2 t\left(\sigma^{2} t^{3 / 2} / \rho^{2}\right)^{1 / 4}
\end{aligned}
$$

$A$ - Volume of oil per unit length normal to $Z$

g - gravitational acceleration

r - maximum radius of axisymmetric oil slick solubility

t - time since initiation of spreading

V - volume of oil in axisymetric spreading

$\sigma$ - interfacial tension

$\mathcal{N}$ - kinematic viscosity of water 


$$
\begin{aligned}
& \rho \text { - density of water } \\
& \Delta-\rho \text { water } \rho \text { o1 } 1 / p \text { water } \\
& \mathrm{K} 21=1.14 \\
& \mathrm{~K} 2 \mathrm{v}=1.45 \\
& \mathrm{~K} 2 \mathrm{t}=2.30
\end{aligned}
$$

\section{Evsporation}

The evaporation algorithm follows Yang and Wang (1976). The o11 is described by eight fractions:

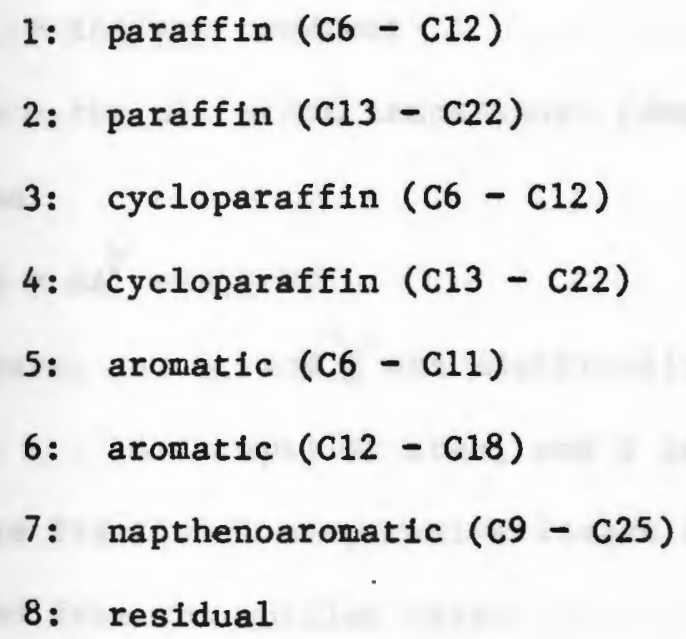

At each time step, the mass of each spillet is separated into its present eight mass fractions and the evaporation from each of these fractions is computed according to:

$$
\frac{d \bar{C}_{i}}{d t}=-\hat{D}_{i e} \overline{C_{i}}
$$

where:

$$
\bar{c}_{i}=\text { average value of the percent weight of fraction } 1 \text { over }
$$


the slick thickness.

$D_{i e}=$ average value of the evaporation diffusion coefficient over the slick thickness.

$$
D_{i p}=\mathrm{km} \frac{\left(P_{i}-P_{\infty}\right)}{R T S}
$$

where:

PI = hydrocarbon vapor pressure of fraction 1 at the interface.

$P_{\infty}=$ hydrocarbon vapor pressure of fraction 1 at infinite altitude.

$R=$ the gas constant

$T s=$ the ofl slick temperature [degrees absolute]

and

$\mathrm{Km}=2 \mathrm{~A}^{\gamma} \exp (\mathrm{q} U)$

where: $a, q$, and $\gamma$ are empirically derived constants

$A$ is spillet area, and $U$ is windspeed

These fractional evaporative losses are then summed and subtracted from the spillet mass.

\section{Drface Advection:}

The movement of the spillet is determined by the vector sum of the surface water movement and a percentage of the wind speed. The Wnd-driven response of surface oll has been a consistent feature of ollsp1ll models to date (Huang and Monastero, 1982), and is one of the modeled properties open to interpretation. A drift factor of 
$1.1 \%$ of the observed wind for the surface slick over the surface water was reported from observations during the Argo Merchant spill (Grose and Mattson, 1977). Because many of the o1lspill models eplemented thus far have not included in their formulation a echodology for estimating wind-driven surface currents, there has evolved a so-called " $3 \%$ rule" (Huang and Monastero, 1982). This apirically derived "rule" has the surface advection of the spill defined by around $3 \%$ of the over-water wind velocity, with a deflection of between 0 and fifteen degrees clockwise, in some models, to account for Coriolis deflection. See further discussion of the wind-driven component of advection under Chapter 3 , Invironmental Data. The simulations reported here used no deflection angle.

\section{Entrainment:}

On a spillet-by-spillet basis, the mean current, wind, and temperature are averaged across the spillet. The mass to be entrained into the water column is calculated with a methodology derived in accord with a vertical transport of momentum argument by Reynolds analogy to the transport of suspended material (Audunson, 1979). Audunson's formulation:

$$
\lambda_{n}=\lambda_{c}\left(\frac{U}{U_{c}}\right)^{2}
$$

where:

$$
\mathrm{Uo}_{0}=8.5 \mathrm{~m} / \mathrm{sec}
$$




$$
\begin{aligned}
& U=\text { observed wind speed } \\
& \lambda_{0}=0.1 \text { (empirically derived constant) }
\end{aligned}
$$

has been modified in three ways. First, a exponential decay with a folding time of one day has been added to address the expected decrease in entrainment of oil as it weathers, or changes in chemical and physical properties when exposed to the external environment (Huang and Monestero, 1982). Second, a maximum value for U of 12 $\mathrm{m} / \mathrm{sec}$ has been set, beyond which no further entrainment is generated. This value was estimated from standard deepwater-wave forecasting tables for unlimited fetch, fully developed sea (Ippen, 1966) and also from an estimate of the approaching maximum of the probability distribution of breaking wave heights (Nath and Ramsey, 1976). Third, a minimum wind velocity for entrainment is set at $5 \mathrm{~m} / \mathrm{sec}$ (Nath and Ramsey, 1976). Breaking waves are assumed to be the major mechanism responible for ofl entrainment, and breaking waves do not occur below the $5 \mathrm{~m} / \mathrm{sec}$ wind speed threshold. The modified formulation is defined as:

$$
H_{e}=\left[M_{s} A_{0}\left(\frac{U}{U_{0}}\right)^{2}\right] \exp (T / 1)
$$

where:

$$
\begin{aligned}
& \text { Me }=\text { mass of oil entrained from spillet / day } \\
& \text { Ms }=\text { mass contained in spillet } \\
& \text { AO }=0.1 \\
& \text { VO }=8.5 \mathrm{~m} / \mathrm{sec}
\end{aligned}
$$




$$
T=\text { age in days of spillet }
$$

and

$$
\begin{aligned}
& \text { if } U<5=>U=0 \\
& \text { if } U>12=>U=12
\end{aligned}
$$

The mass of oil $\mathrm{Me}^{\prime}$ is partitioned into $\mathrm{n}$ particles according to a user-set mass-per-particle parameter, and each of these particles is injected into the water column by a uniform spatial random scheme across the spillet-water interface.

\section{SUBSURFACE PROCESSES}

The subsurface subroutine calls the seven main subroutines which advect and diffuse the subsurface droplets in the water column. The method is based on the Water-Advective-Particle-In-Cell method developed by Pavish (1977). A brief overview of the numerical scheme, along with a discussion of those factors which have been modifled specifically for this application, is presented below.

The three-dimensional mass transport equation is solved using a particle-1n-cell method. The volume which these "marker" particles occupy is then divided into a number of rectangular cells. The concentration distribution of the particles is determined by calculating the number of particles in each cell, yielding an effective concentration positioned at the center of that cell. The model then obtains the concentration gradient within this field and calculates the resulting diffusive velocity, which 1 t adds to the advective velocity input to the program, to obtain the total particle 
velocity. Finally, the particle velocity is used to move the individual particles for the time step in execution.

The fundamental equation being solved is the transport diffusion

equation:

where:

$$
\begin{aligned}
& \frac{\partial C}{d t}=\stackrel{D}{\longrightarrow} \cdot\left(\overrightarrow{\omega_{T}}\right)=C \\
& \overrightarrow{U_{T}}=\overrightarrow{U_{A}}+\overrightarrow{U_{D}}
\end{aligned}
$$

$$
\begin{aligned}
& \frac{U_{T}}{U_{A}} \text { - Total particle velocity } \\
& \widehat{U}^{- \text {Adective velocity }}
\end{aligned}
$$

and

$$
\begin{aligned}
& \vec{U}_{0}-\text { Diffusion velocity, defined by: } \\
& \left.\vec{U}_{0}=-\left(K_{i j}\right) C\right) \vec{C}
\end{aligned}
$$

The total particle velocity is solved using a finite difference representation on a space-staggered grid.

An 1mportant feature of the subsurface portion of the model is the mixed Eulerian-Lagrangian coordinate system. Currents, bathymetry, and computational cells are defined on the Eulerian coordinate system. 011 droplet concentration is defined on the Lagrangian system. The Lagrangian system expands and translates, always including all particles. Variables defined on the Eulerian system are interpolated to the Lagrangian system. 


\section{CHAPTER 3}

URI/OSFM Input Data Description

\section{ENVIRONMENTAL DATA}

The quality of environmental data, especially the wind and current flelds, is of critical importance to successful simulation. Optimally, one would have error-free real time sampled wind and current data from the spill site and affected advection areas. Such data is not avallable, nor can we expect it to be in the future. The modeller is presented with several forms of 1nadequately described wind and current fields and must make some determination about which combination is the most reasonable to use.

\section{Environmental Parameters:}

Winds:

A continuum of complexity of wind field data exists for use in oil spill simulation. Examples from this continuum include: single station land site weather station data (National Climatic Center); a few long-term fixed-position continental shelf buoys;

pressure-inferred two-dimensional wind fields computed on coarse three degree latitude-longitude grids on a world-wide basis and much smaller grids for special areas by the Fleet Numerical Weather Center (FNWC) In Monterey, California; and full three-dimensional 
wind-field models including topographic effects and surface boundary layer formulations. Sophisticated analyses at offshore wind fields are currently under development for certain areas (Mooers, 1978; Weisberg and Pietrafesa, 1983). At present, however, no estimates are generally available which are directed at obtaining fine-mesh wind fields for high-risk oilspill areas.

\section{Currents:}

A similar continuum of complexity exists for current estimation. Data collection efforts along the continental shelf regions of the continental United States which focus on high-risk oilspill areas are becoming commonplace. These efforts are funded by the U.S. Minerals Management Service in support of offshore oil lease sale environmental impact studies. These data collection efforts suffer relative to their atmospheric analogs from few data stations at irregular sampling intervals. On the U.S: East Coast, historical drifter studies (Bumpus and Lauzier, 1965) have served to give overviews of the general patterns of continental shelf flow. First-order geostrophic models with dynamic topographic surfaces inferred from many years' hydrographic data (e.g. the U3 dataset introduced below) give pictures of the seasonally stable flow fields which exist over continental shelf areas. More ambitious three-dimensional time-dependent hydrodynamic models incorporating wind, tidal, and density forcing, with various numerical solutions 
and boundary condition specifications, are now in the development stage (Blumberg and Mellor, 1981). An Important advantage to these more aphisticated modeling approaches is that the wind, tidal, and density forcing functions are coupled explicitly within the model. When modeled currents used as environmental input for oilspill models are not coupled within the specification of the hydrodynamics model, arguments of superposition must be used in suming the numerical estimation of a wind-driven flow field with a separate estimate of a density-driven flow field (see discussion on current field U3, below).

\section{Spill Parameters:}

0i1 Fractionation:

When ofl is released into the environment, weathering processes begin to change its composition (Overton, 1981). Processes included in this weathering include evaporation, dissolution, emulsification, absorption onto suspended sediments and detritus, photochemical oxidation, and microbial degradation. These weathering processes alter the physical and chemical properties of the oil, transforming it into several distinctly different types of petroleum residues. An oilspill model must address this weathering process through some partitioning of the spilled oil into physically and chemically different sub-classes. The approach taken in the URI Model is based 
on gross molecular welght and hydrocarbon species classification (see Table 1). Spectral absorbtion analyses can give much more detalled information about the relative abundances of specfic compounds and compound amalgams (Boehm et al., 1982; Gundlach et al., 1983) which are of particular use in "fingerprinting" particular oil mixtures. The simple eight-class approach employed here matches the levels of complexity of the physical and chemical changes needed to describe the dovironmental partitioning of the spilled ofl mass.

\section{0il Spill Rate:}

Estimation of the rate at which oil is released into the marine environment from a well blowout hinges on instantaneous oil volume estimates derived from sea-surface ofl area and thickness estimates. Spatial extents are measured in the hundreds of thousands of square kilometers across the ocean surface and hundreds of meters in the water column. The hydrocarbons present on the sea surface may be from on the order of a few molecules to tens of centimeters thick, will assume irregular patterns, and often will undergo some dynamic subsurface entrainment as droplets which are entrained are displaced upwaru to the surface. Phytoplankton blooms and cloud shadows can be wislaken for oil slicks (OSIR, 1983), further confounding the estimation procedure. 
CHAPTER 4

Ixtoc 1 Hindcast

Input Data Description

Table 1 summarizes the input data for the simulations discussed below.

Sp111 Paramaters:

Oil Volume Input:

Figure 3 summarizes the spill rate estimation used in the simulations reported. Estimation of the spill rate of ofl from a well blowout is difficult. Following a best approximation procedure employed previously (Spaulding et al., 1982), volume flux estimates have been generated from a review of the 11terature, and are presented in Figure 3. Estimates of the volume flux of o1l are based upon the area covered and slick thickness. Initial rates were estimated at from 0.42 to 2.94 million gallons per day (1400 to 9800 metric tons per day) (OSIR, 1979, 80a-f). On August 5 1979, PEMEX began injecting steel balls into the well to restrict the flow of the oil (U.S. Dept. of Transportation, 1980). In late November fluid communication was established between the rellef well Ixtoc $1 \mathrm{~B}$ and the blowout well, but escaping ofl was not completely stopped until 11 March. From spill inception until 11 March 1980, when the well site fire was extinguished, five percent of the spilled oil has been assumed to be burned. A comparison of the total spilled volume 
INPUT DATA FOR THE URI/OSEM OESCRIBING THE IXTOC I SPILL

SPILE LOCATION:

THERMOCLINE DEPTH:

TEMPERATURE :

WIND (1)

WIND (2)

WIED (3)

GURRENT ( I)

CURRENT (2)

CURRENT ( 3 )

SURFACE OIL ADVECTION

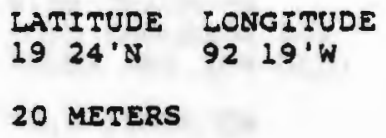

GROSE (MOAA/EDIS) GEOSTROPHIC AND COASTAL CURRENTS

WIND \& CURRENT - (1)

VECTOR SUM OF PREDICTED

SURFACE VELOCITIES PLUS 18

WINDSPEED DCWNWIND

WIND \& CURRENT (2)

VECTOR SUM OF EYDRODYNAMIC MODEL PREDICTED SURFACE CURRENTS RLUS It WINDSREED DOWNWIND

WIND \& CURRENT (3) VECTOR SUM OF GEOSTROPHIC COASTAL CURRENT FIELD PLUS 3.58 WINDSPEED DOWNWIND

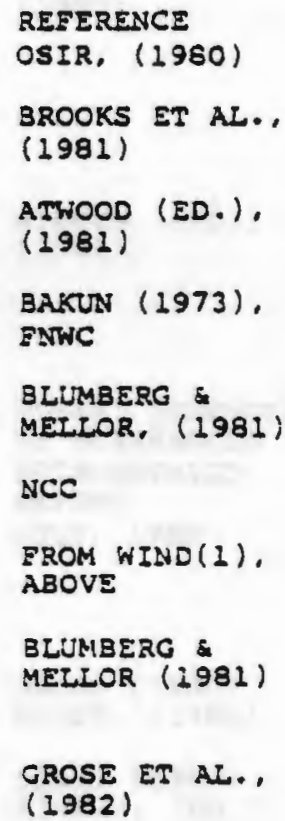

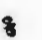




\section{table 1 (b)}

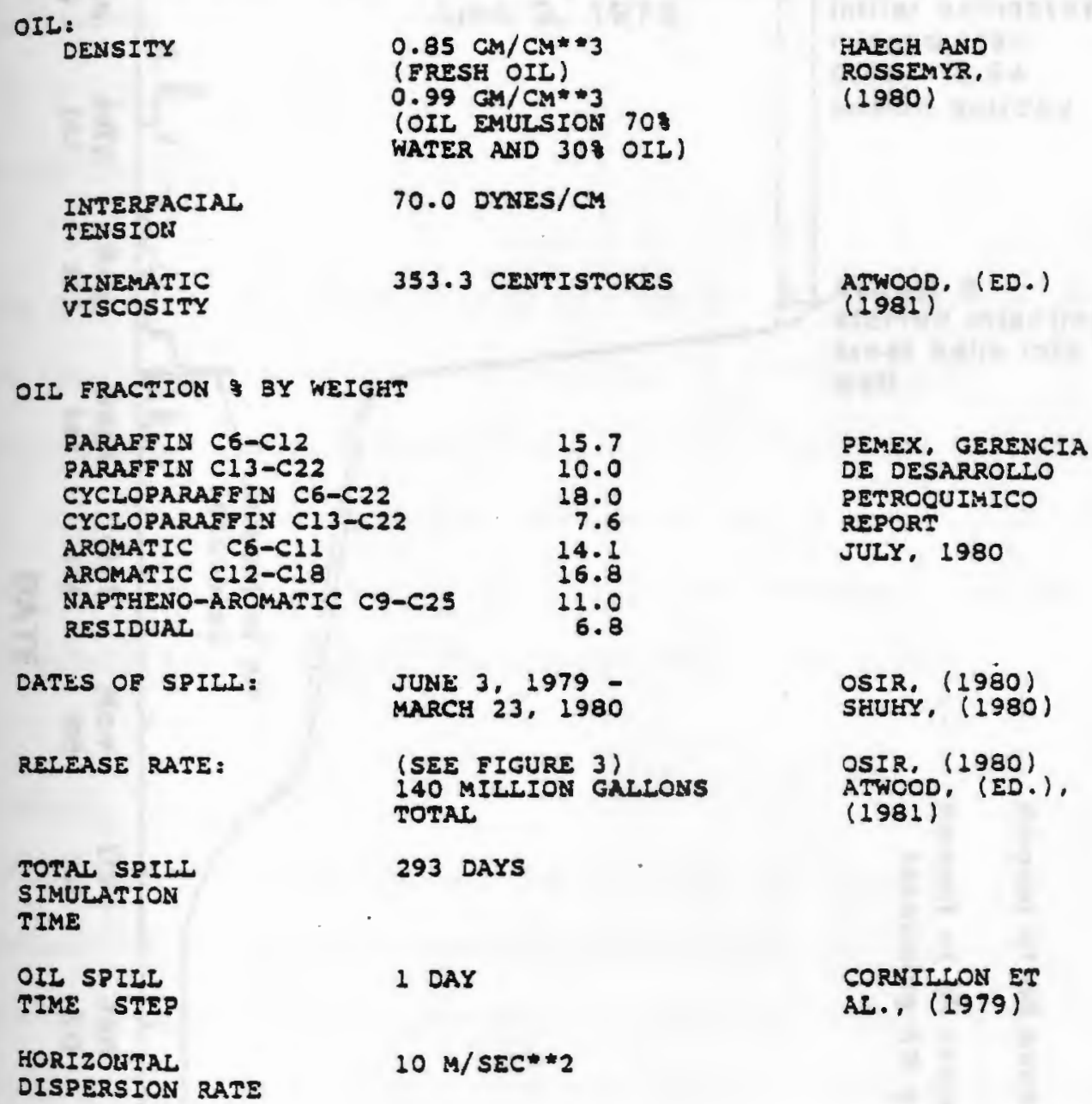




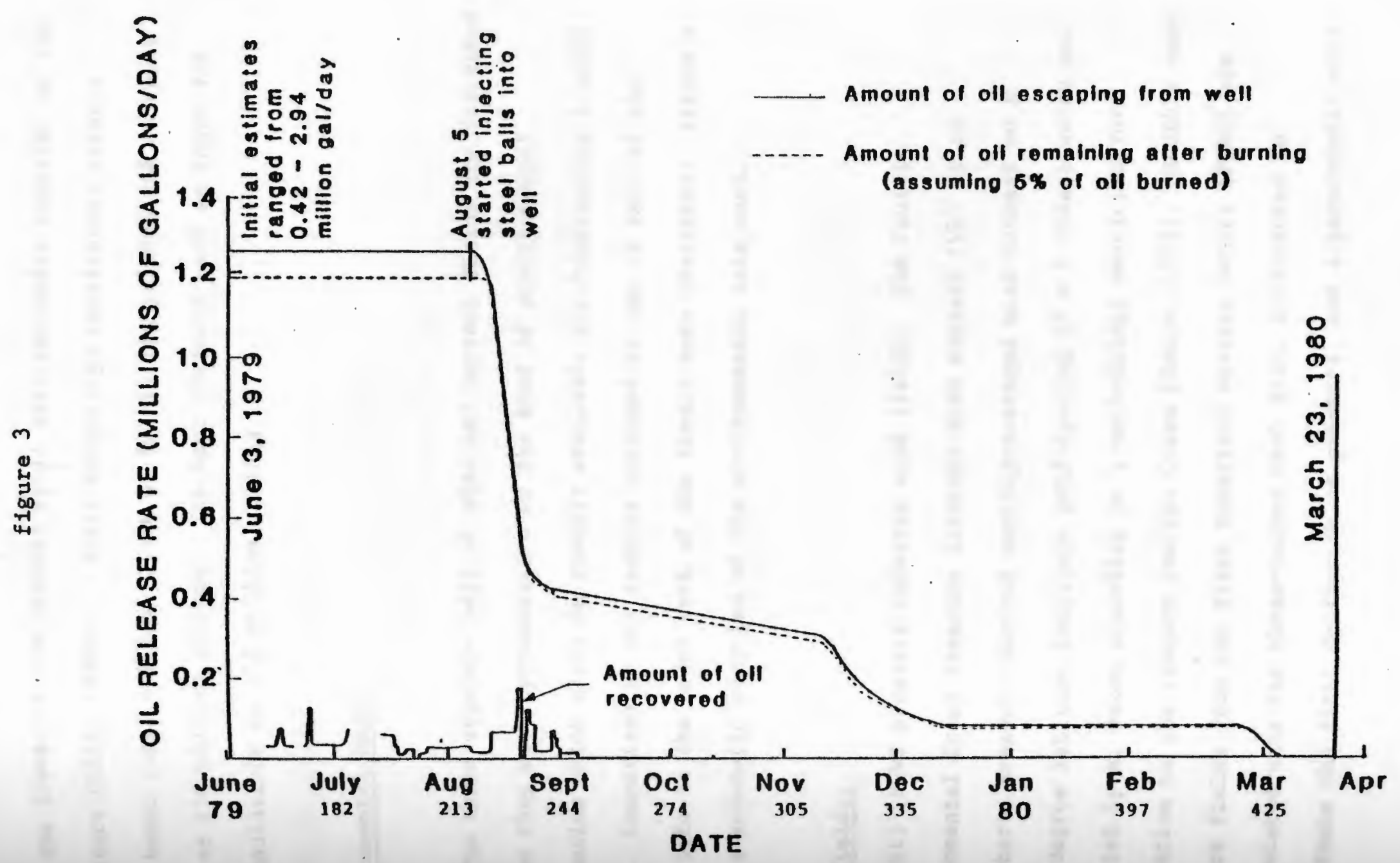

m 
using the lowest vs the highest spill rate estimates reported in the literature (OSIR, 1980a-f; Spill Technology Newsletter) gives a lower bound total spilled volume of 80 million gallons and an upper bound of 430 million gallons. The best estimate used as input for the imulations is 140 million gallons.

\section{Environmental Data:}

The three separate sets of wind and current fields are described because they are representative of the kind of environmental information which might be readily available for hindcasting a spill event. Comparison of the results obtained by use of each of the three sets is the major work of the thesis here presented. Figure 4 gives a schematic overview of the environmental data used.

\section{Wind Fields:}

(W1) (FNWC pressure-inferred wind field): The Pacific Environmental Group pressure inferred wind dataset (WI) is an atmospheric pressure-derived monthly-averaged wind dataset on a three-degree latitude longitude grid spacing ( 7 x 5 nodes) which was generated by A. Bakun according to a methodology developed for application to the eastern Pacific Ocean (Bakun, 1973). Monthly mean pressure fields from the Fleet Numerical Weather Center (FNWC) are interpolated onto the three-degree wesh grid, differenced to approximate the first derivative of pressure, and a geostrophic wind 


\section{figure 4 (1)}

Envirommental Dataset Preparation overview

Hind and Cuzzent set One:

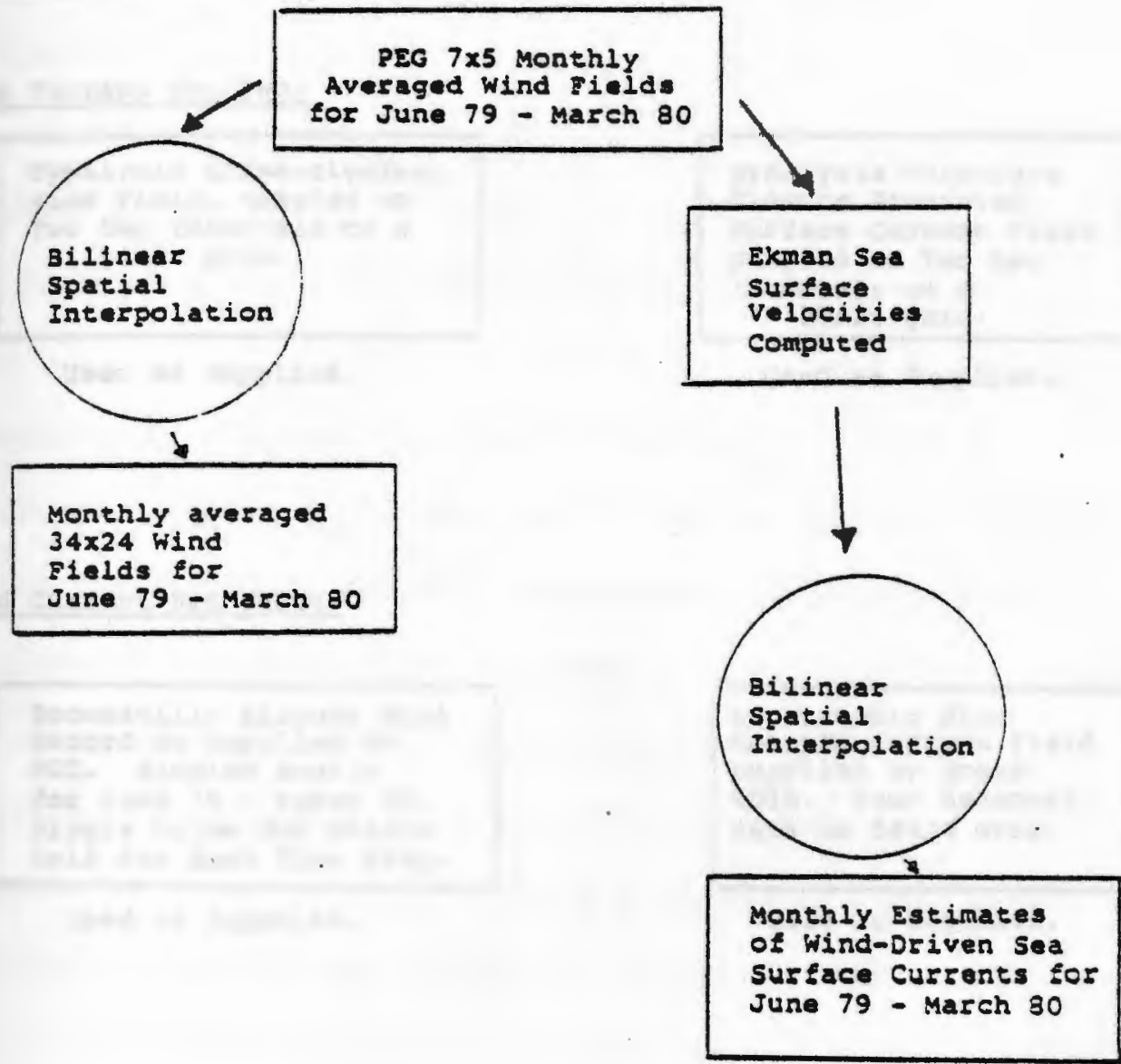


Wind and Curzent Set Two:

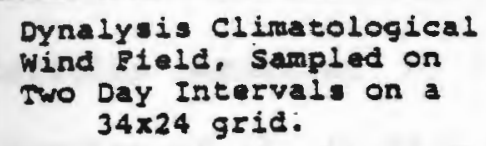

used as supplied.
Dynatysis Turbulant closure predicted surface Current Field Sampled on Two DaY Intervals on a $34 \times 24$ grid.

Used as Supplied.

\section{Wind and Current set Three:}

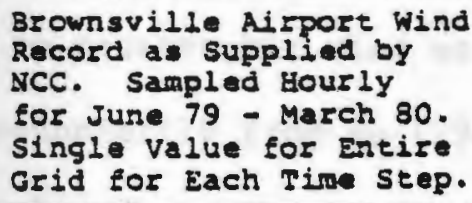

used as supplied.
Geostrophic Plus Coastal Current Field Supplied by crose. EDIS. Four seasonal sets on $34 \times 24$ Grid.

Used as supplied. 
is computed according to:

$u_{g}=-\frac{1}{f_{\rho a} R} \frac{\partial_{P}}{\partial \phi} ; \quad v_{g}=\frac{1}{f p_{a} R \cos \phi} \frac{\partial P}{\partial \lambda}$

where:

$\mathrm{Ug}=$ northward component of geostrophic wind velocity

$V_{g}=$ eastward component of geostrophic wind velocity

$\phi=$ northward coordinate

$\lambda=$ eastward coordinate

$f=$ Coriolls parameter

$\rho_{a}=$ density of air $(1.22 \times 10 \mathrm{~g} / \mathrm{cm})$

An estinate of the wind near the sea surface is formed by rotating the geostrophic wind vector by 15 degrees counterclockwlse and reducing its magnitude by $30 \%$ to approximate boundary layer effects. These values are within the range of the computed 10 meter wind speed to geostrophic wind estimates reported by Stolzenbach et al (1977) secondarily from wu (1969); and correspond also to an empirical rule of thumb value based on observation of ocean winds under a variety of conditions (Stolzenbach et al., 1977).

The $7 \times 5$ pressure-inferred sea surface wind data for the Gulf of Mexico have been bilinearly interpolated (Wendell, 1972) onto a 34 x 24 grid system for model input. The primary usefulness of these wind field predictions is seen to be in defining the large scale spatial and temporal features of the wind field across the western Gulf. Figures 5A-D show four representative (WI) wind fields at the 
supplied three degree spatial mesh.

(W2) (Climatological "synthetic" yearly wind): The Dynalysis climatological wind dataset was constructed through a data-intensive interpolation procedure from National Climatic Center (NCC) TDF-11 data files (Blumberg and Mellor, 1981). The raw data (consisting of over a million Gulf surface ship observations) were edited and converted with the aid of standard bulk aerodynamic exchange formulas to produce monthly estimates of the wind stress statistics. The stresses were then interpolated onto a finer numerical grid by a statistical interpolation technique (Kantha et al., 1981). Since the (w2) wind record is designed to drive a hydrodynamic model, the higher frequency component of wind stress from the passage of weather systems would be lost by a simple monthly averaging technique. The model used has three time-varying parameters representing wind energies in the seasonal, cyclonic weather system passage, and diurnal frequency partitions as follows:

$$
\begin{aligned}
& \tau_{x}=\tau_{0}(x, y)\left[\left(1+A \cos \omega_{1} t\right) \cos \left(\omega_{1} t+\phi\right)+0.1 \cos \omega_{2} t\right] \\
& \tau_{y}=-T_{0}(1, y)\left[\left(1+A \cos \omega_{1} t\right) \sin \left(\omega_{1} t+\phi\right)-0.1 \sin \omega_{2} t\right] \\
& \text { where: } \quad \omega_{1}=\frac{2 \pi}{T_{1}} ; \omega_{2}=\frac{2 \pi}{\tau_{2}}
\end{aligned}
$$

and

38 


\section{5 (JULIAN DAY)}

PEG PRESS-INFERRED MONTHLY AVG. WIND. YEAR $=79$

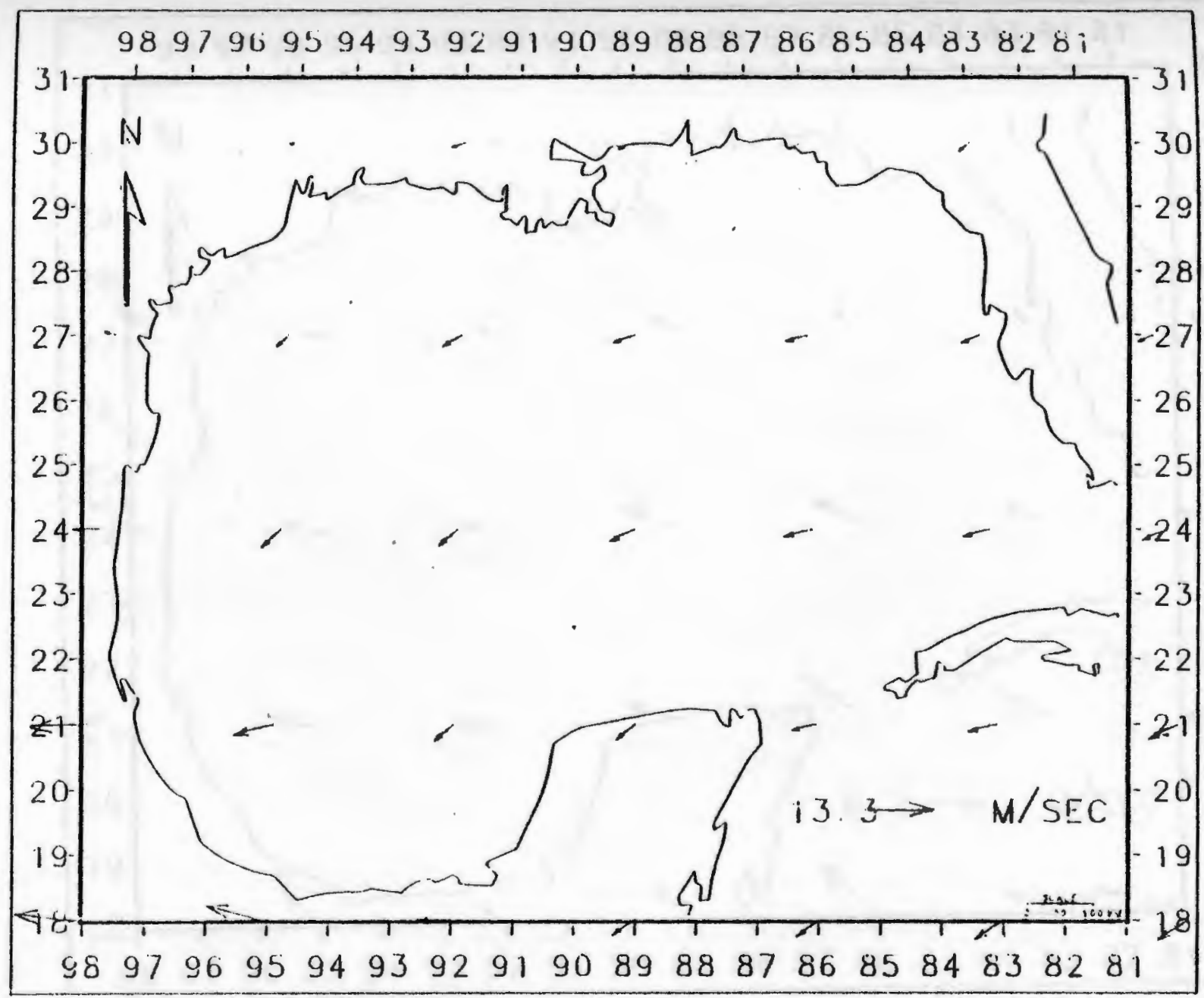




\section{0 (JUL. [AN DAY)}

PEG PRESS-INFERRED MONTHLY AVG. WIND, YEAR $=80$

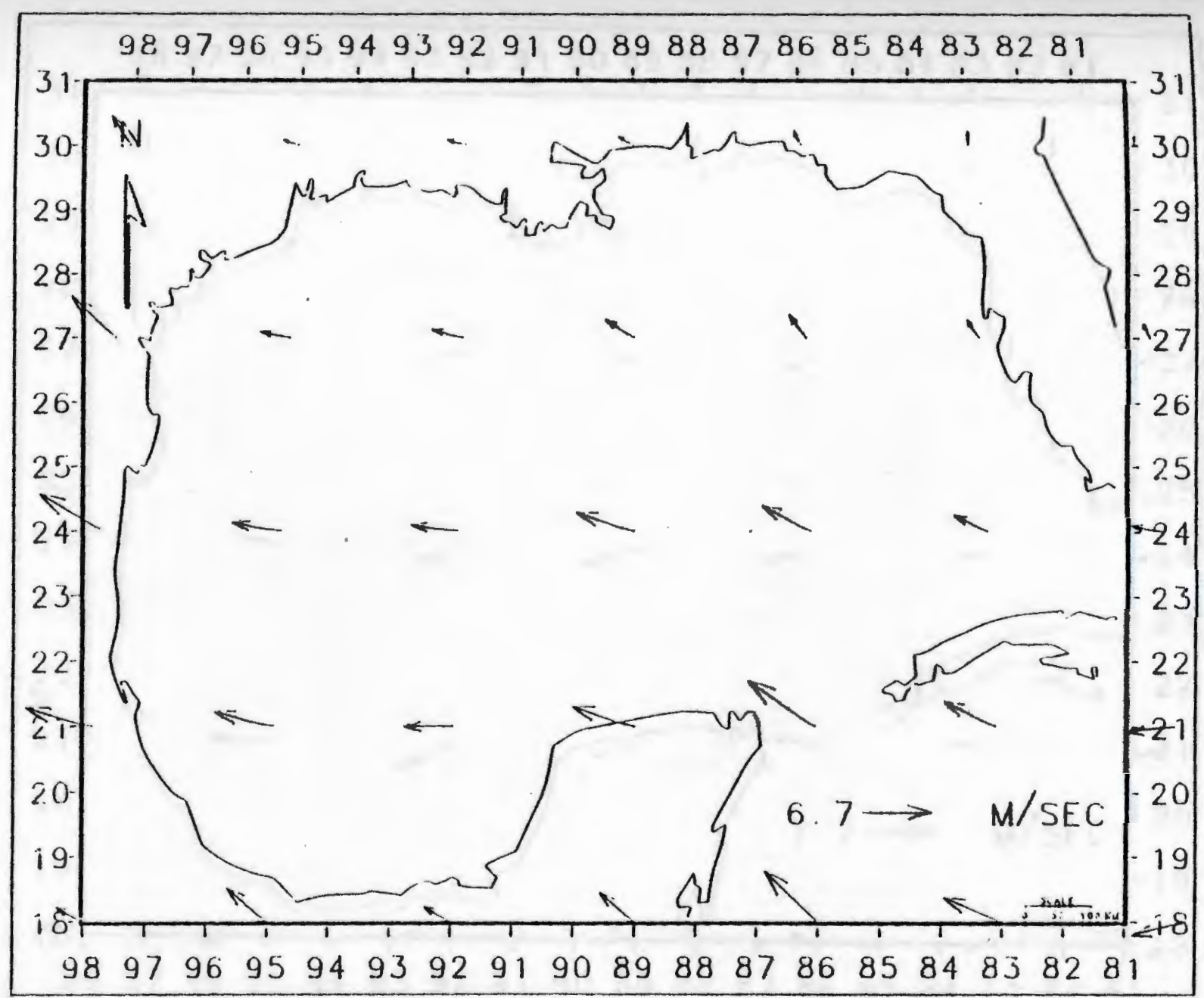


181 (JULIAN DAY)

PEG PRESS-INFERRED MONTHLY AVG. WIND. YEAR $=79$

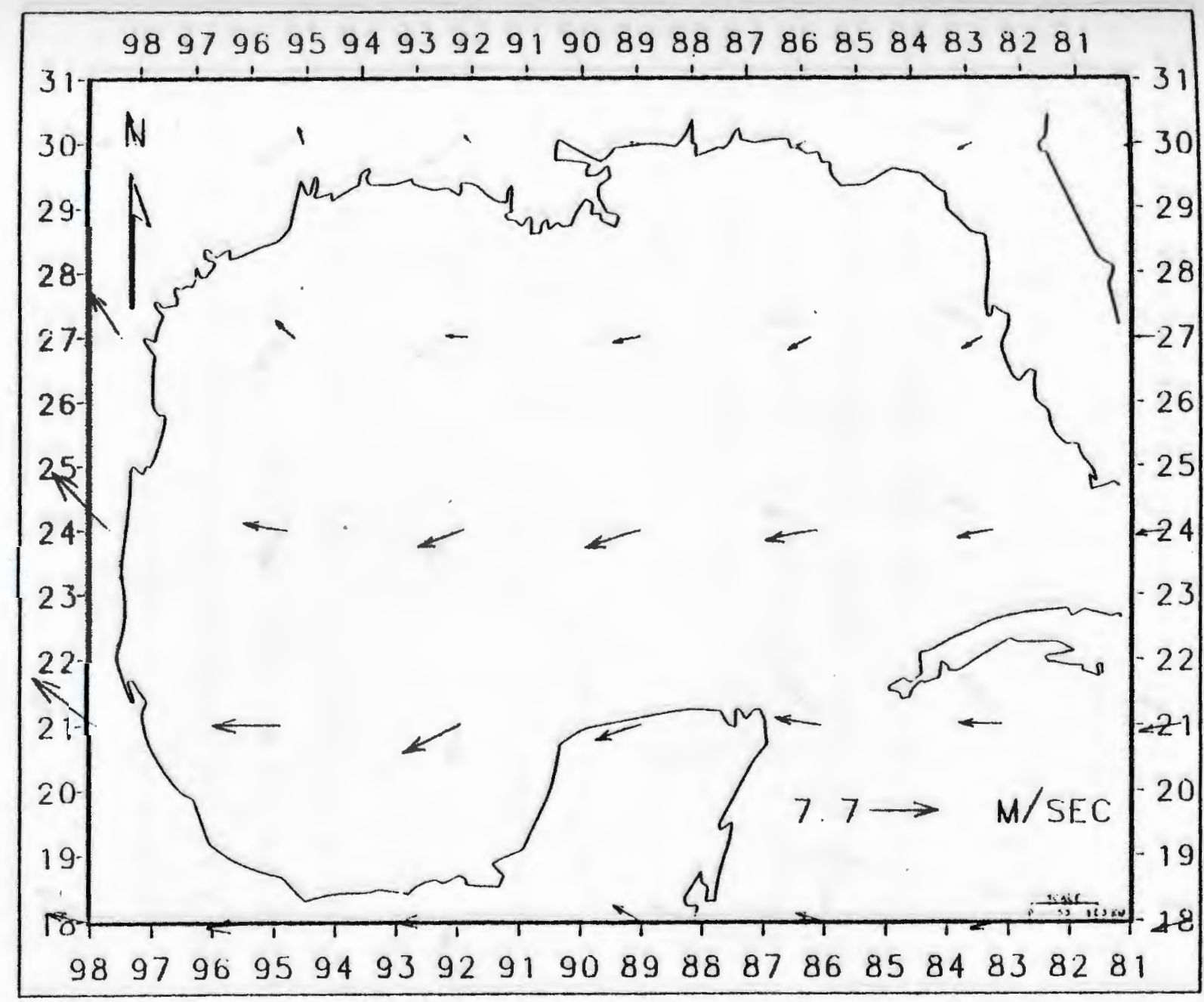




\section{3 (JULIAN DAY)}

PEG PRESS-INFERRED MONTHLY AVG. WIND, YEAR $=79$

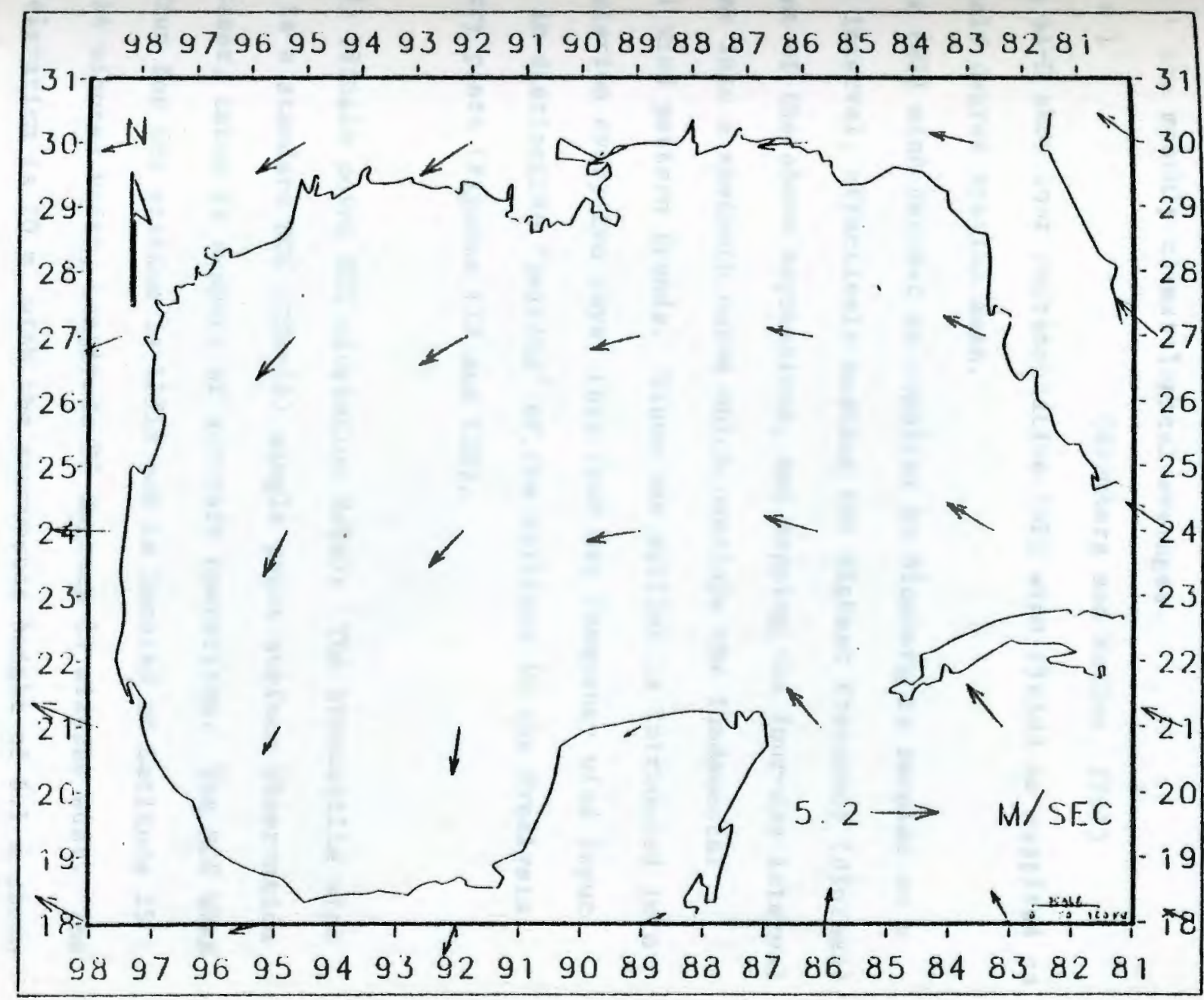


$T$, has a period of four days

$\mathrm{T}_{2}$ has a period of one day

$\tau_{0}$ and $\phi$ are slowly varying functions of time interpolated from the monthly climatological averages.
$A=1$
(Blumberg and Mellor, 1981)

Figures $6 A-D$ show four representative (W2) wind fields as supplied on a one-half degree spatial mesh.

The (W2) wind dataset as supplied by Blumberg is sampled on a two-day interval, effectively masking the highest frequency (diurnal) component of the above expressions, and mapping the four-day interval component into a sawtooth curve which overlays the fundamental seasonal wind pattern trends. Since one spillet is introduced into the simulation every two days, this four day frequency wind input results in distinctive "pairing" of the spillets in the Dynalysis trajectory plots (Figures $11 \mathrm{~B}$ and 13B).

(W3) (Single point NCC airstation data): The Brownsville wind dataset is a standard NCC (TDF-14) single point surface observation wind dataset, taken in support of aircraft operations. The NCC WBAN designation for the station is 12919 and is located at Latitude 25 degrees 54 minutes North, Longitude 97 degrees 26 minutes West. The station elevation is $10 \mathrm{~m}$, with the anemometer height of $6.1 \mathrm{~m}$ above ground level $35 \mathrm{~km}$ west of the coastline. Figure 7 is a stickplot of the (W3) record used for the Ixtoc simulation. 


\section{0 (JUL IAN DAY)}

DYNALYSIS TURB. CLOSURE MODEL WIND FIELD

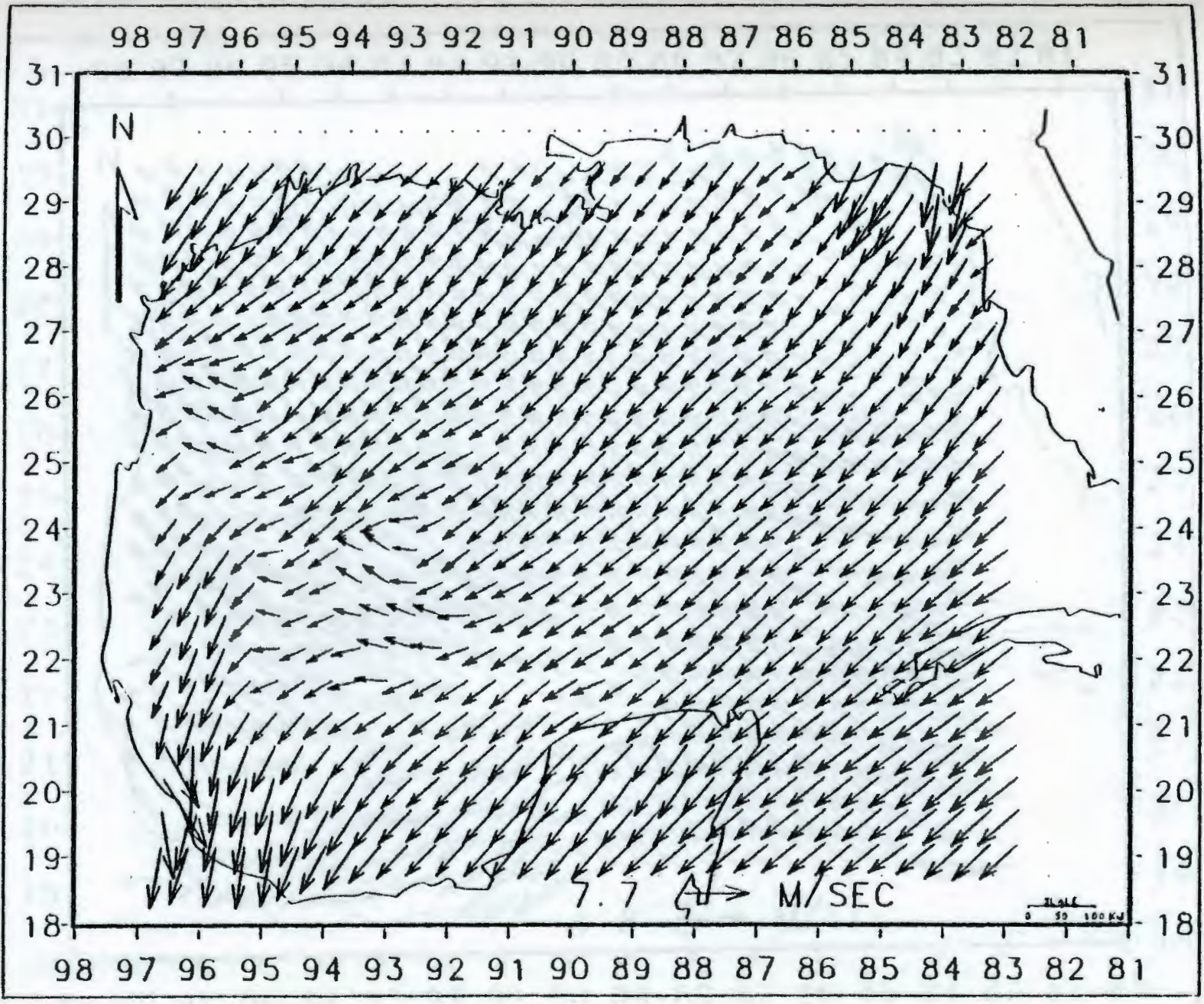


90 (JILIAN DAY)

DYNALYSIS TURB. CLOSURE MODEL WIND FIELD

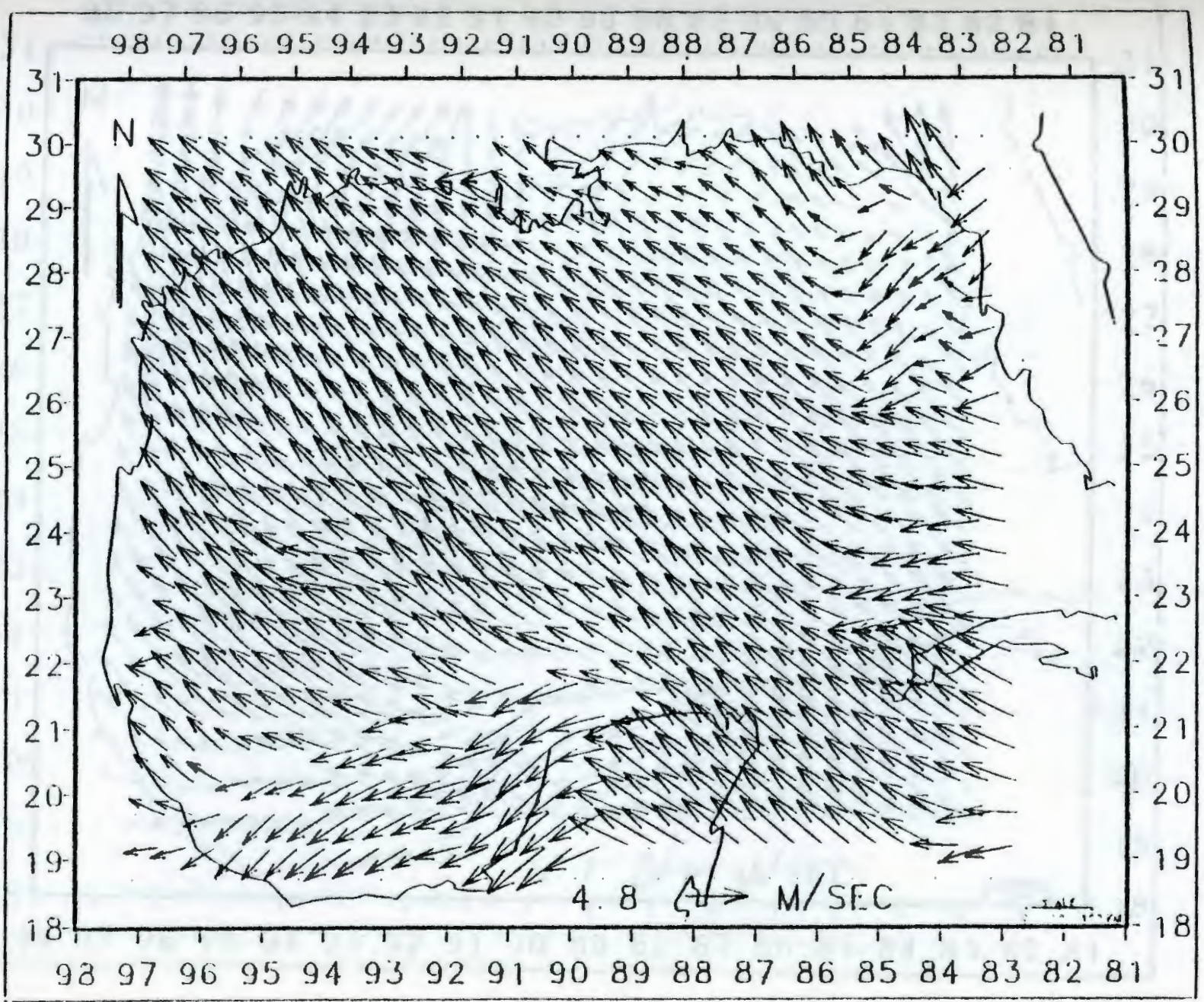


DYNALYSIS TURB. CLOSURE MODEL WIND FIELD

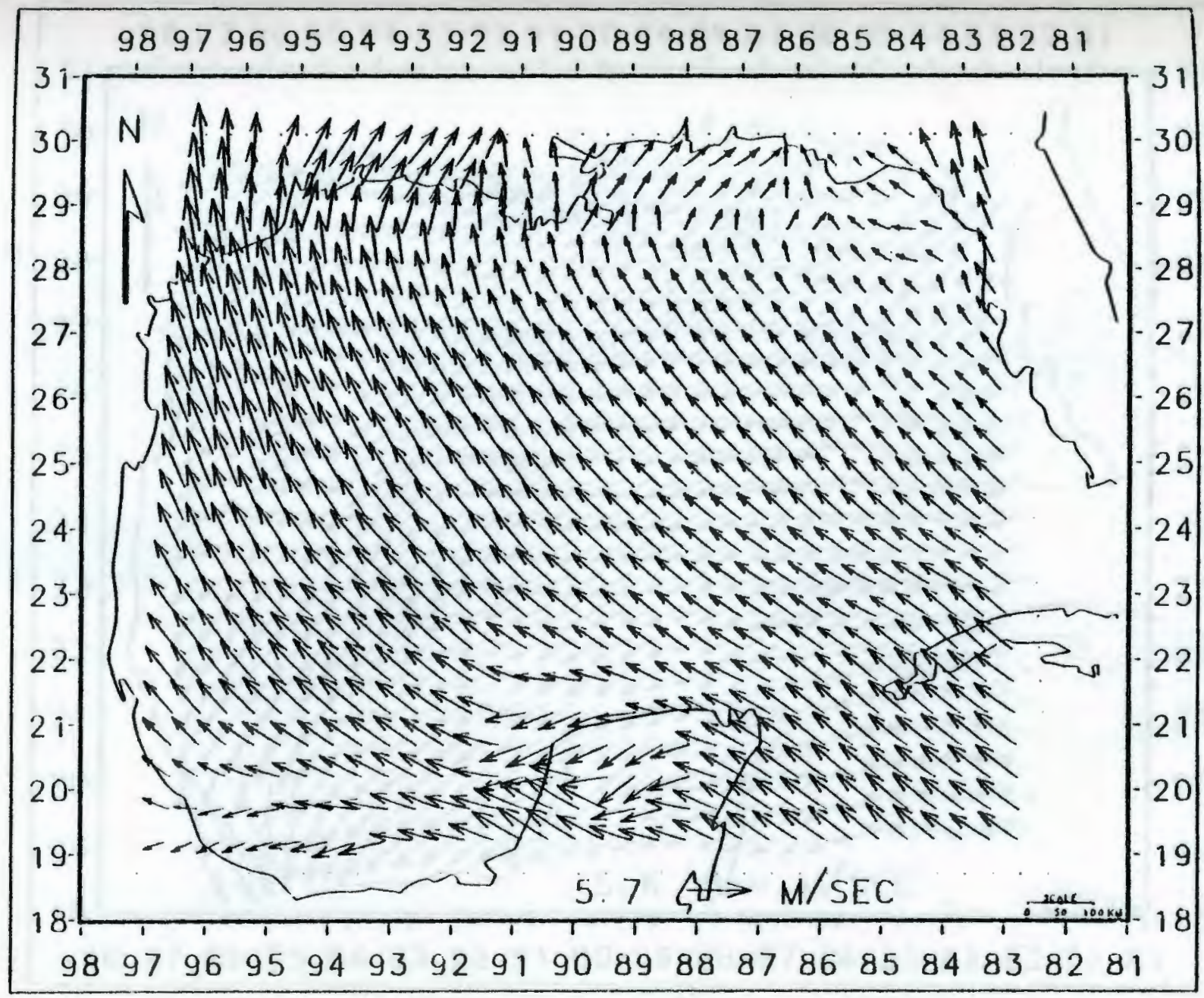




\section{0 (JULIAN DAY)}

DYNALYSIS TURB. CLOSURE MODEL WIND FIELD

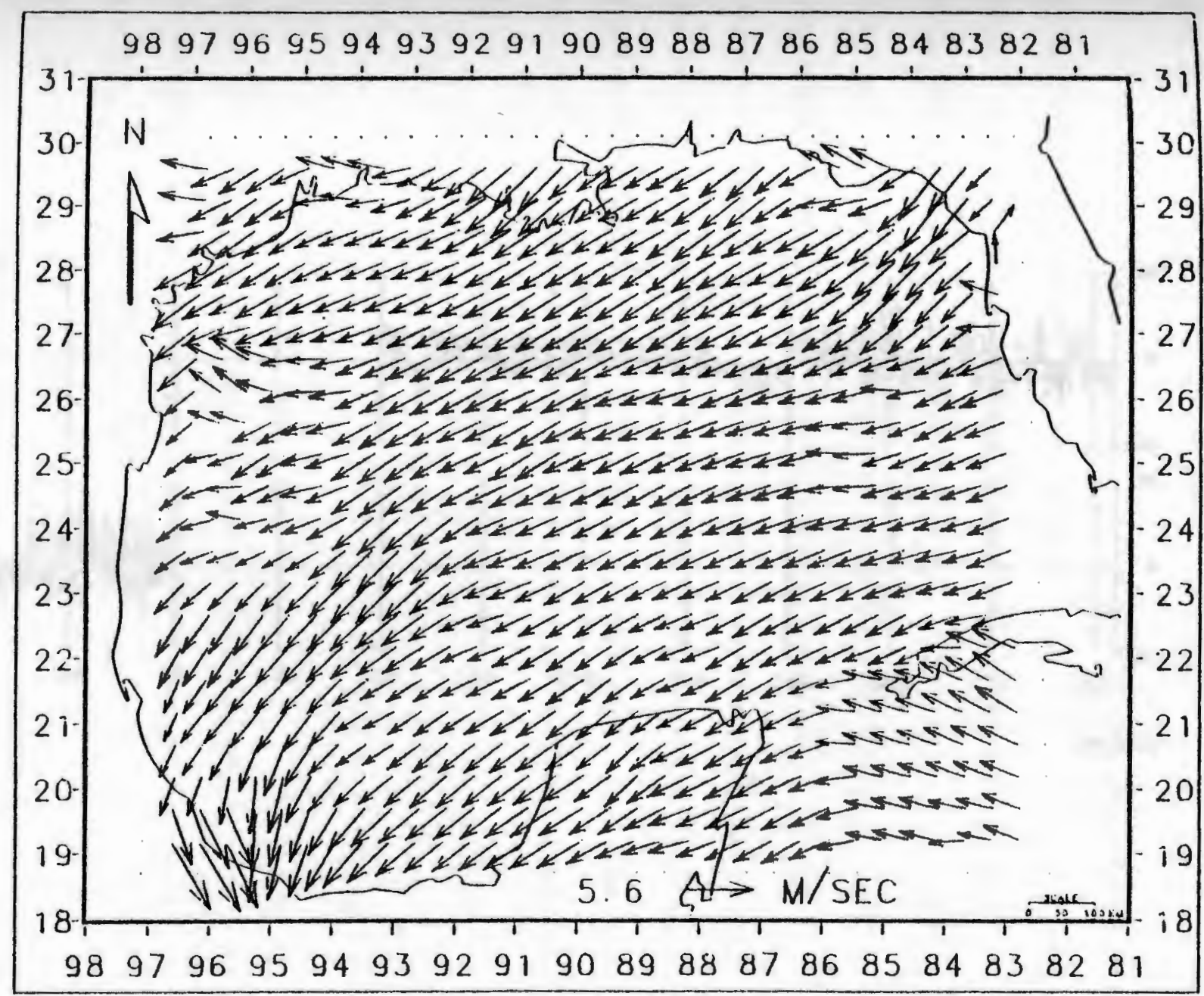


figure 7

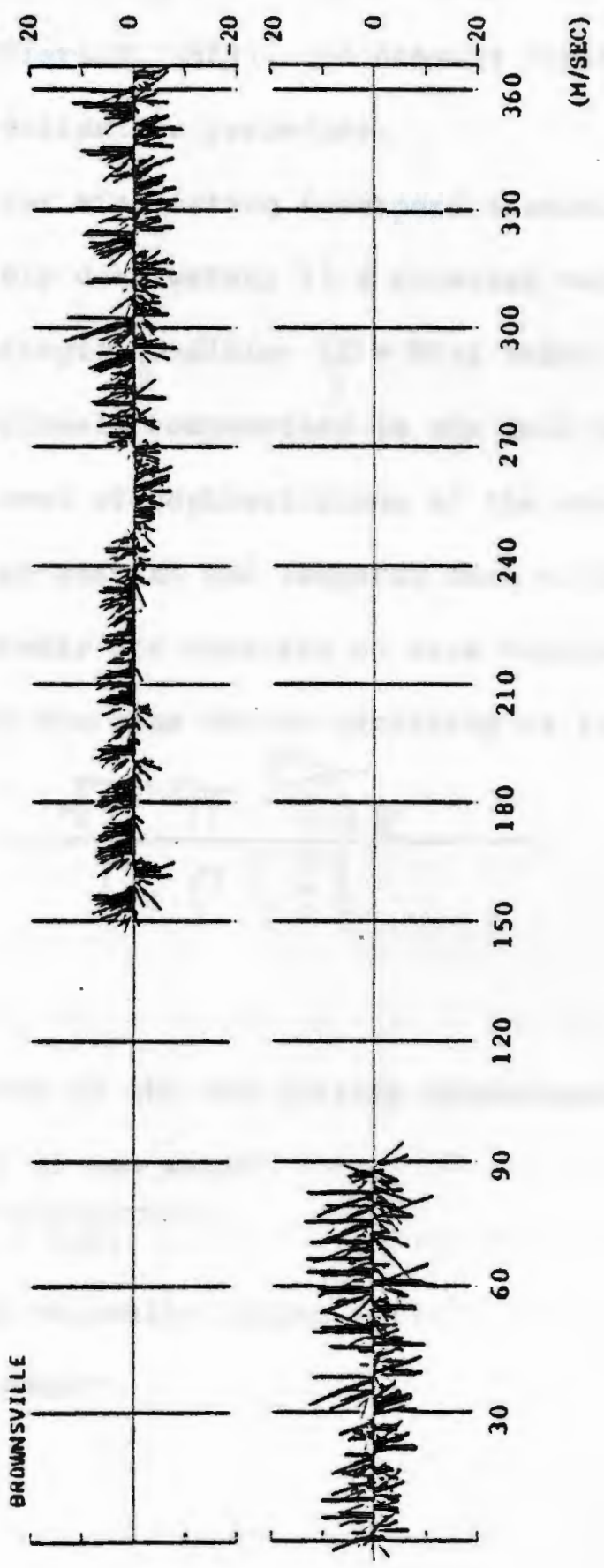




\section{Current Fields:}

(U1) (Classical Ekman wind-driven): The sea surface wind vectors from the 3 degree mesh PEG wind fleld (W1) were used to compute a surface current using the Ekman solution for surface currents (Neumann and Pierson, 1966). No density forcing is included In this current field estimation procedure.

Ekman's solution for wind-driven transport assumes: 1) no boundaries, 2) infinitely deep water, 3) a constant vertical eddy 1scosity, and 4) barotropic condition $(\rho=F(p)$ only). All four of the assumptions are seriously compromised in the Gulf of Mexico application, but the level of sophistication of the analysis seems consonant with the large spatial and temporal mesh of the FNWC data.

Ekman surface currents are computed on axes rotated so that the $Y$ axis is parallel with the wind vector according to the solution:

where:

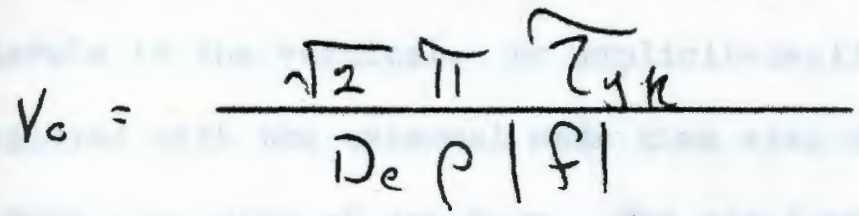

\footnotetext{
$7 y k$ is the magnitude of the sea surface windstress

$\rho$ is the density of sea water

$D_{e}=\pi \sqrt{2 A z /|f|}$

$A z=$ vertical eddy viscosity (taken as:

$f=$ Coriolis parameter
} 
For the Northern hemlsphere, the direction of Vo is $\mathrm{P} 1 / 4$ radians clockwise to the wind stress.

(U2) (Wind and heat-flux driven 3D hydrodynamic model): The Dynalysis turbulent closure current dataset is the product of an ambitious modeling effort by Blumberg and Mellor (1981). The model is driven at the surface by winds and surface heat flux derived from climatological atmospheric surface data from an intensive data analysis study (Rantha et al., 1981). Lateral boundary conditions for temperature, salininty, and hydrographlc-forced geostrophic velocity at the Straits of Yucatan and Florida are obtained from climatological ocean data. Mean velocity, temperature, salinity, turbulent kinetic energy and turbulence on the macroscale are the predicted variables. The grid spacing for the model is $50 \mathrm{~km}$ by 55 $\mathrm{km}$ with 15 levels in the vertical. An explicit-implicit split mode scheme is employed with the external mode time step of 36 seconds and an internal mode time step of one hour. The simulation has been run for one full year. An analytical second moment turbulence closure scheme embedded within the model provides an estimate of surface mixed layer dynamics. The purpose of the modeling effort was to estimate the impact of Ocean Thermal Energy Conversion (OTEC) power plants on the Gulf's temperature, salinity, and current regimes (Blumberg and Mellor, 1981). 
(U3) (Seasonal dynamic topography driven): Grose et al (1982), In reporting on the development of a strategic assessment model for the chronic discharges of oil into the Gulf of Mexico, presented results of an Ixtoc spill hindcast surface trajectory. Grose supplied a copy of the current field used in this hindcast and a verbal description of its generation. The main deep-water features were generated by a dynamic-topography-derived geostrophic model simulation by Blumberg and Mellor. Blumberg (personal communication) confirmed that the hydrographic data used as input to the current Bimulation was the same data set as that reported in Blumberg and Mellor (1981). This hydrographic data set is referenced as "the complete set of Gulf temperature and salinity data files maintained by the National Oceanographic Data Center (NODC)....archived prior to 1979, and consists of over half a million temperature and salinity observations." (B1umberg and Mellor, 1981). Despite the large number of observations, the temporal and spatial coverage of the data set justified only four seasonal flow field estimates. Blumberg (personal communication) indicated a criterion for data adequacy to be a minimum of ten observations per cell per time interval for at least $80 \%$ of the cells. These four seasonal current flelds were upplied to the United States Geological Survey (USGS) for use in ollspill trajectory modeling. Grose, at the Marine Environmental Assessment Division, Environmental Data and Information Service (EDIS) NOAA, obtained the hydrographic-forced current fields from USGS and overlayed estimates of coastal currents determined by a 
review of available 1iterature. Grose (personal communication) did not supply more detalled information on the derivation of the current fields. Of particular note with reference to the Ixtoc 1 hindcast is the small amount of hydrographic data of the southwestern Gulf included in the NODC archive mentioned above. Much of the hydrographic data used in de la Cerda's (1975) analysis was collected and archived in Mexico, and not available to Blumberg and Mellor.

Discussion; Coupling of Wind and Current Datasets:

Two oflspill model surface ofl movement formulations were used in the simulations. A $1 \%$ downwind surface slick drift was employed when the current field estimation procedure included wind forcing. A $3.5 \%$ downwind surface slick drift rate was used when the current field estimation procedure did not include wind forcing. The forcing mechanisms included and the coupling of these forcing mechanisms between the wind and current fields used as environmental inputs is discussed below.

Successful oilspill trajectory modeling is dependent on adequate description of both the hydrodynamic flow in the near-surface waters and the wind field. Most ofl spill models simulate wind-driven surface water currents by some variant of the so-called "three percent rule" (Stolzenbach et al., 1977), an extremely simplified model for wind-driven surface water movement. Some approximation of 
the non-wind-driven components of the water flow fleld is superposed with a wind-driven translation component to achieve a resultant translation of the o1l spill element within each time step.

Previous hindcast experience (Spaulding et al., 1982) used several wind-driven simulations of a three-dimensional numerical hydrodynamic model to give a more preclse description of wind-driven water movement for a nearshore spill. It was hoped that the use of the predicted current field from the Blumberg and Mellor (1981) work would give some similar insights in the application to the Ixtoc 1 spil1.

Datasets (WI) and (U1) were used as a first order estimate of the wind-driven flow which might be expected in the Gulf. The surface velocities predicted by the Ekman solution at each of the three-degree grid nodes over water were interpolated onto the model's $34 \times 24$ grid. The oflsp1ll simulation then used this wind-driven flow fleld plus a further $1 \%$ downwind drift to simulate the advection of surface ofl (Grose and Mattson, 1977). The simulation driven by (U1) and (WI) gives a first-order estimate of the movement of the Ixtoc 011 predicted by wind forcing only.

For datasets (U2) and (W2), climatological w1nd forcing as well as the other forcing functions described in the (U2) current field discussion define the surface flow fleld. Density and heat flux forcing and the lateral boundary conditions for salininty, temperature and hydrographically-inferred flows contribute to a model system of great complexity when compared to either (U1)(W1) or 
(U3)(W3) - Again 1\% wind-induced slippage of oil over water is assumed.

Datasets (U3) -d (W3) represent an uncoupled pair of datasets, in that wind forcing other than a climatological seasonal residual one is not included in the (U3) model formulation: forcing mechanisms with a frequency higher than seasonal are not represented in (U3) because of the ensemble averaging of the hydrographic data used as input. Advection of surface ofl is simulated in the hindcast by the vector sum of the (U3) flow field plus $3.5 \%$ of the wind speed, downwind.

D1scussion: Use of the Brownsville (W3) WInd Data Record:

The location of the (W3) wind record is far from the sp1ll site and inland. Both these characteristics make it a less than optimum wind record to force an Ixtoc hindcast. It would have been preferrable to acquire a wind record from the area of the spill site itself, but this was not possible. The NCC Brownsville wind record was acquired and used in this analysis because of its ready avallability. In retrospect it is clear that the wind record from Buoy 42002 , located at 26.0 degrees North, 93.5 degrees West, and supported by the National Data Buoy Center (NDBC), NOAA would have been a better cholce. Efforts to make use of quickly obtainable wind statist1cs for Buoy 42002 (National Data Buoy Center, 1979, 1980) 
collected over the time span of the Ixtoc 1 spill to modify the Brownsville wind record to more accurately reflect open ocean conditions were not successful using the technique of Williams and Godshall (1977). The monthly wind statistics computed for the Brownsville wind record were not sufficently similar to those recorded by the NDBC for Buoy 42002 to enable this statistical technique to yield satisfactory results. The methodology uses a monthly mean wind matrix with several windspeed intervals and directions to characterize both the shore and the offshore wind records. A two-parameter transform for the shore wind record results from a comparison of the two mean wind speed matrices. The transform is subsequently applied to the shore wind record values. The methodology gave reasonable results for some months, but completely unreasonable results for others.

The use of the wind record to approximate the "three percent rule" wind-driven surface transport is consistent with the seasonal low band-pass filtering of the geostrophic solution of (U3).

\section{D1scussion: Comparison of the Flow Fields (U1), (U2), (U3):}

Figures $8 \mathrm{C}, 9 \mathrm{C}$, and $10 \mathrm{C}$ represent the three input current fields at the start of the spill simulations: Figure $8 \mathrm{C}$, the (U1) current fleld for the Ekman-derived surface currents from one month's average pressure-inferred wind centered on Julian day 79181; Figure 9C, the (U2) current field for climatological Julian day 180; and Figure 
10C, the (U3) seasonal-dynamic-topography-driven current solution plus coastal currents for the season encompassing the month of June. The (U1) current field is plotted on the three-degree mesh grid on which the (W1) wind data were supplied. The fleld has been interpolated onto the $34 \times 24$ one-half degree mesh grid for the aimulations. It is immediately obvious that the level of spatial definition of the (U2) and (U3) data sets is far greater than that of the (U1) data set.

Comparison of the magnitude of the surface velocities of Figures $8 \mathrm{C}, 9 \mathrm{C}$, and $10 \mathrm{C}$ in the southwestern Gulf region reveals much higher values for the (U2) and (U1) predicted current fields in the Ixtoc well-head area, consonant with the exclusion of higher frequency wind-driven flows in the (U3) solution. The broad features of the (U1) surface flow field reflect the spatial and temporal smoothing of the large mesh solution space. The loop current feature which shows most dramatically in the (U3) solution is not reflected in the (U1) field because of the Loop Current's non-wind-driven forcing. Ev1dence of the predominant loop current shows in the (U2) current fleld, as does what appears to be a considerable response to wind-driven forcing. Since the scaling on Figure $9 \mathrm{C}$ (U2) is almost twice that of Figure $8 \mathrm{C}$ (U1) and more than three times that of Figure $10 \mathrm{C}$ (U3) it is apparent that the (U2)-predicted flow regime is considerably more energetic than either (U1) or (U3).

If we consider the directionality of the flows represented in $8 \mathrm{C}, 9 \mathrm{C}$, and $10 \mathrm{C}$, paying particular attention to the flow around the 


\section{5 (JULIAN DAY)}

PEG PRESS-INFERRED EKMAN SURF VEL. (79)

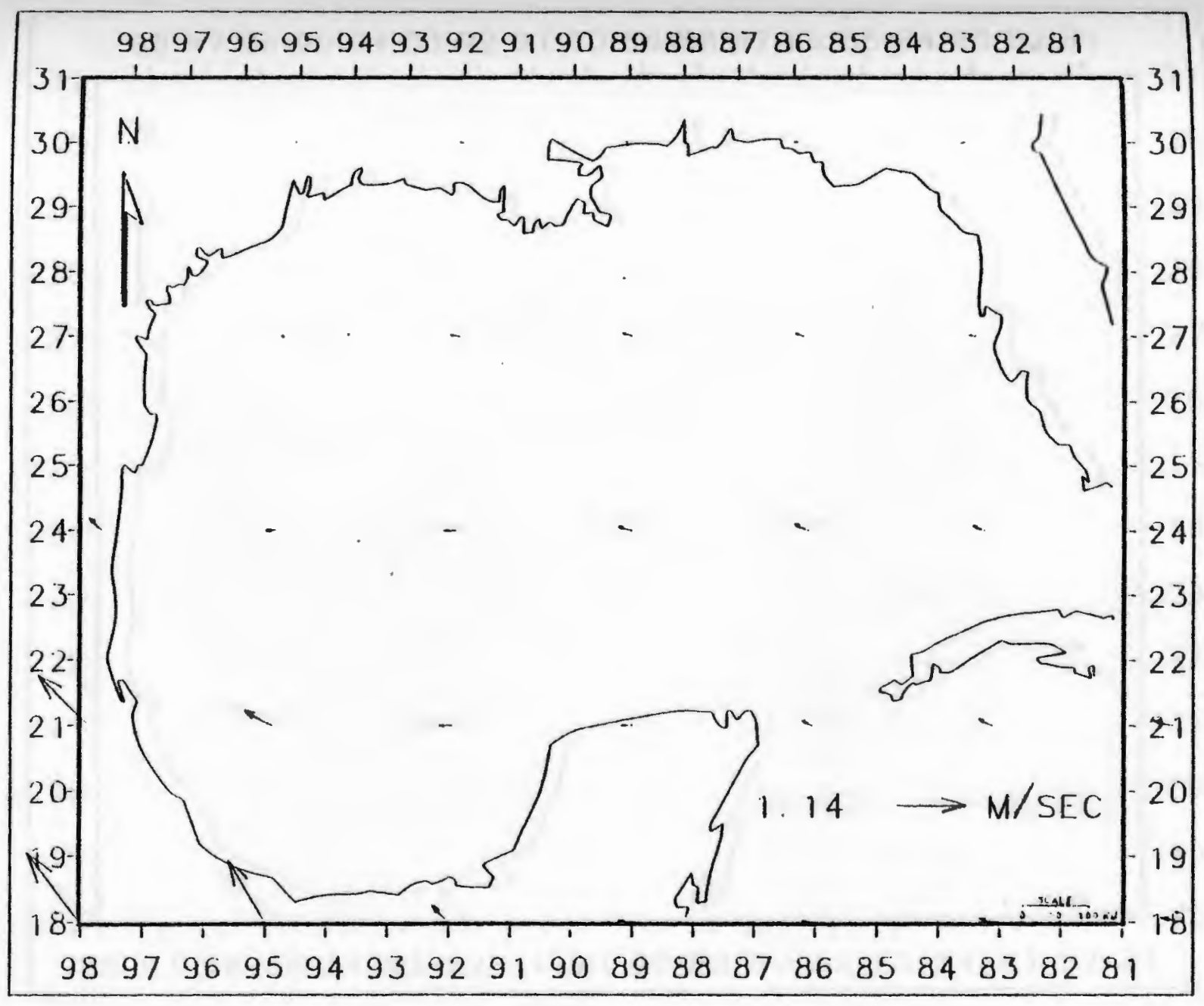

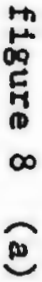


31 (JULIAN DAY)

PEG PRESS-INFERRED EKMAN SURF VEL. (79)

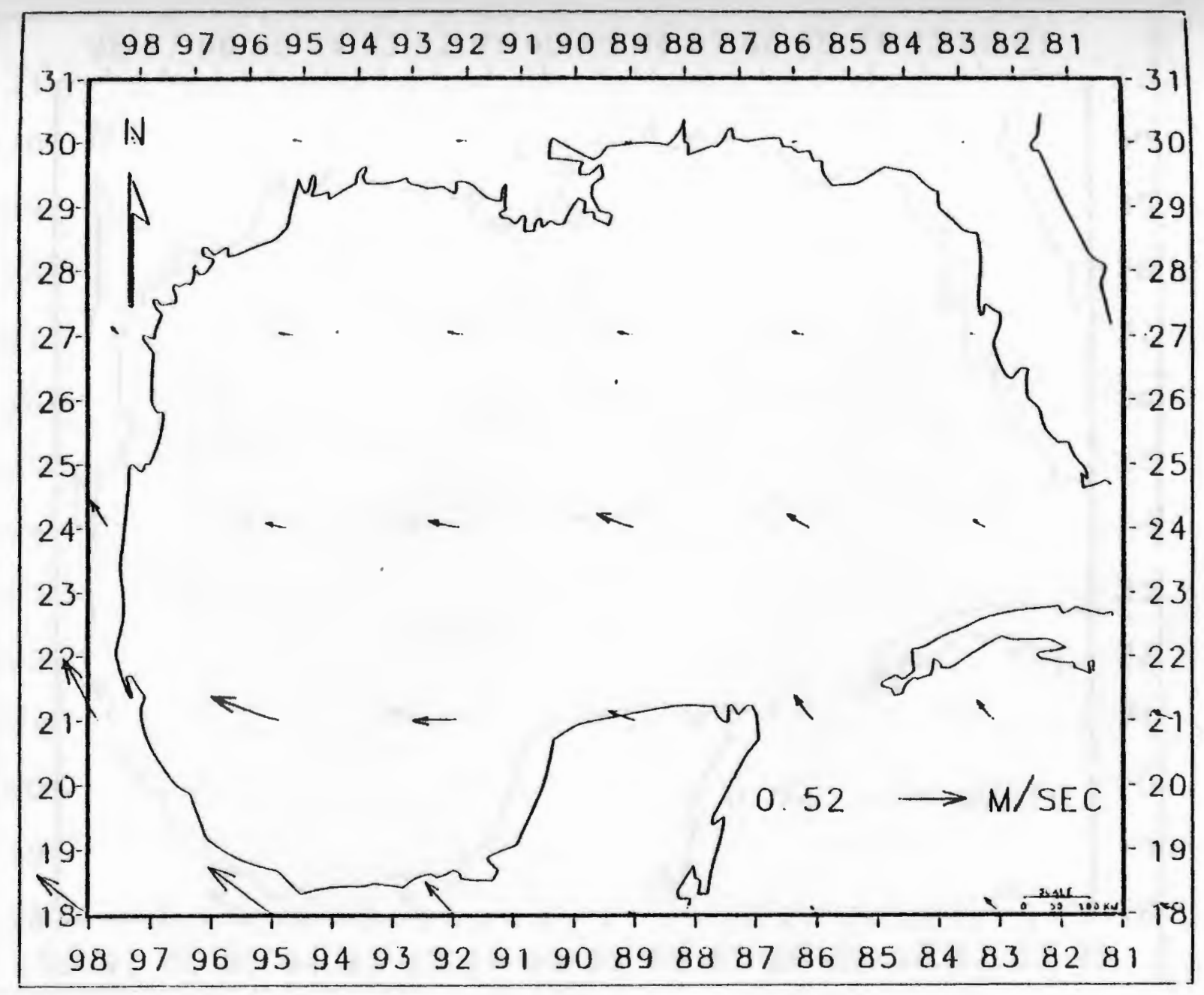


181 (JUL IAN DAY)

PEG PRESS-INFERRED EKMAN SURF VEL. (79)

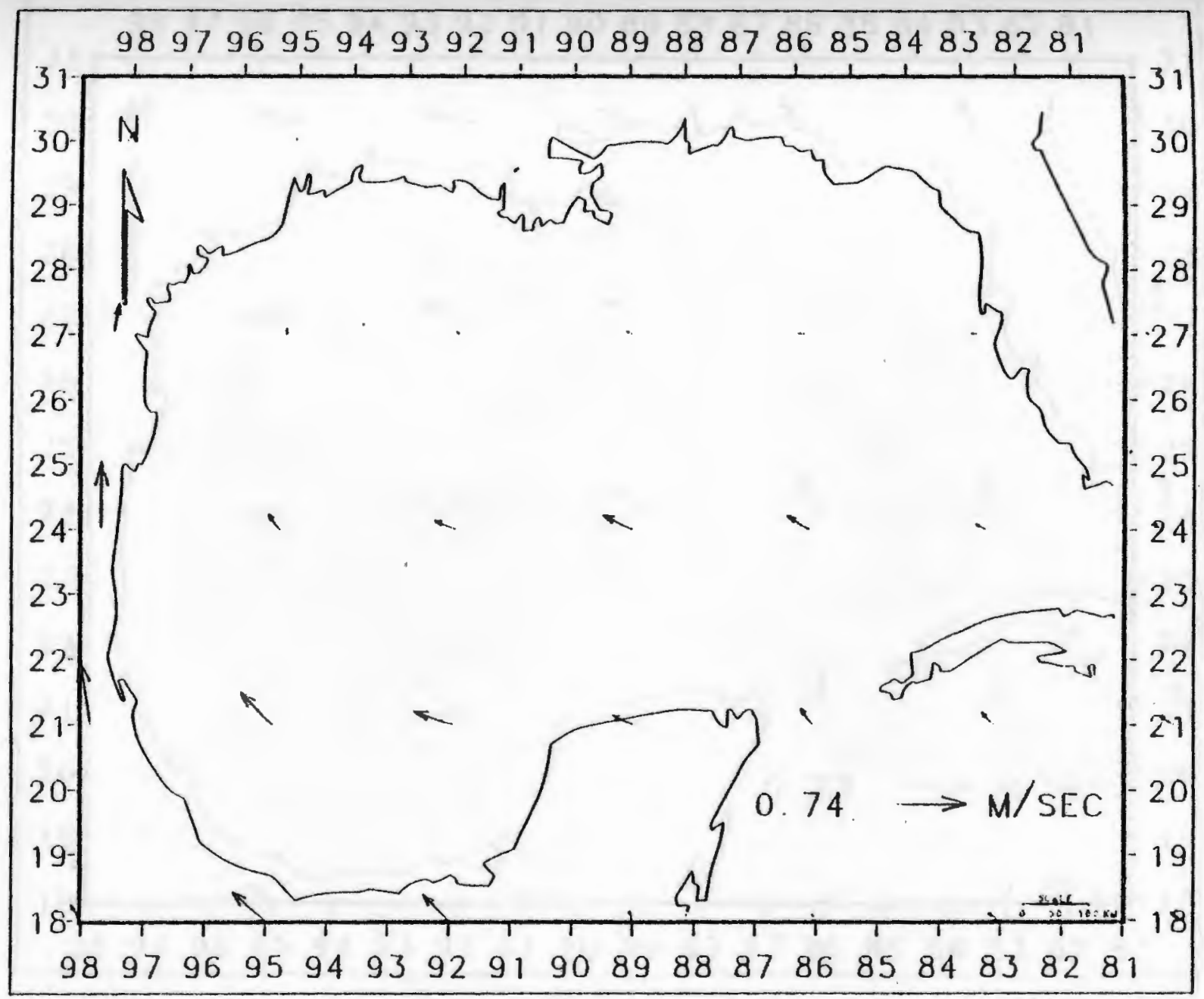




\section{3 (JUL.IAN DAY)}

PEG PRESS-INFERRED EKMAN SURF VEL. (79)

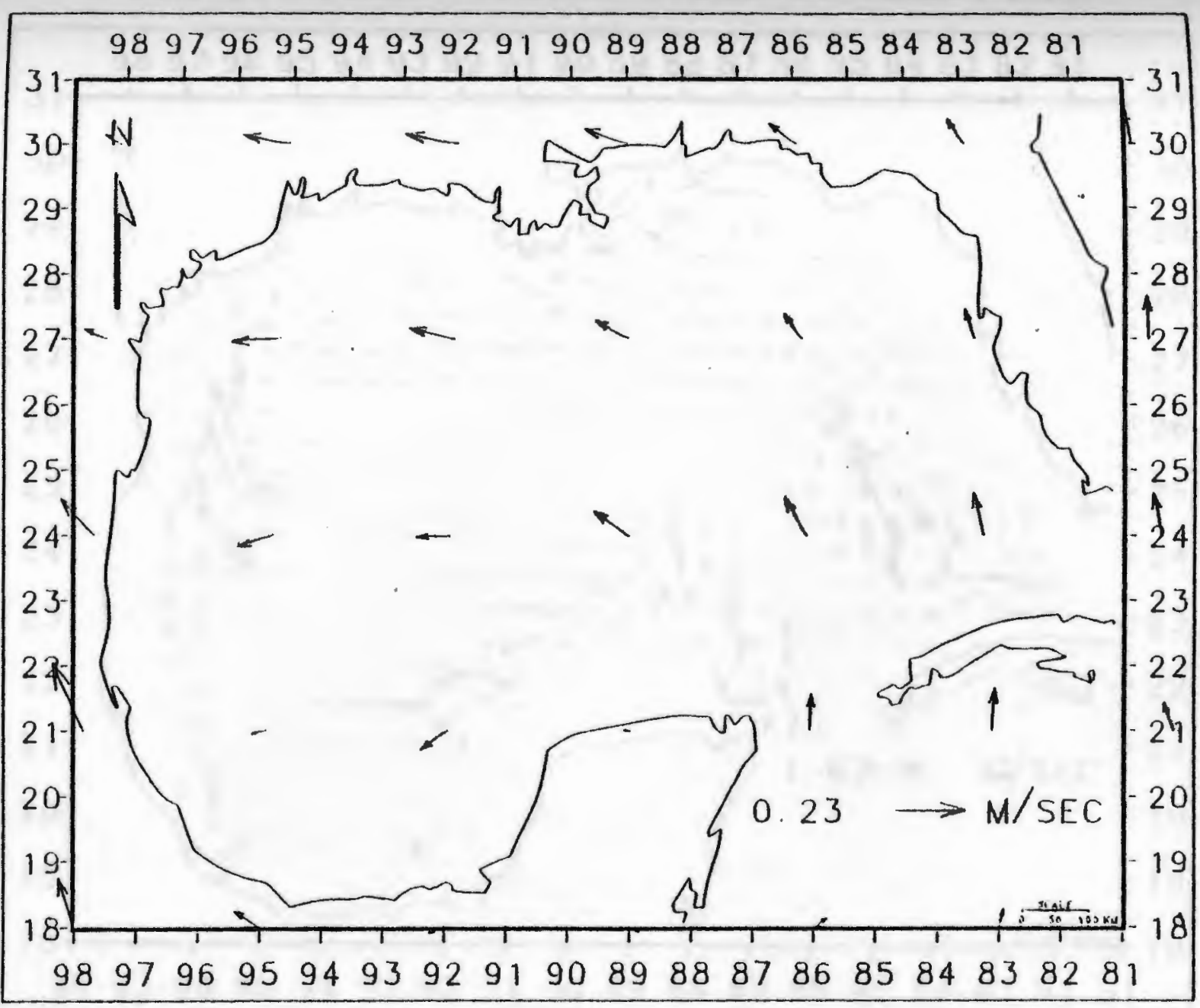




\section{8 (JUL IAN DAY)}

DYNALYSIS TURB. CLOSURE MODEL CURRENT FIELD

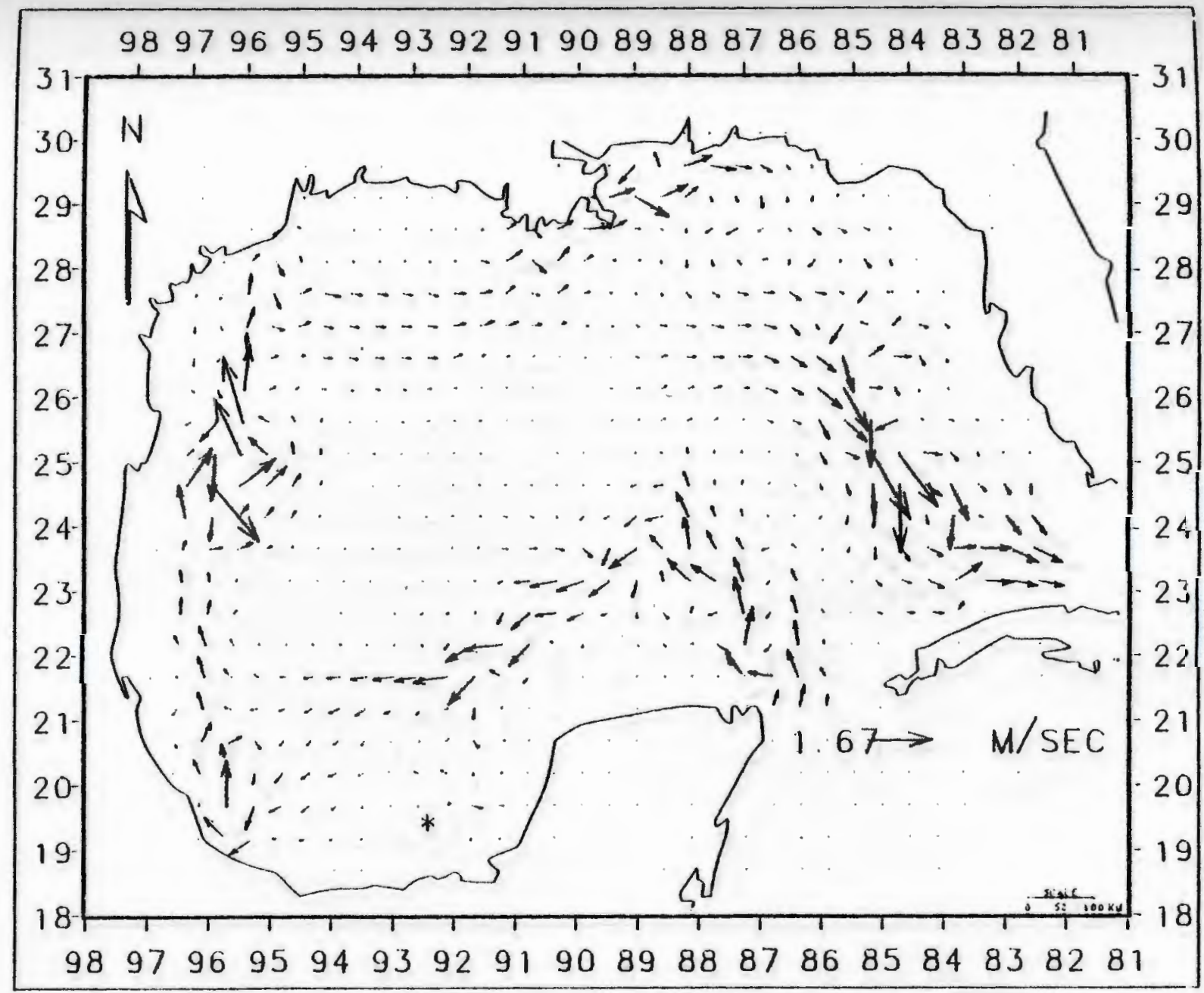




\section{0 (JULIAN DAY)}

DYNALYSIS TURB. CLOSURE MODEL CURRFNT FIELD

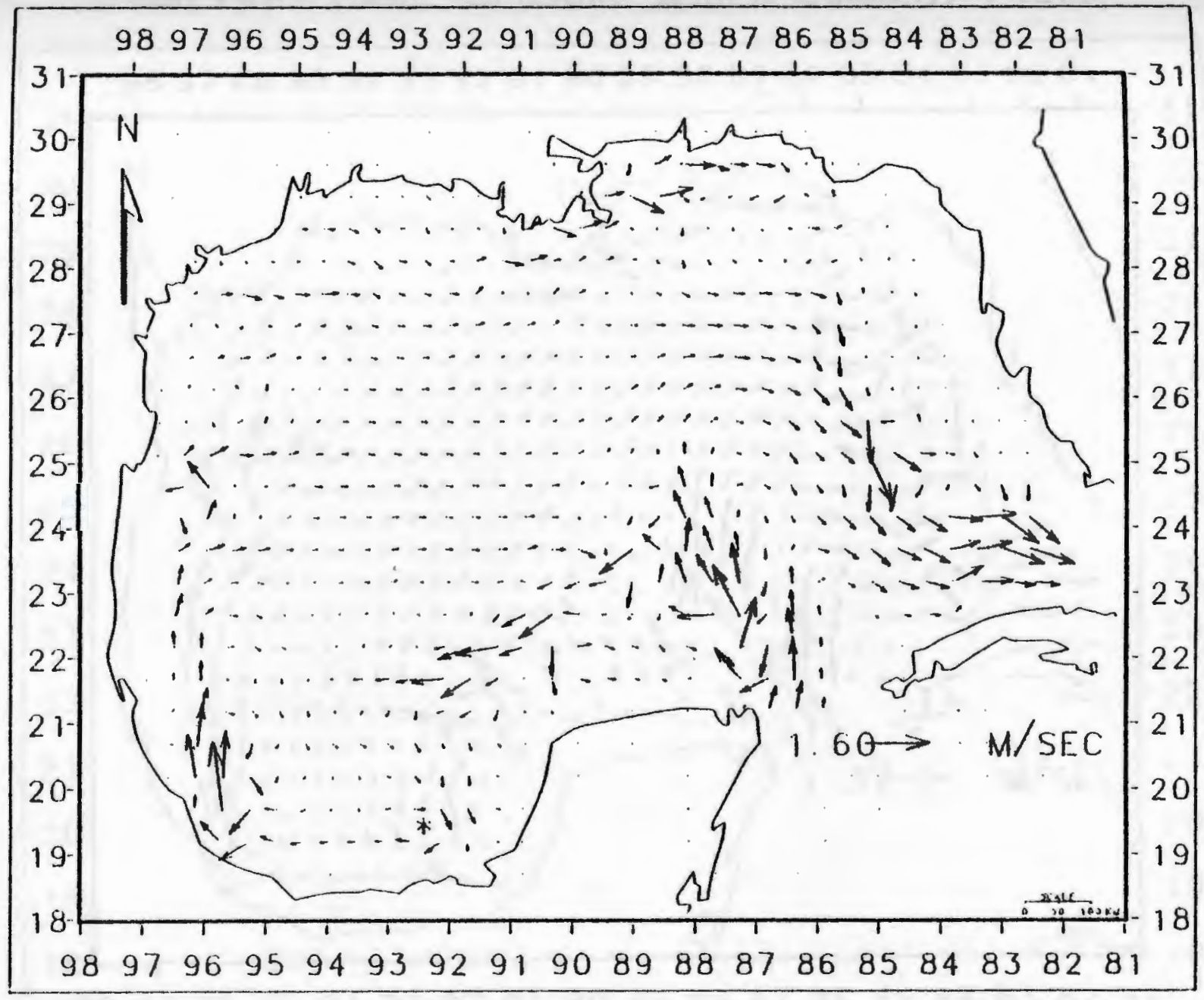




\section{0 (JULIAN DAY)}

DYNALYSTS TURB. CLOSURE MODEL CURRENT FIEL.D

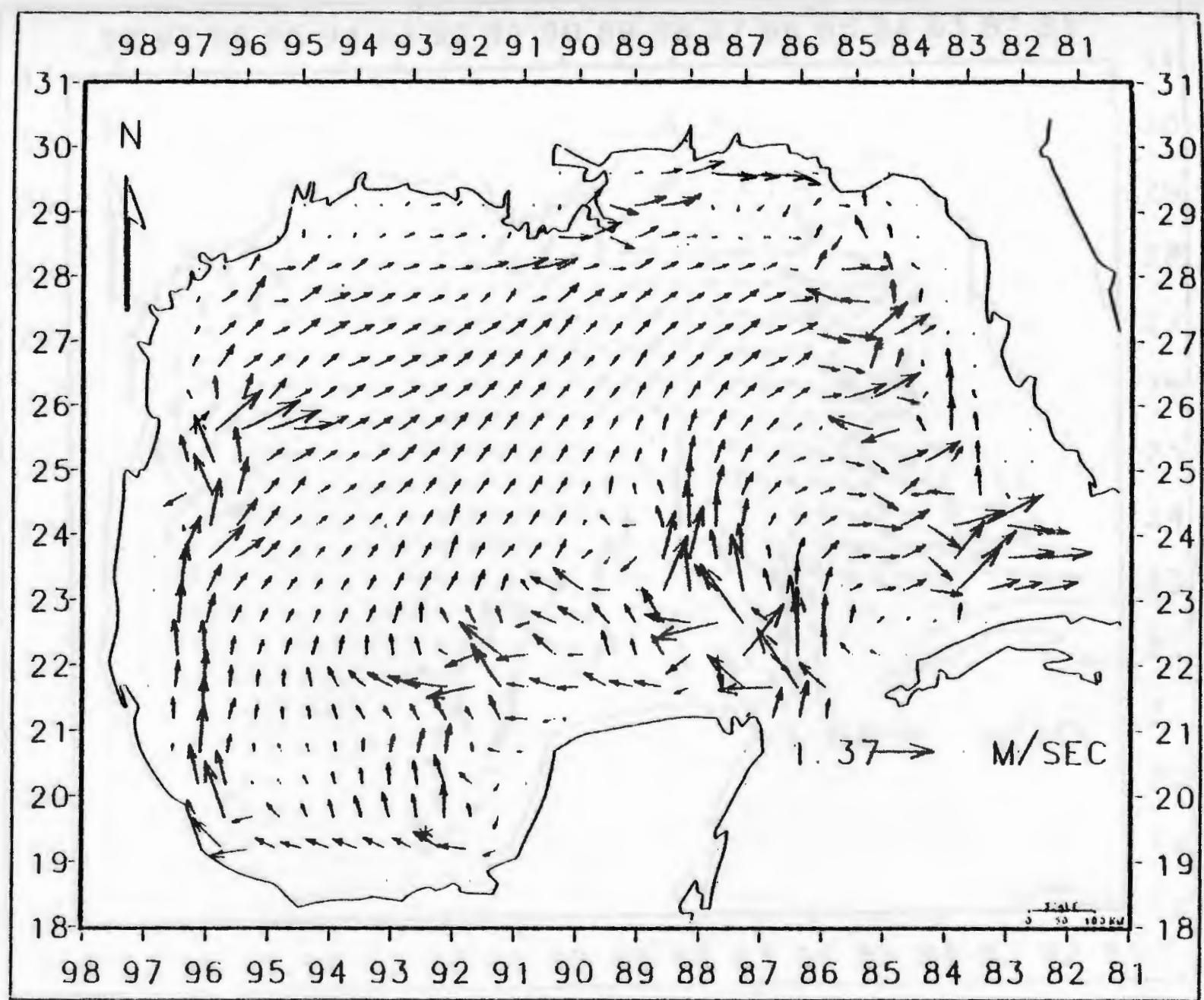




\section{0 (JUL IAN DAY)}

DYNALYSIS TURB. CLOSURE MODEL CURRENT FIELD

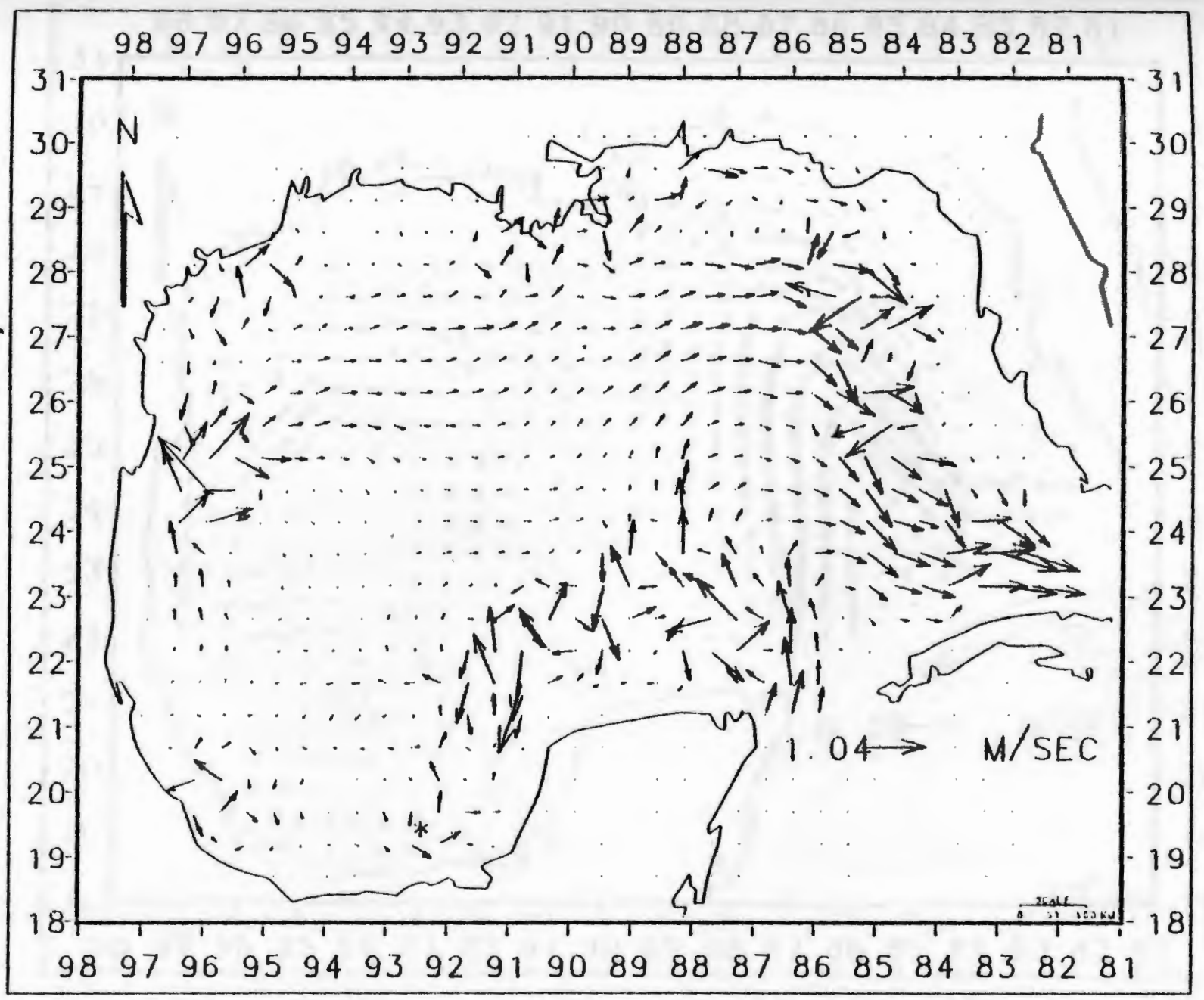


3 (JUI. IAN DAY)

GROSE (EDIS/NOAA) GEOSTROPHIC + COAST. CURRENTS

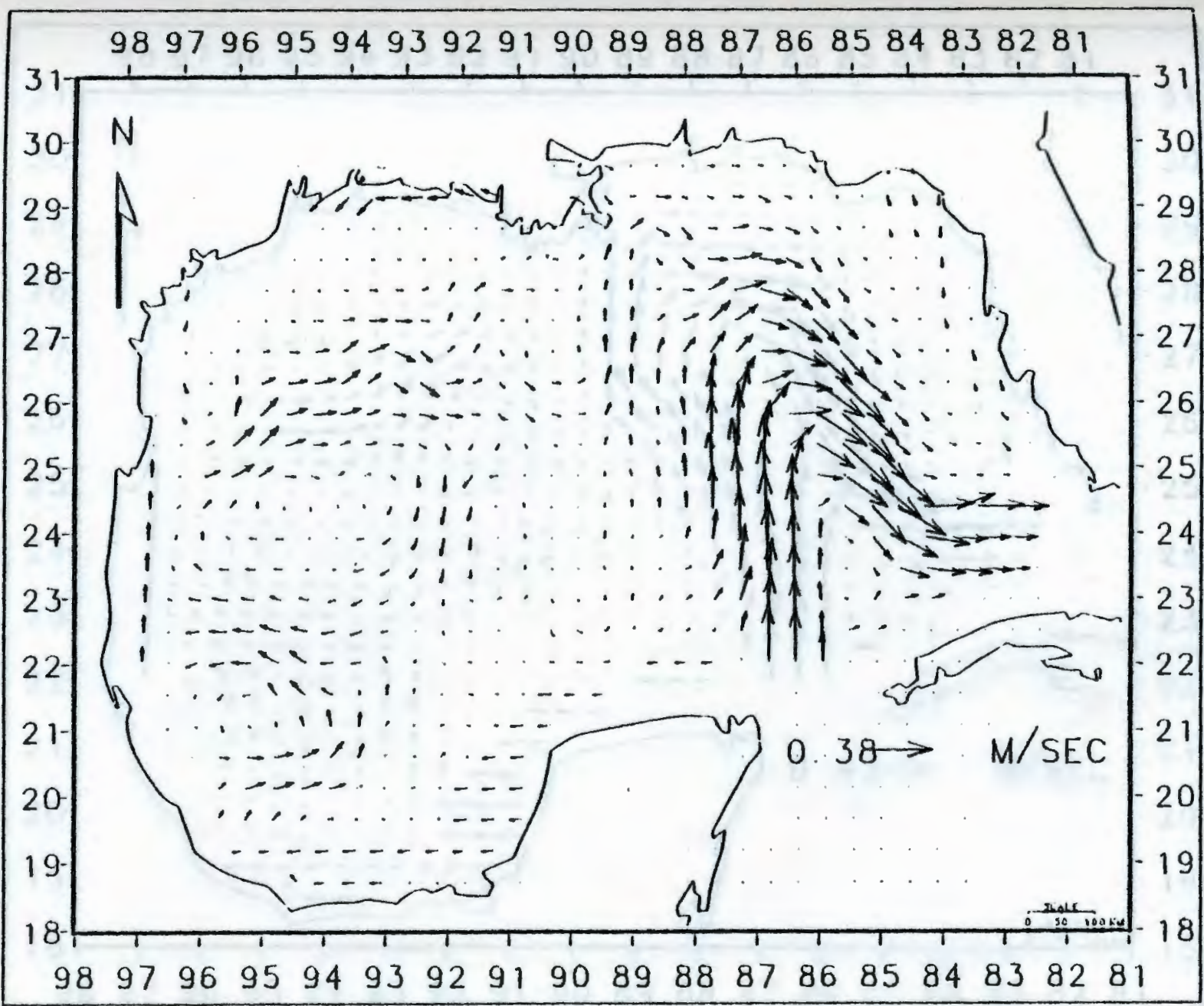


93 (JUL IAN DAY)

GROSE (EDIS/NOAA) GEOSTROPHIC + COAST. CURRENTS

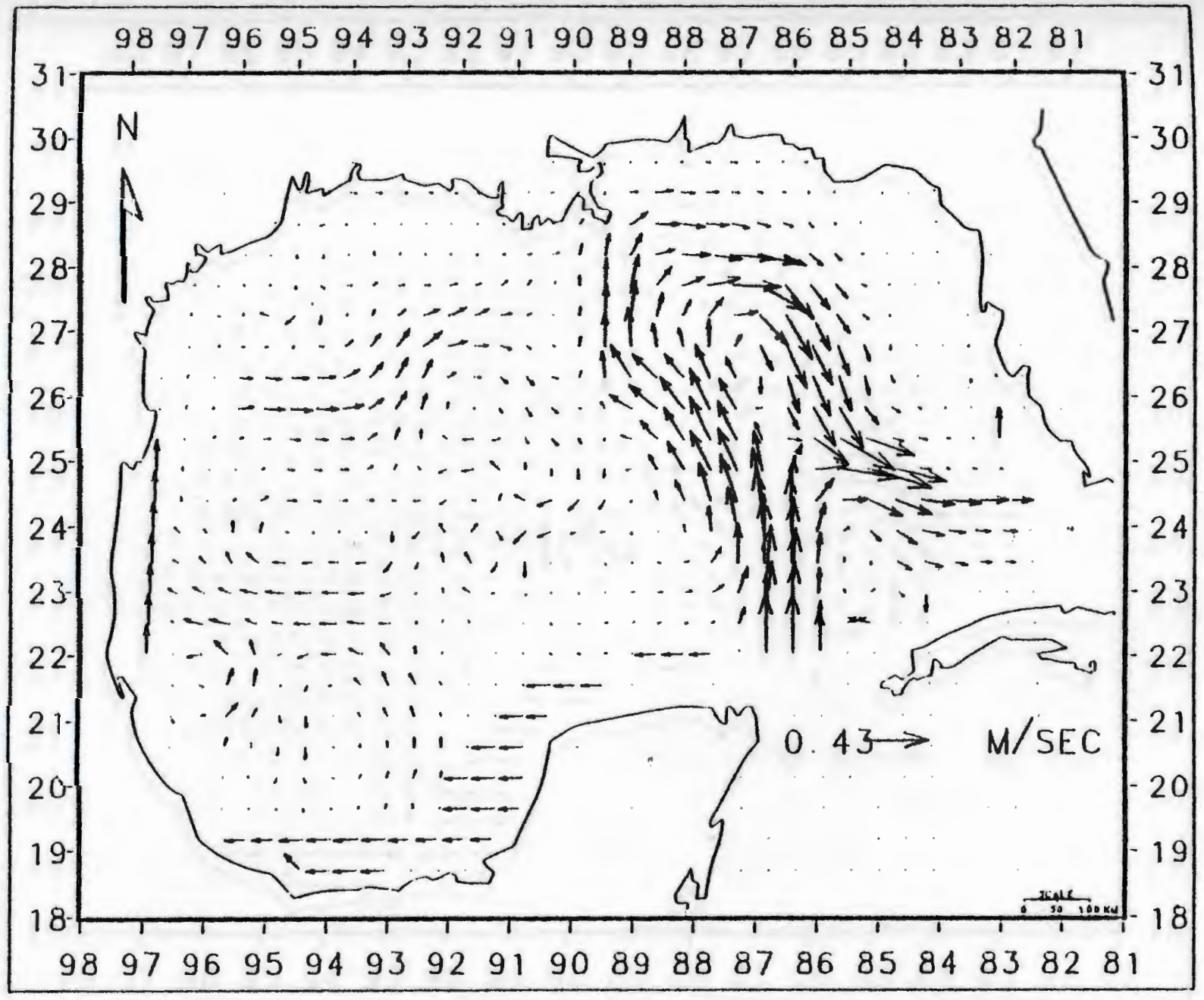


183 (JUL IAN DAY)

GROSE (EDIS/NOAA) GEOSTROPHIC + COAST. CURRENTS

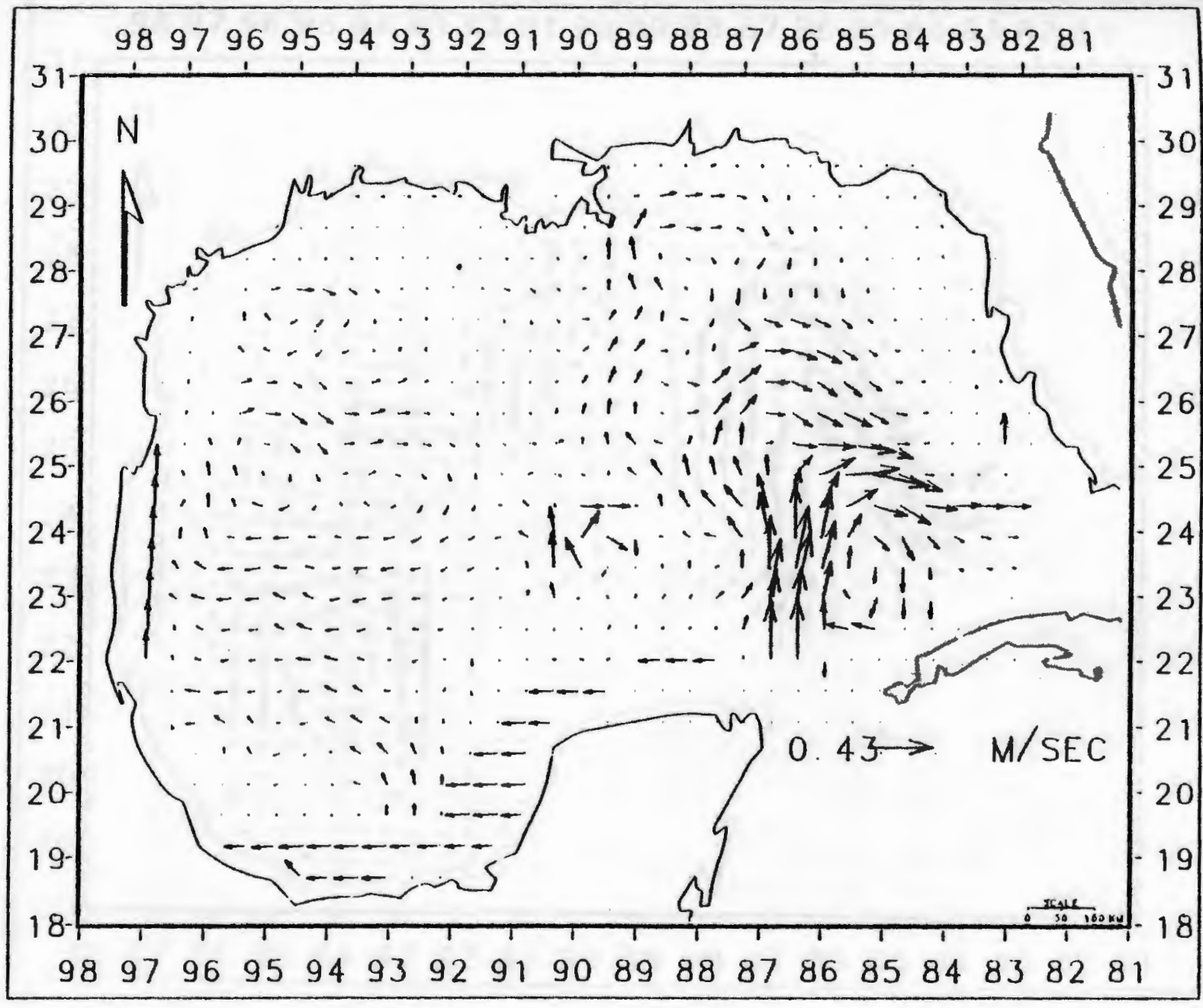




\section{3 (JULIAN DAY)}

GROSE (EOIS/NOAA) GEOSTROPHIC + COAST. CURRENTS

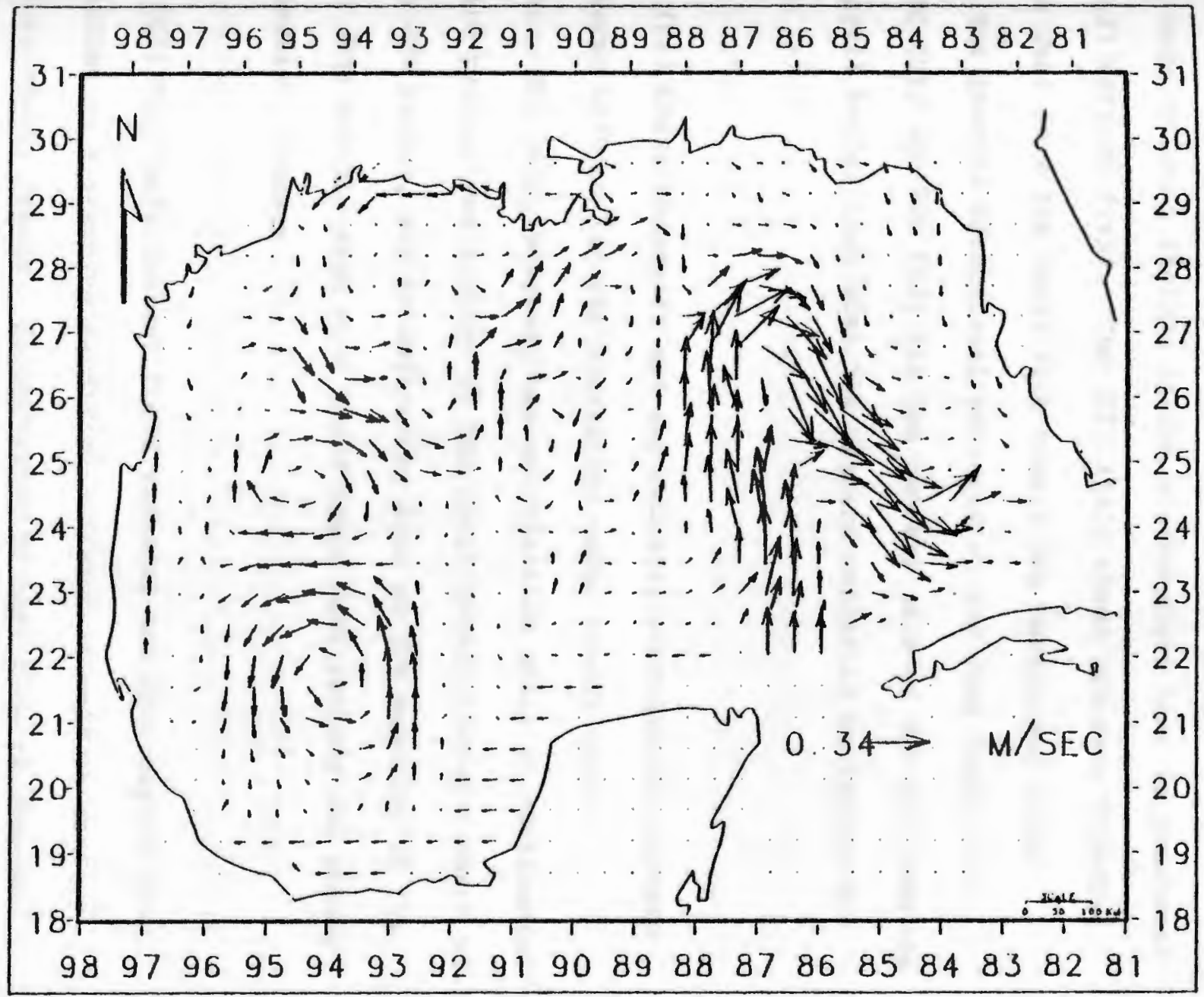


Ixtoc spill site (marked by an asterisk in Figure 9C), we see that the current field predicted by Figure 9C leads North and Northwest, away from the reported sightings of oil in the extreme southwestern Gulf. A weak cyclonic feature in the southwestern Gulf is predicted in the (U3) current field. The (U1) field shows currents directed North and West from the spill site toward the Mexico and Texas coasts. The general directional patterns of the flow fields of Figures $8 \mathrm{C}$ (U1) and $10 \mathrm{C}$ (U3) fit the general path of the ofl from the Ixtoc 1 spill better than does the pattern exhibited by Figure $9 \mathrm{C}$ (U2).

The (U1) Ekman transport set approximates wind-driven currents in deep water with no lateral boundaries under steady wind conditions. The Gulf, however, has considerable areas of continental shelf, with perhaps one quarter of 1 ts areal extent having a depth of less than 200 meters, and is defined by land at the majority of its boundary. The monthly mean wind field input does satisfy the steady wind assumption, however.

The (U2) Dynalysis current field includes the geostrophic flow approximations as a starting condition and wind as well as surface heat flux as energy inputs. Conservation of mass flow is observed. To the extent that the model is successful, one could expect the Dynalysis current field to give the best estimate of the climatological features of the flow field. It is apparent from 
rigure $9 \mathrm{C}$ that the cyclonic and anticyclonic features of the couthwestern Gulf described by de la Cerda (1975) are not in strong aldence in the (U2) current field.

The (U3) current set is derived from salinity, temperature, and pressure profiles ensemble averaged seasonally over many years. Density and wind-driven forcing mechanisms of a seasonal frequency contribute to this flow field. The addition of coastal currents based on values obtained from the literature is an ad hoc solution to a problem prevalent in all nearshore oilspill modeling: adequate description of the nearshore flow fleld. The addition of the northerly current vectors along the Mexican coast south of Texas (the Mexican Coastal Current) ignores the bi-annual reversal observed in this coastal current (Galt, 1981; Merrell and Morrison, 1981), but In substance is typical of the kind of approximations which are comonly used in the modeling of coastal oil spills. Galt's ethodology for description of the coastal current regimes along the western boundary of the Gulf is differentiated from this crude approach by the collection of a large amount of near-synoptic field thervations collected by several federal and state government agencies involved in the spill response and by a hydrodynamic nodeling procedure which created a mass-conserving flow field with composites of analytically-derived current patterns combined to echleve a "best fit" to these obseved data (Galt, 1981). The general Mariptions of the cyclonic and anticyclonic features of the 
southwestern Gulf in Sturges and Blaha (1976) and Merrell and Morrison (1981) give needed overview of the general circulation of the area, but do not give a basis for prediction of the magnitude, direction, or extent of the Mexican Coastal Current as it extends over the continental shelf. Field observations and current meter data as employed by Galt (1981) are necessary to more prec1sely define this important current feature. Similarly, the analysis of de la Cerda (1975) explains another significant feature of the flow field not explained by the current data sets used in the present study: the bathymetric limiting of a strong cyclonic feature centered around 20.5 degrees North, 92 degrees West, in the central and western part of the Bay of Campeche. None of the current datasets used in the present study begin to describe this strong cyclonic feature, which Galt (1981) refers to as the Campeche Gyre.

\section{Temperature}

Temperature is used as a state variable only in the evaporation routine, where it appears in the denominator of the expression for the diffusion coefficient in units of degrees Kelvin (see p. 14) The range of surface water temperatures reported for the Gulf of Mexico in Capurro and Reid (1970) is 19 degrees to 30 degrees Celsius, or 292 degrees to 303 degrees Kelvin, yielding a four percent variation in the denominator. Windspeed shows as the exponent of the natural logarithm base, and thus for an expected range of zero to ten meters 
second, yields a variation of 1 to 8,000 in the numerator. Because of the relative insensitivity of the evaporation algorithm to temperature, a value of 28 degrees Celsius (Blumberg and Mellor, 1981) has been used for all simulations. 
CHAPTER 5

Results of Model Simulations

\section{face Trajectory}

Using the wind and current data sets presented, nine cases of surface trajectory simulations are presented. Six of these are test cases showing the surface trajectory predictions of wind only and current only forcing, and three cases are presented for comparison of each of the combined wind and current datasets. A Julian calender has been used as the time reference, with Julian day (79)154 being the inception of the spill. All of the surface trajectory cases have been run through day 243, the beginning of September, because of surface apill observations introduced below. The Julian dates have been modified to give a monotonically increasing timeline for the sp111. Thus (80)00I is labeled as (79)366. In all figures with URI/OSFM predicted trajectorles overlayed with overflight abservations the simulated trajectory is for the same day as the overflight observations.

The cases are broken into three current and wind field inputs: (WI)-(U1), (W2)-(U2), and (W3)-(U3).

\section{Ind Drift Factor}

For wind and current sets 1 and 2 , a down-wind drift of the illet over the current field advection of $1 \%$ is used, based on aperimental observations at the Argo Merchant spill site (Grose and 
Mattson, 1977). For wind and current set 3, a wind drift factor of $3.5 \%$ of the wind speed downwind is used.

\section{Predicted Spill Trajectories:}

Figures 11, 12 and 13 depict simulations with differing wind and current forcings 90 days after the spill inception.

\section{Diagnostic Environmental Data Input Simulations:}

For each of the three input environmental data combinations, two diagnostic simulations were run. Figures 11 represent Current forcing only; Figures 12 Wind forcing only. Figures 11 and 12 are of use in showing the relative contributions of each of the environmental forcing fields separately. Comparison of the three Current only driven cases (Figures 11A, 11B, 11C) shows the relatively larger surface water transports induced by wind forcing (U1) and (U2) than by the seasonal hydrographic forcing (U3). The (U1) current field, with its simple Ekman forcing (Figure 11A), gives a surface trajectory which is closer to the observed Ixtoc oll movement than does the much more sophisticated (U2) Dynalysis (F1gure 11B) current field. In Figure 11C (U3 only) the seasonal nature of the ensemble averaging of the input hydrographic data effectively low-band-passes the dally and cyclonic scale wind-driven flows, and reveals only the seasonal residual of combined density and wind 


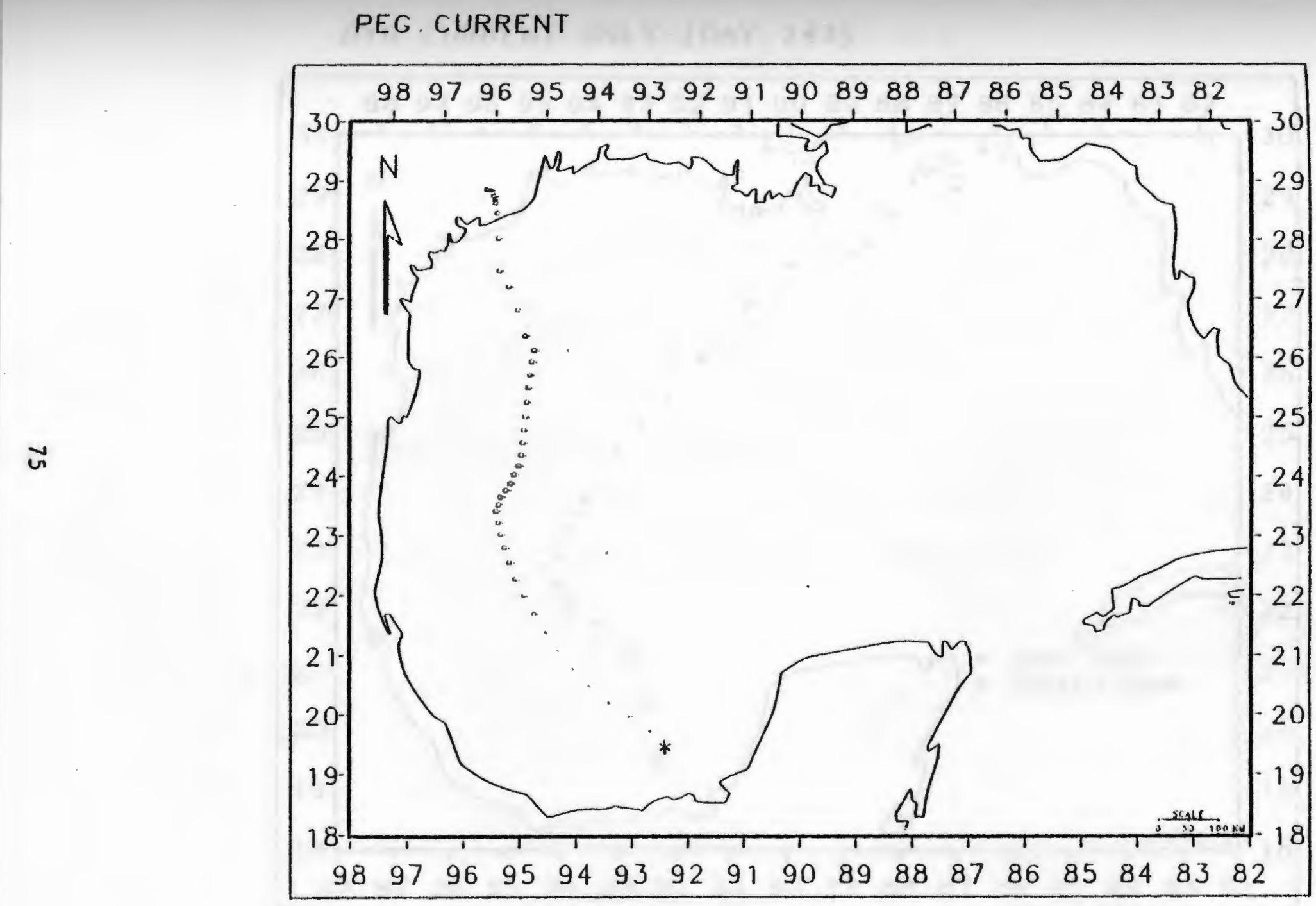


DYN. CURRENT. ONLY-(DAY. 243)

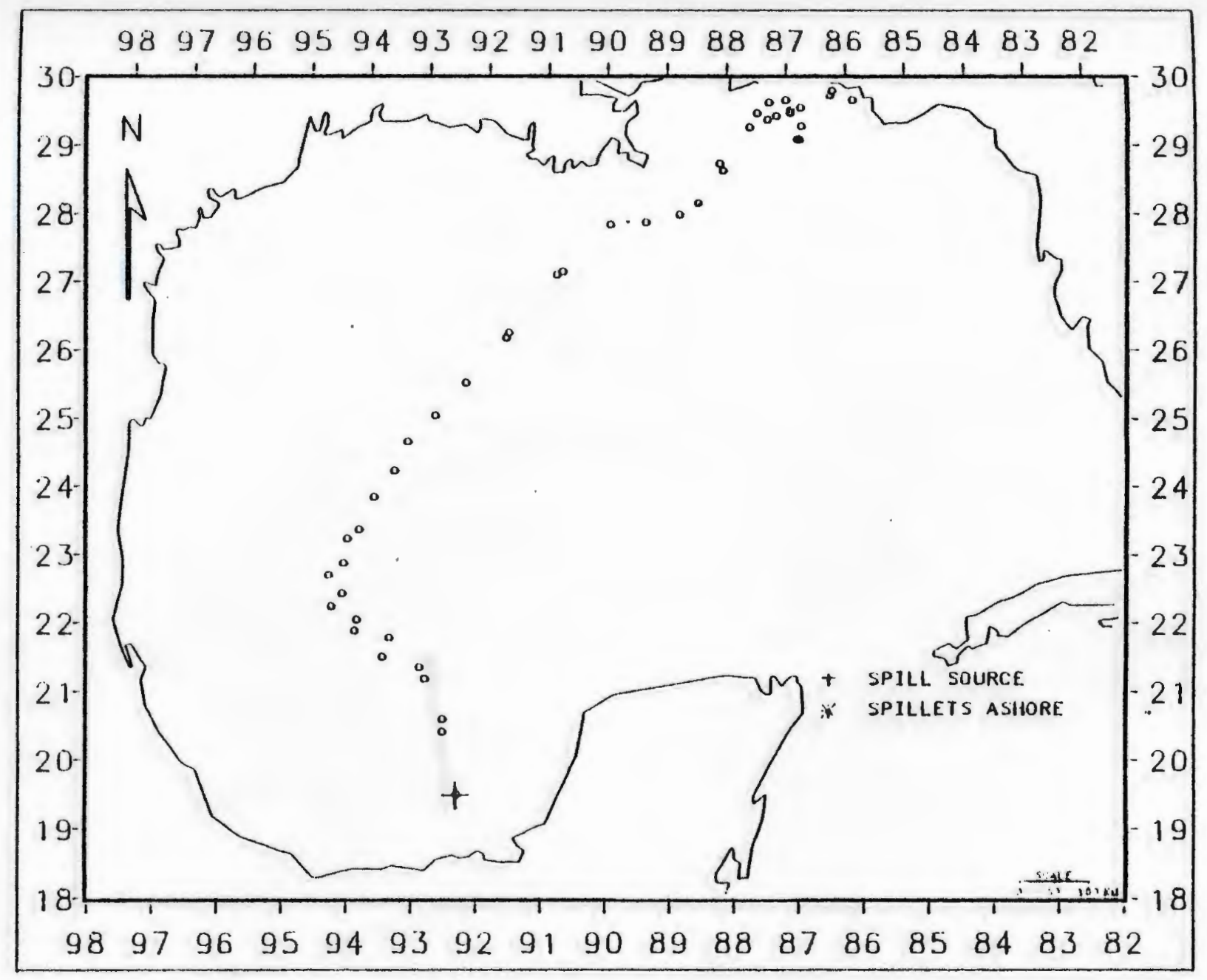

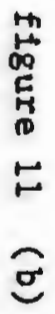


GROSE . CURRENT. ONLY (DAY. 243)-3. 5

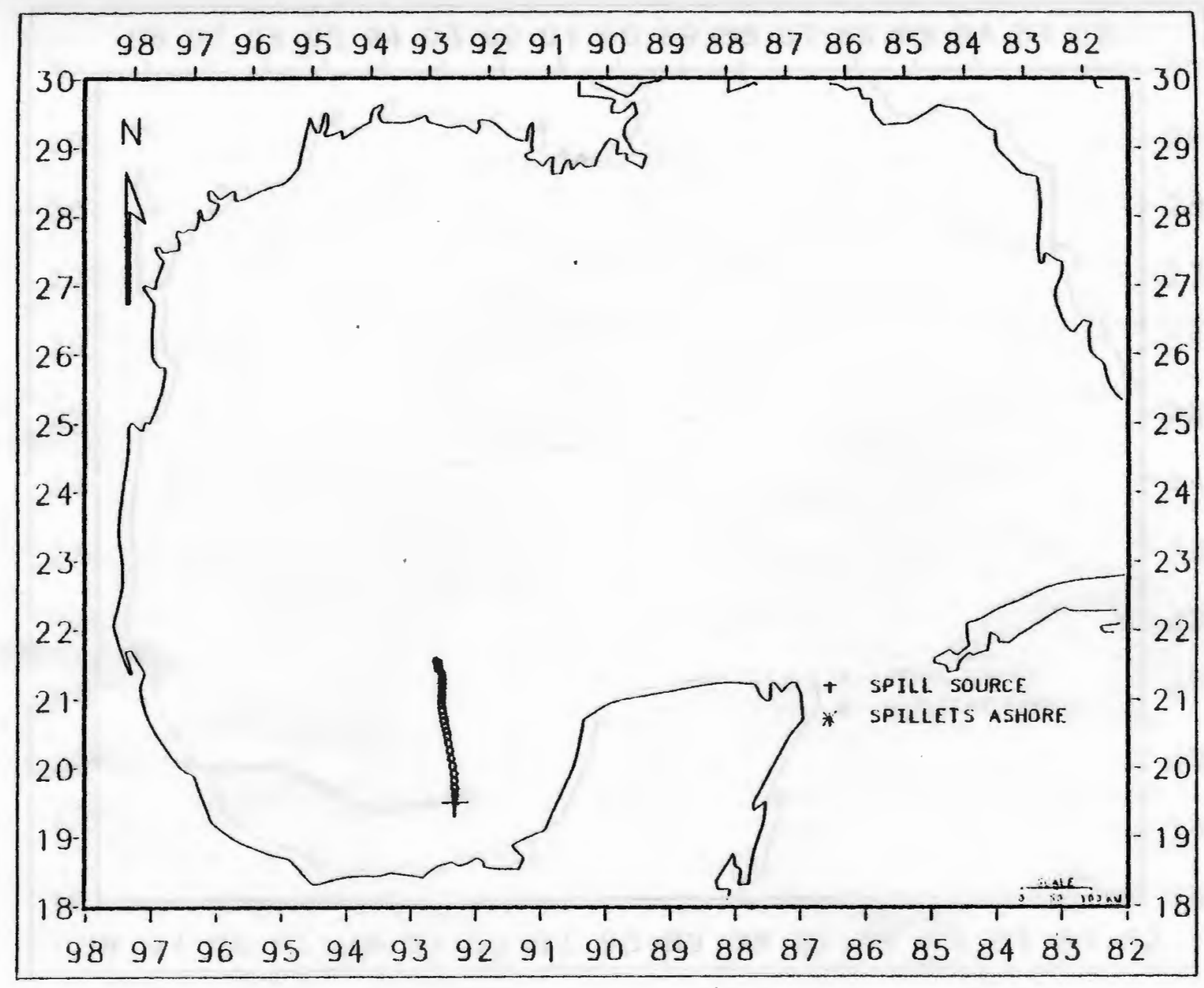

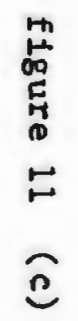


PEG. WIND -ONLY (DAY. 243)-1. OPC

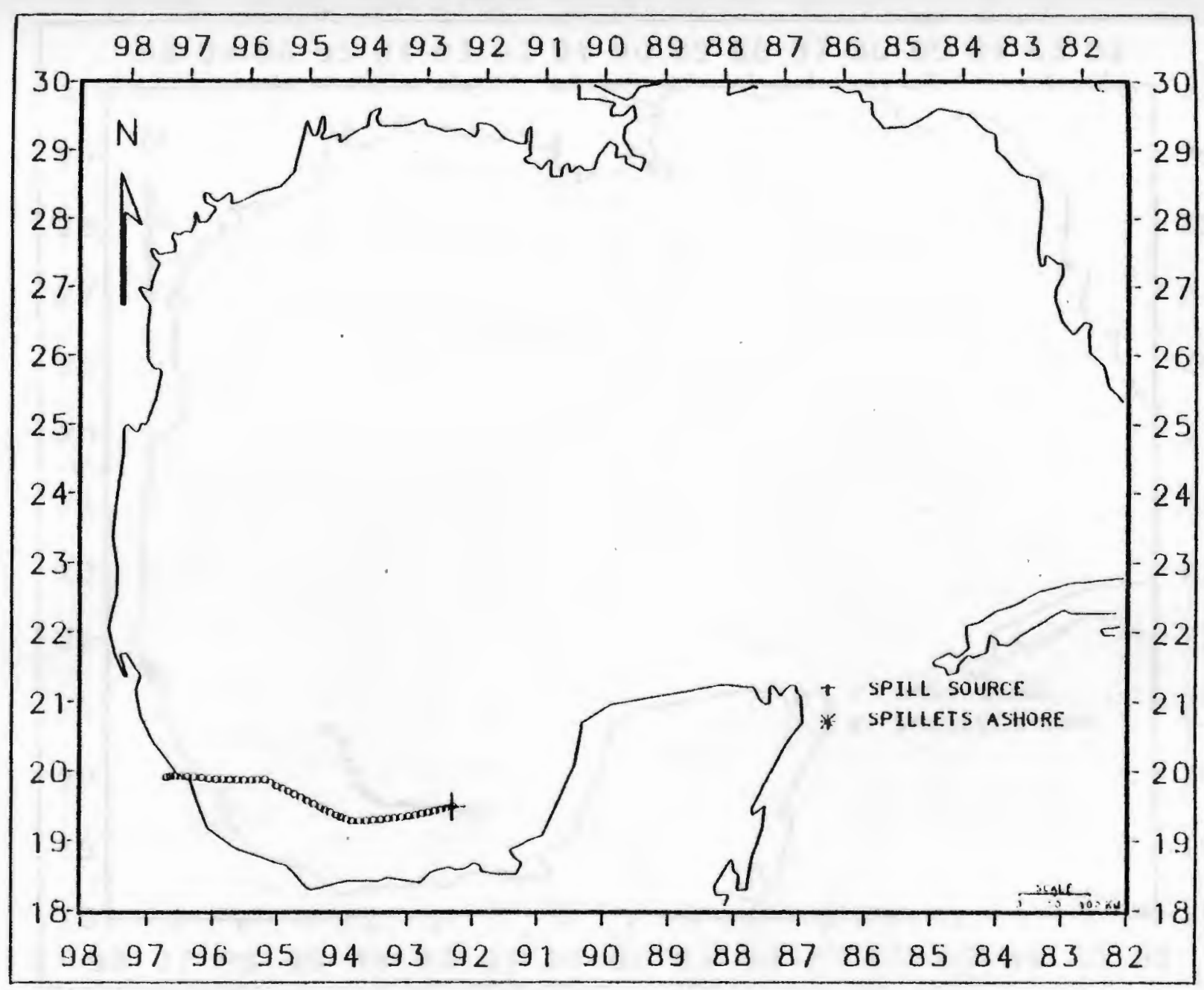


DYN. WIND. ONLY-(DAY. 243)-1. OPC

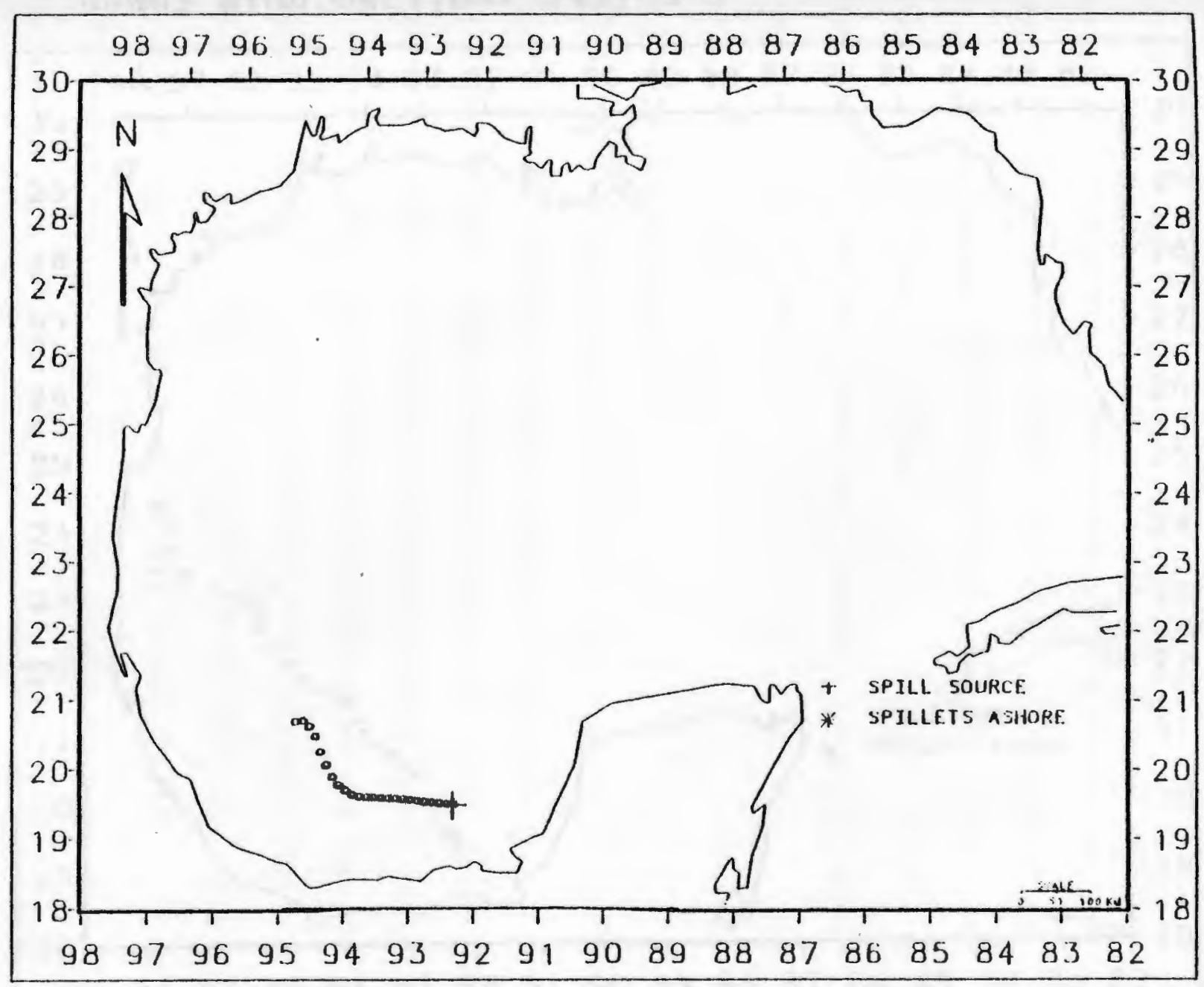


GRWNS. WIND. ONL Y (DAY. 243)-3.5

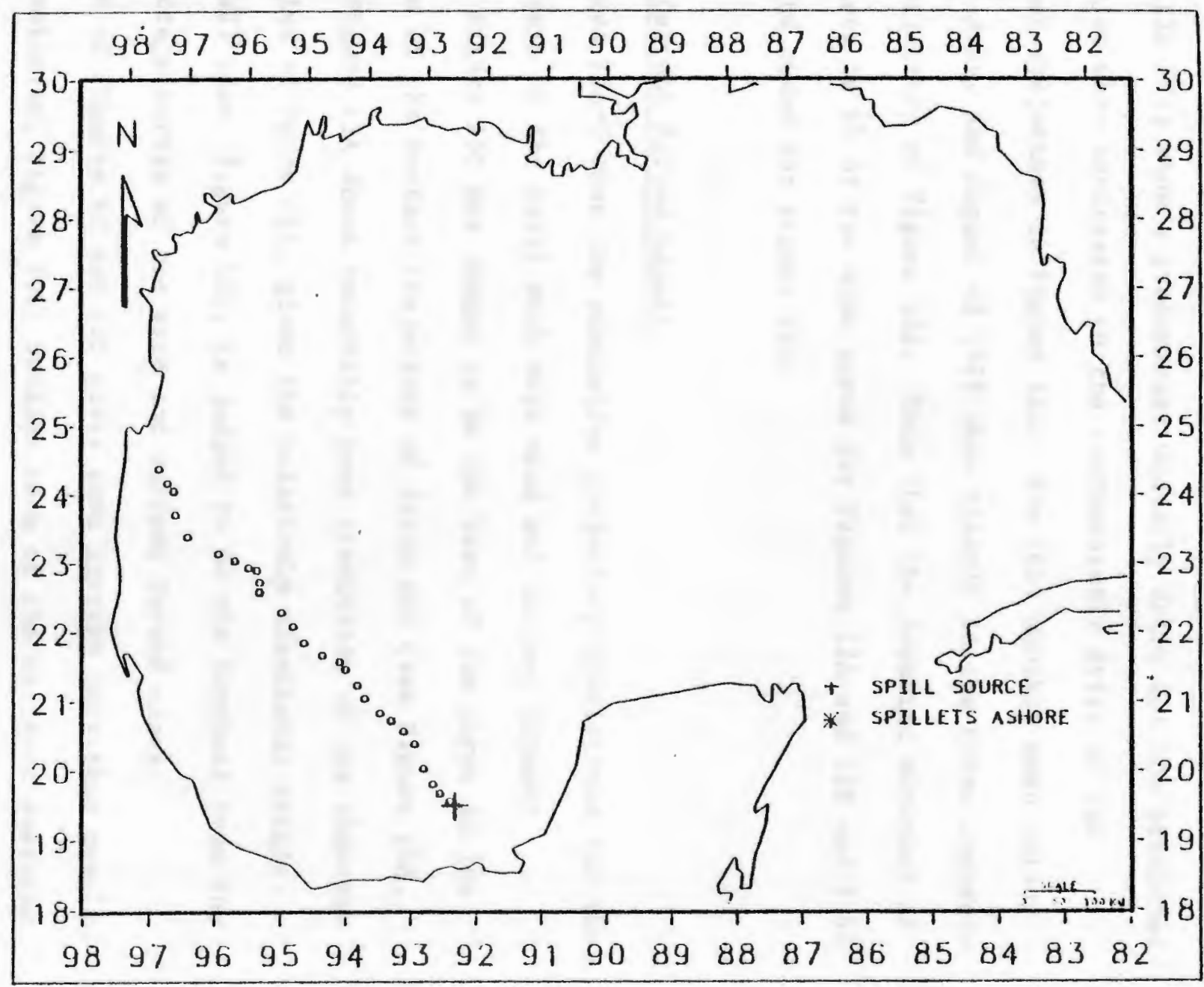


forcing.

Comparison of the three Wind only driven $(12 \mathrm{~A}, 12 \mathrm{~B}, 12 \mathrm{C})$ cases indicates a spatial variablity of the wind field. Both Figures $12 \mathrm{~A}$ (U1) and 12B (U2) show a predominant westerly drift for the predicted trajectories when contrasted to the northwesterly drift of the (w3)-driven trajectory in Figure 12C. The (U1) monthly mean values for June, July, and August of 1979 show clearly in the three segments of the trajectory of Figure 12A. Note that the downwind movement of the spillets is $1 \%$ of the wind speed for Figures $12 \mathrm{~A}$ and $12 \mathrm{~B}$ and $3.5 \%$ of the wind speed for Figure $12 \mathrm{C}$.

\section{Wind and Current Forced Cases:}

Figures $13 \mathrm{~A}-\mathrm{C}$ show the simulation trajectory predictions for the first 90 days of the spill with both wind and current dataset forcing. Figure $13 \mathrm{C}$ was judged to be the best of the three in its prediction of the surface trajectory of Ixtoc oil (see Figure 14A, below). Flgure 13A shows remarkably good prediction of the observed trajectories of Ixtoc oil, given its relatively simplistic origin. The (U2)(W2) case, Figure 13B, is judged to be the furthest from the observed trajectories of the wind and current forced cases. Comparison of Figures $9 \mathrm{C}$ and $10 \mathrm{C}$ gives some insight into this result. The (U3) solution; Figure 10C, retains wore of the cyclonic features which would tend to keep the Ixtoc oil circulating within the extreme southwestern Gulf. The (U2) current field, Figure 9C, does not reflect any of the circulation features of the area, and surface oil 


\section{PEG . WIND . CURR-1. OPC}

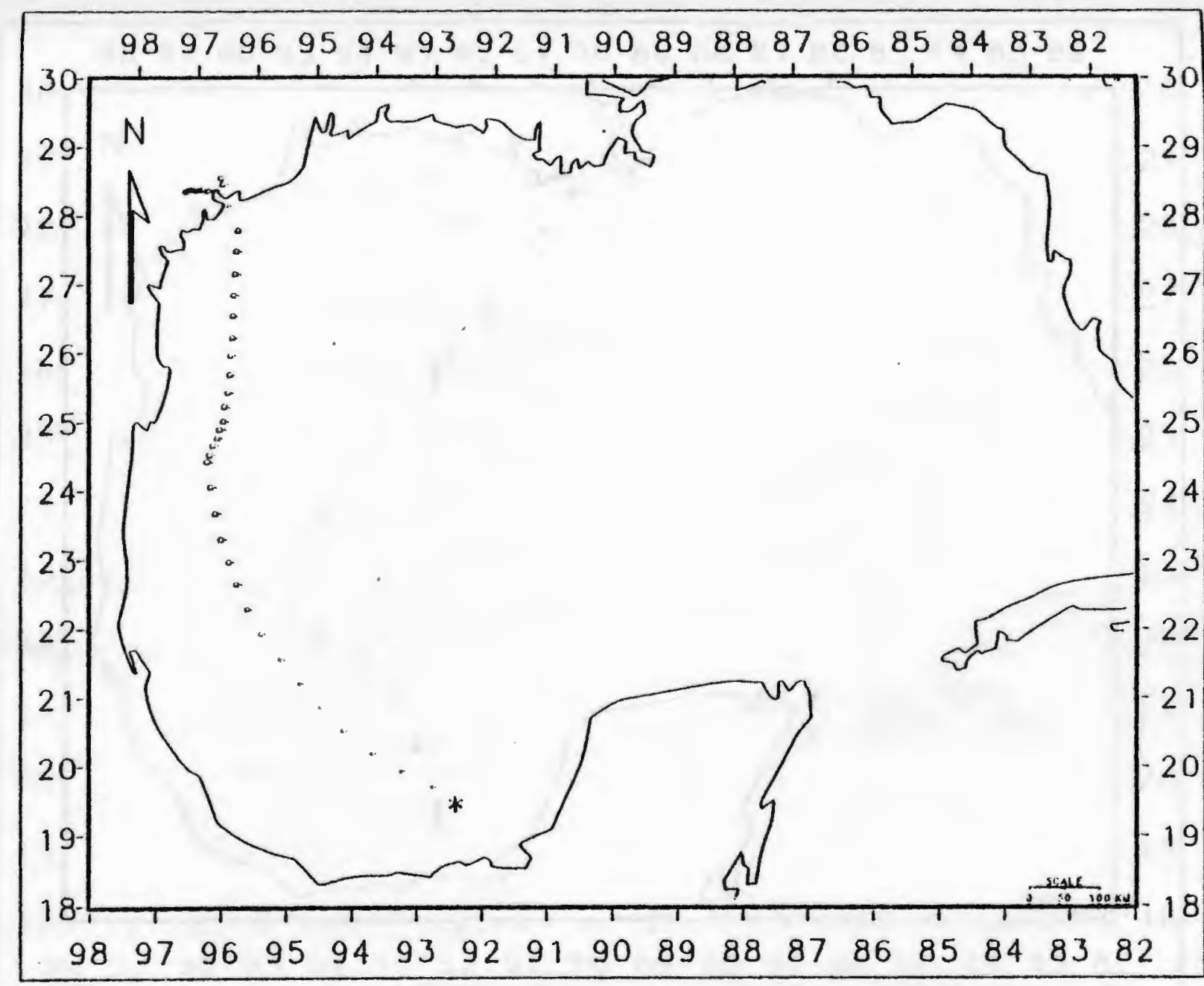


DYN. CURR. WIND-(DAY. 243)-1. OPC

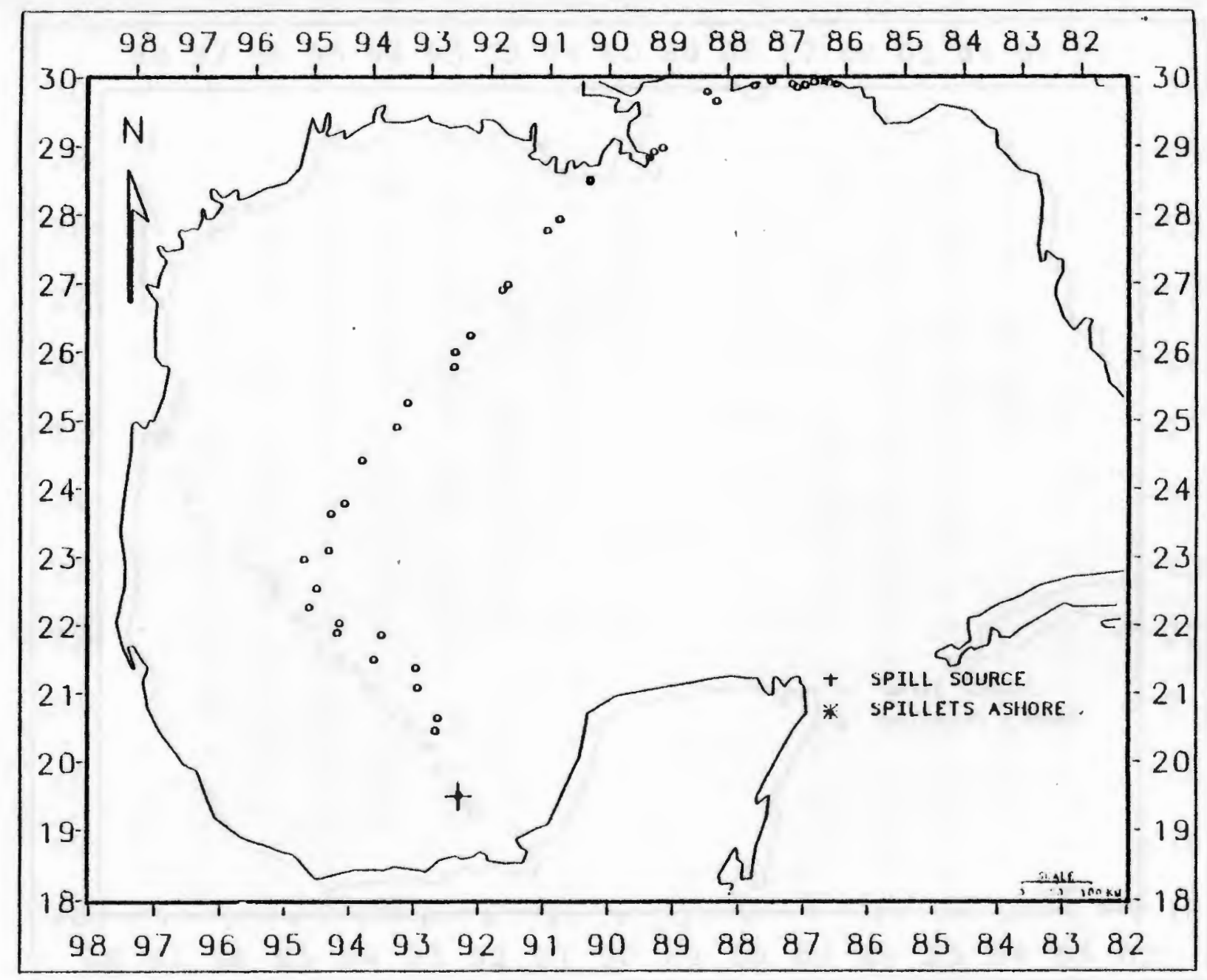




\section{3 (JUL IAN DAY)}

GROSE . C. BRWNS. W-3. 5PC-5OPPB

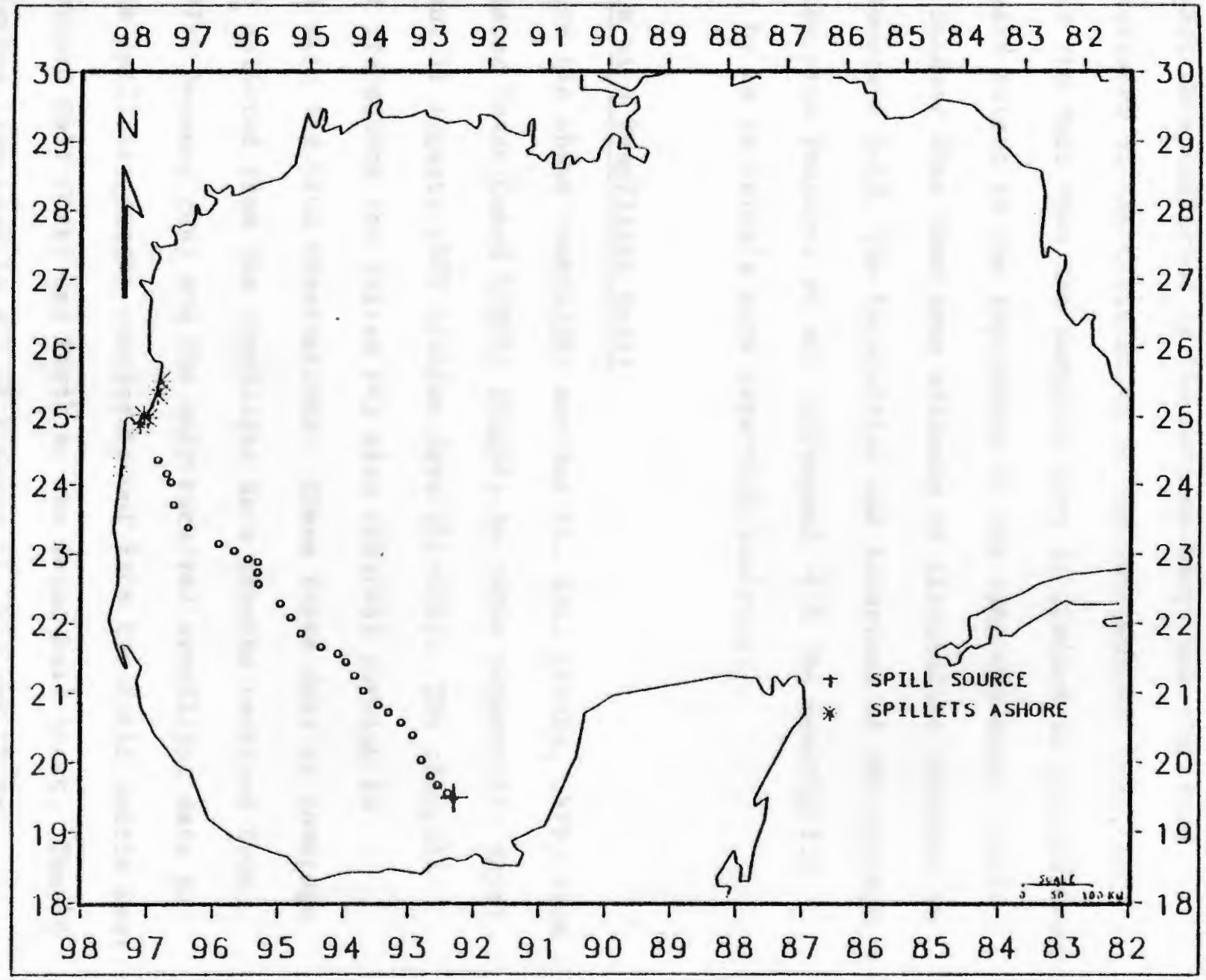

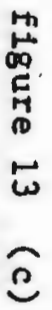


would be advected in a NNE direction away from the reported impact areas of the Southwest Gulf given this current field as the sole moironmental input. De la Cerda (1975), who had access to hydrographic data collected by the Mexican Navy, has clarifled several features of the circulation in the southwestern Gulf, in prticular the fact that the Campeche Gyre is limited in its northern and westward extent by the topography of the Campeche Bank. While the (U3) dataset does show some evidence of circulation features in the southwestern Gulf, the intensities and locations of the centers of the predicted features do not correspond with the description generated by de la Cerda's more data-rich analysis.

Comparison with Overflight Data:

Figure 14A shows overflight surface o11 data (Shuhy, 1979) from United States Coast Guard (USCG) flights on three consecutive days: 29, 30, and 31 August, 1979 (Julian days 241-243). The oflspi11 predicted trajectory for Julian 243 with (U3)(W3) forcing is overlayed wh the USCG observations. These three days of coverage have been selected from the overflight data reports recelved from Shuhy (1979) because they are the only recelved overflight data to follow the spill trajectory completely out from the spill source West to the Mexican Gulf Coast and North to the Texas Gulf coast. The 90 day simulation time used in all of Figures 11, 12, and 13 is predicated on the availablity of this complete set of overflight data logs. A triangle is plotted at every occurrence of mousse 


\section{3 (JULIAN DAY)}

GROSE/C. BRWNS/W-3. 5PC

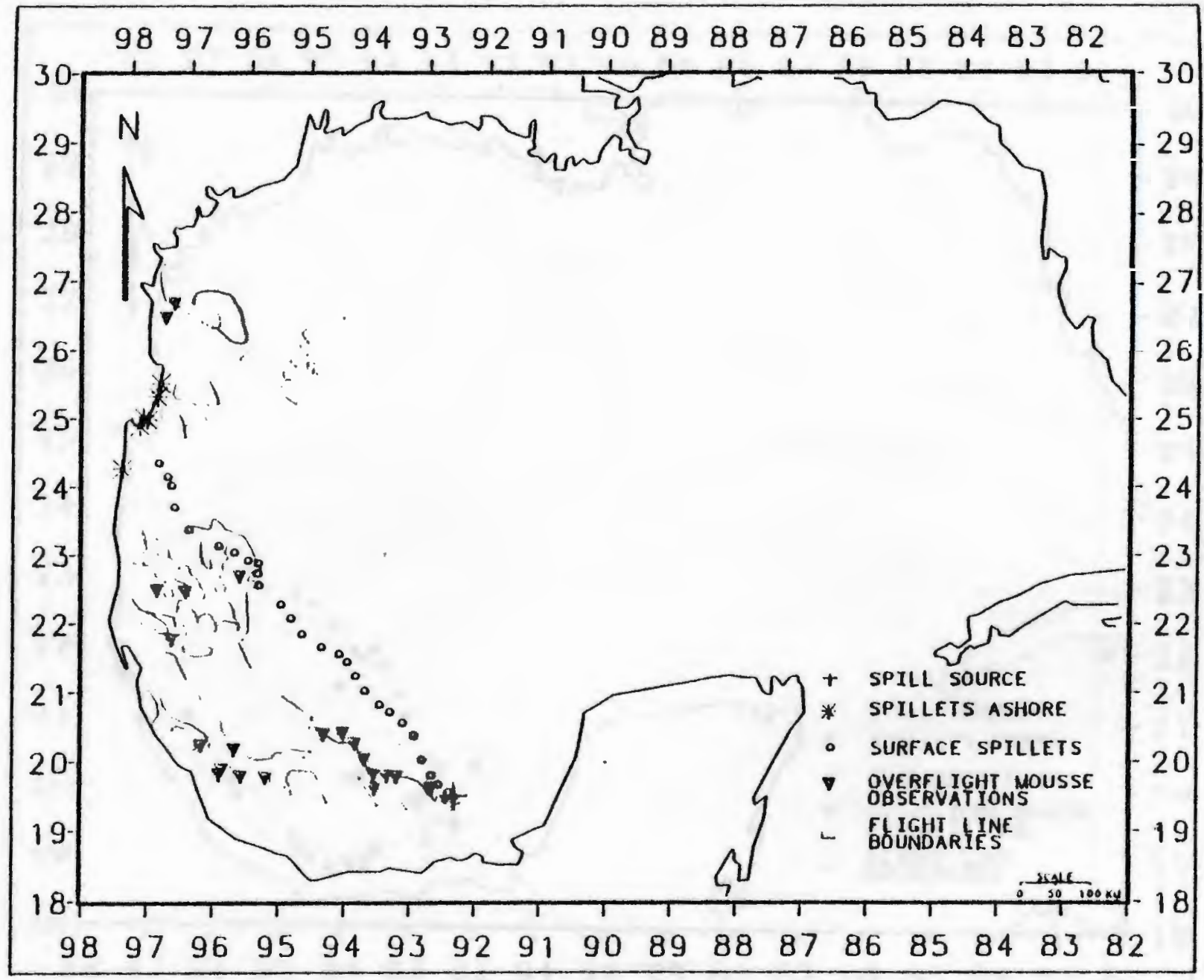




\section{5 (JULIAN DAY)}

GROSE/C. BRWNS/W-3. 5PC--GALT. OVERFLIGHT

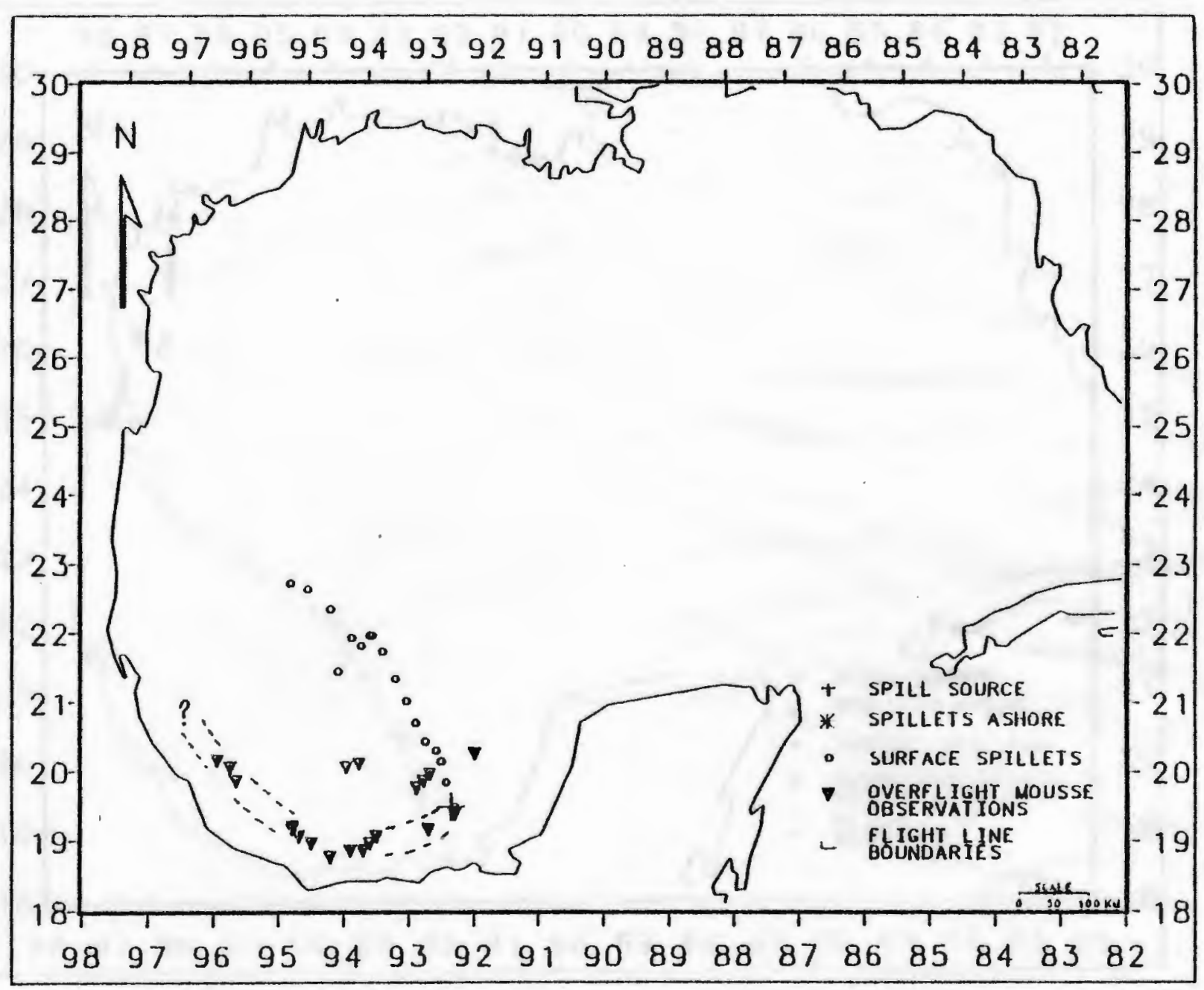




\section{5 (JULIAN DAY)}

GROSE/C. BRWNS/W-3. SPC

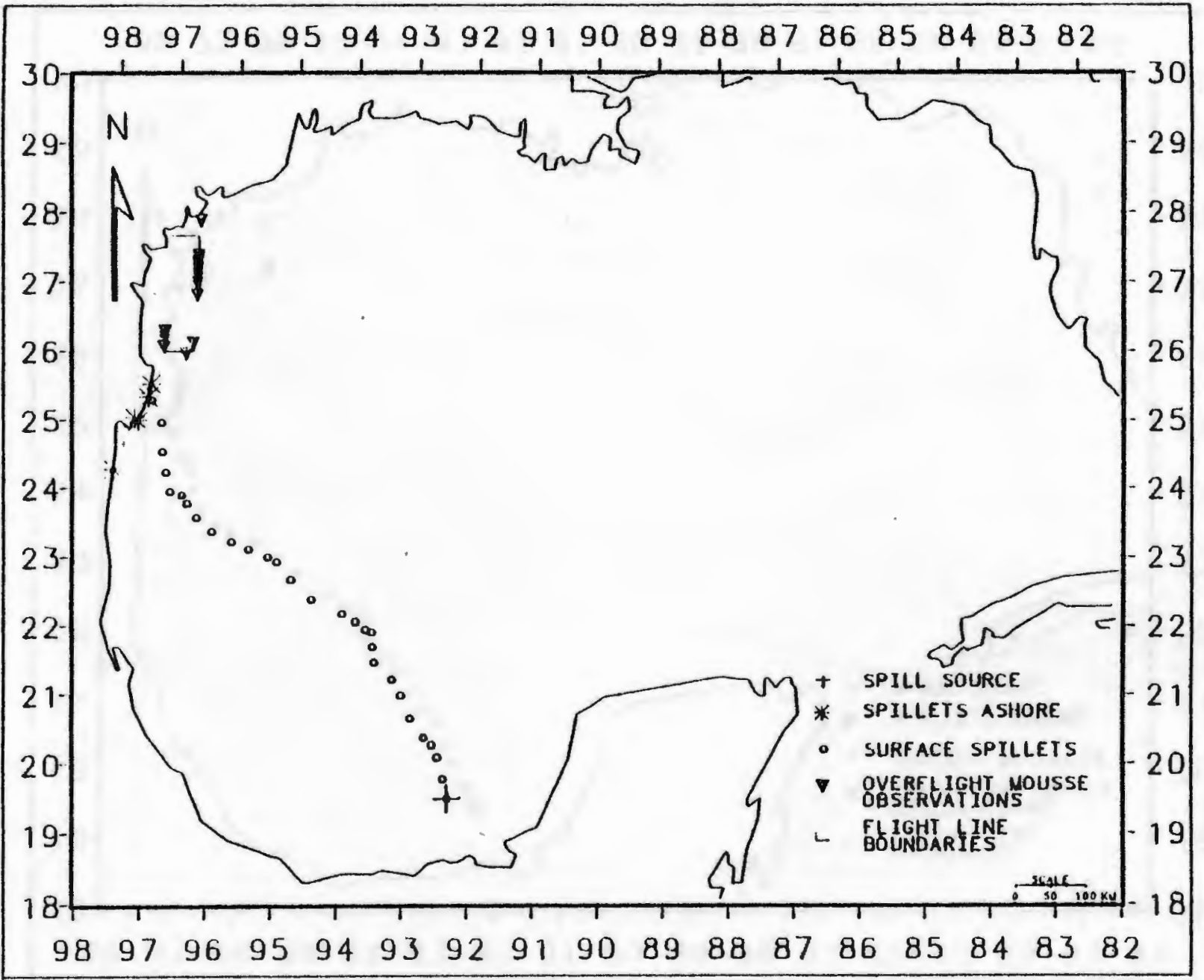

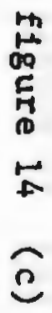


231 (JULIAN DAY)

GROSE/C. BRWNS/W-3. SPC

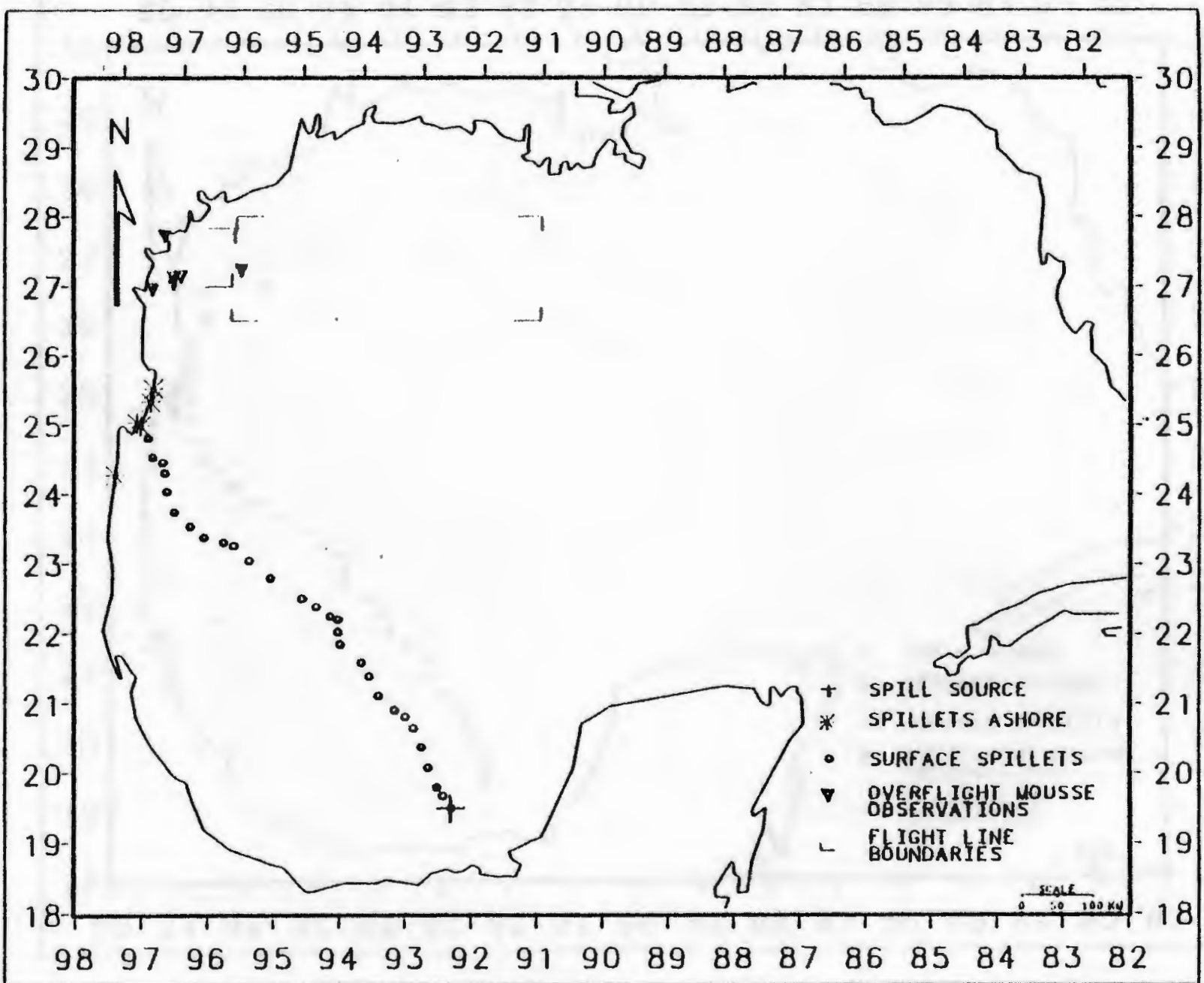




\section{5 (JUL IAN DAY)}

GROSE/C. BRWNS/W-3. 5PC

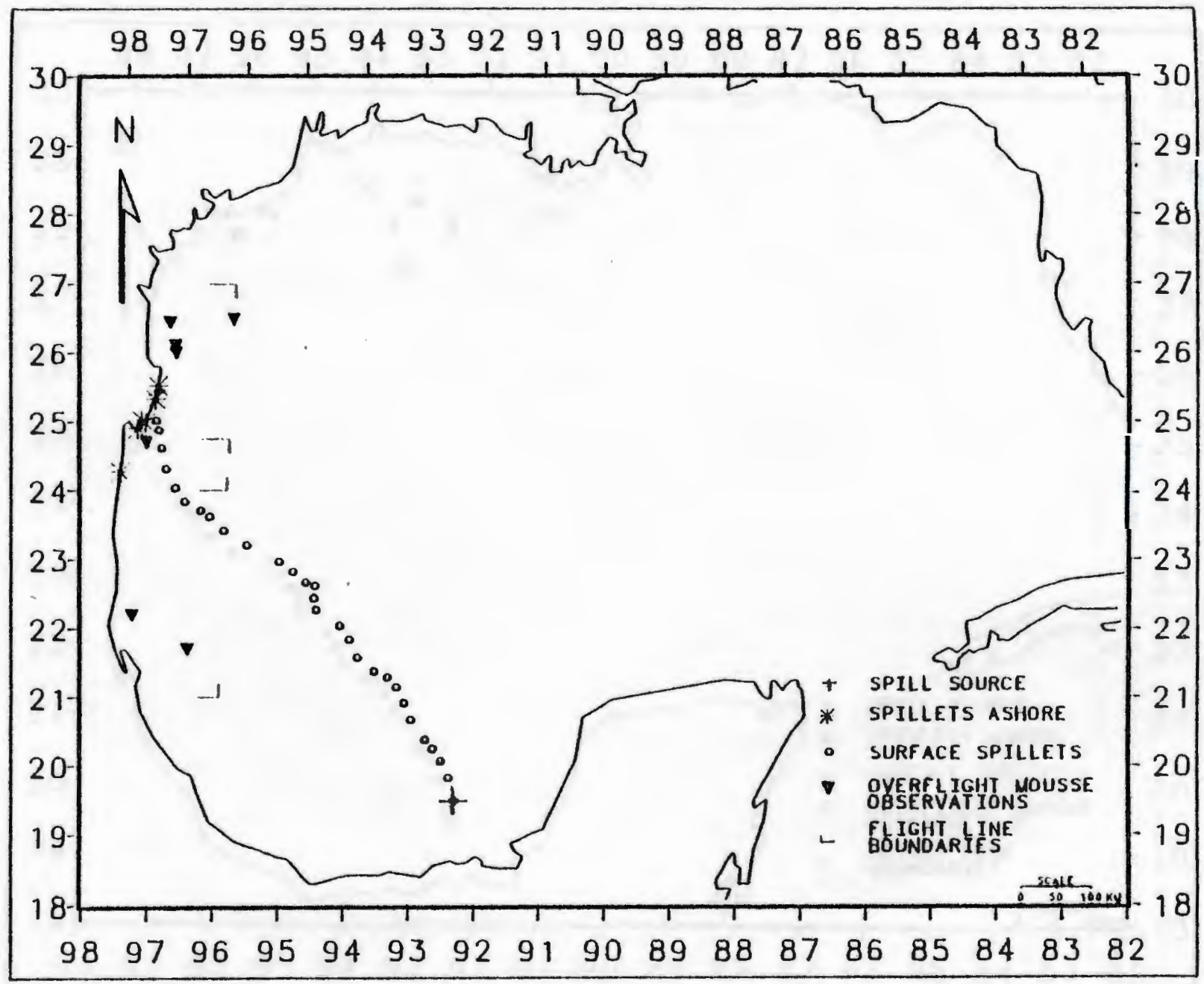




\section{7 (JUL IAN DAY)}

GROSE/C. BRWNS/W-3. SPC

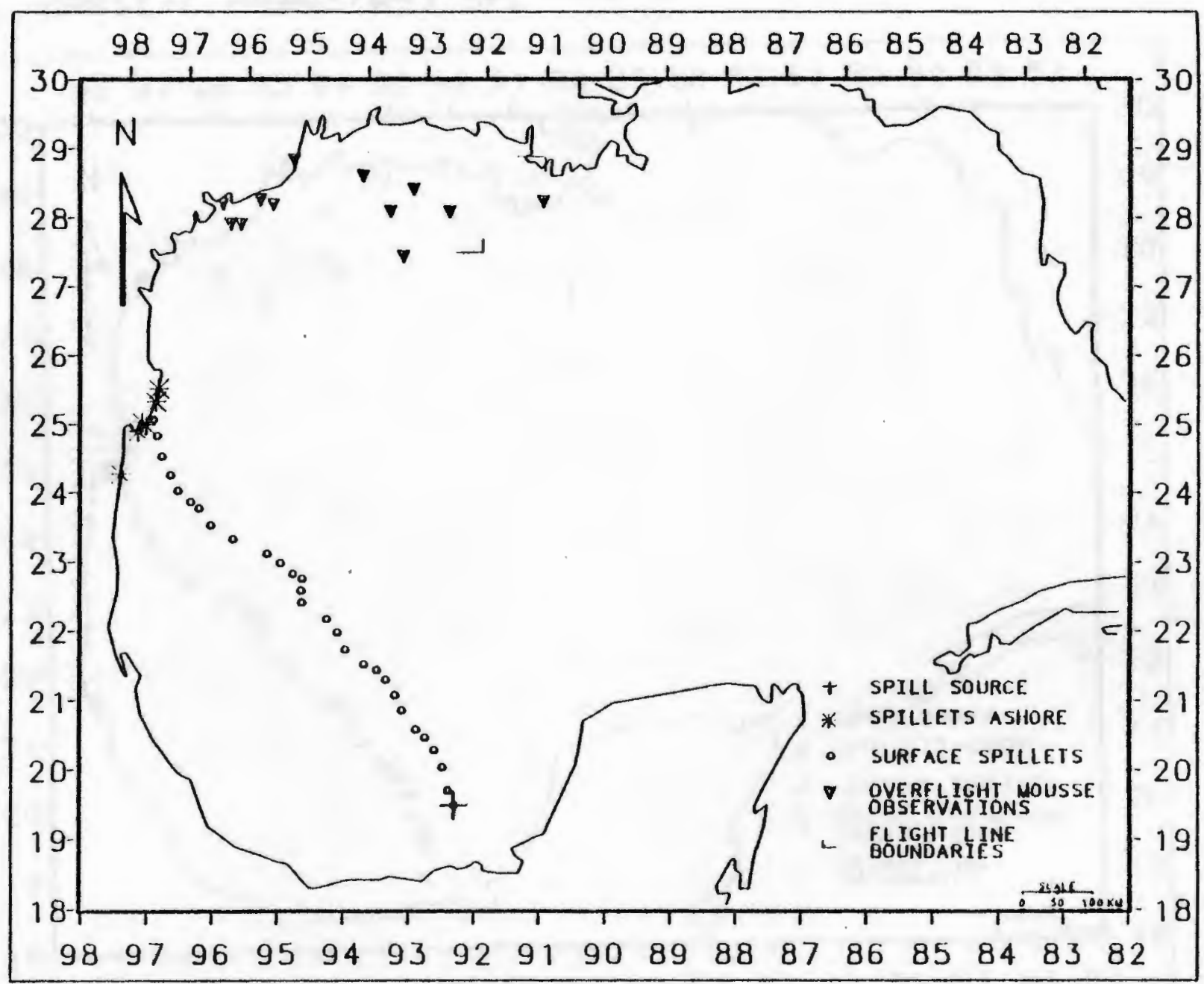




\section{9 (JUL IAN DAY)}

GROSE/C. BRWNS/W-3. SPC

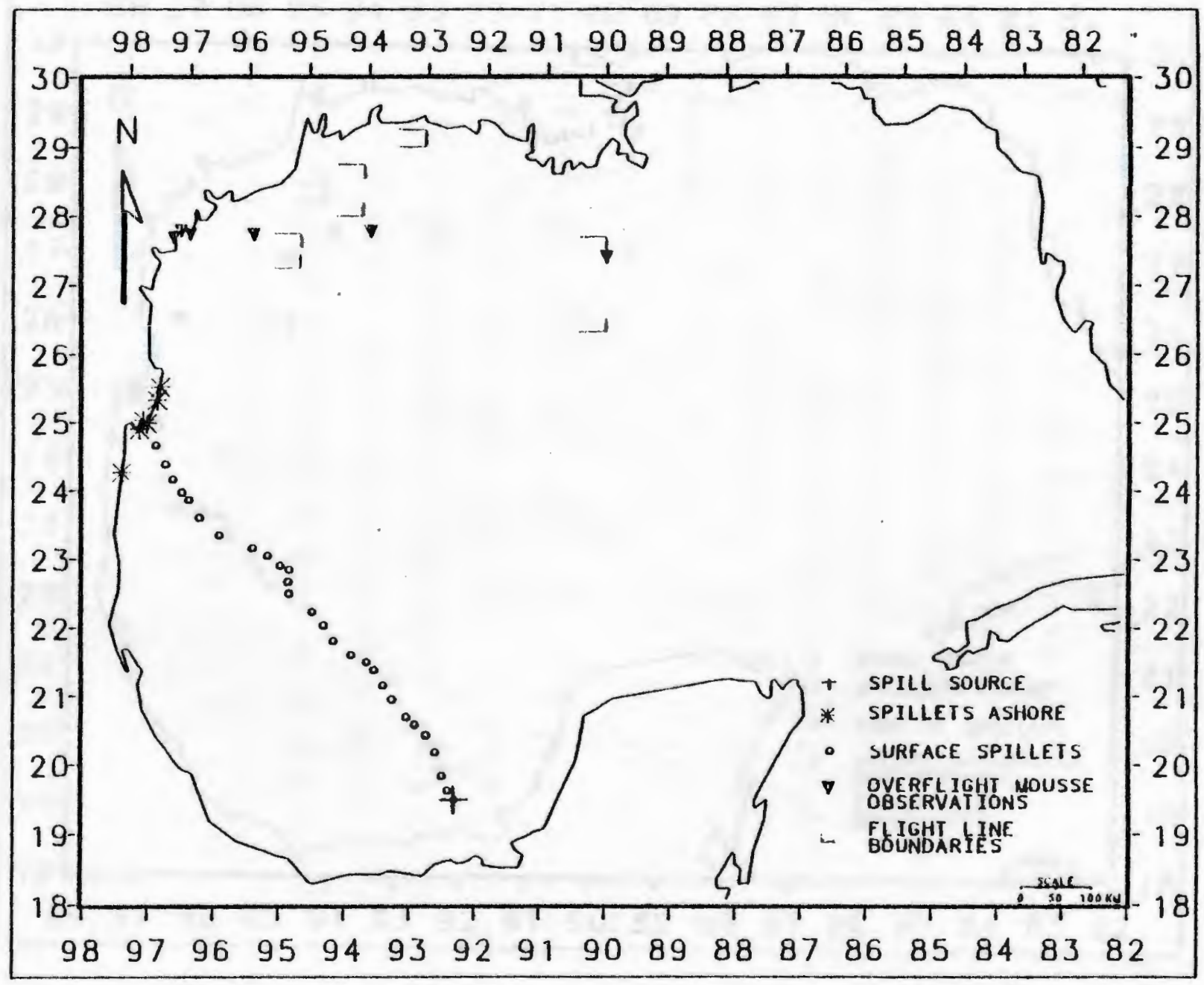




\section{7 (JUL IAN DAY)}

GROSE/C. BRWNS/W-3. 5PC

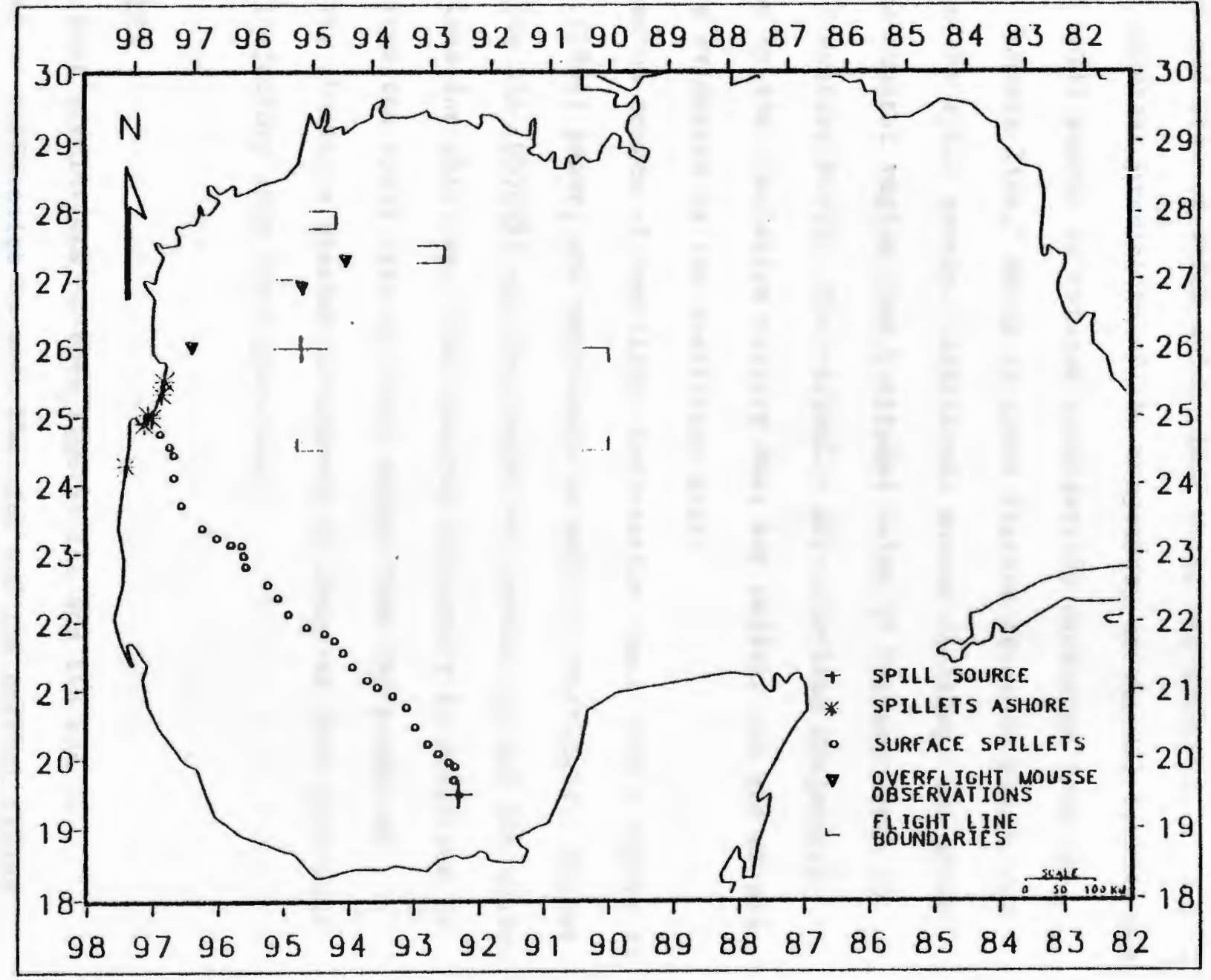


observations in the flight logs. Of particular interest in Figure $14 \mathrm{~A}$ is the sinuous line extending West and North from the spill source. This line is labeled "mousse line," and is the boundary to the North and East of which which clear water was observed.

The hindcast prediction of the trajectory of the oil leading out from the spill source is rotated considerably clockwise from the observed "mousse line," which in gross feature proceeds almost due West from the spill source. Additional mousse sightings are shown along the coastal region from Latitudes below 20 degrees North to almost 27 degrees North. The virtually straight-line trajectory predicted by the simulation clearly does not reflect the arc of oil sightings evidenced by the overflight data.

A second source of overflight information comes from a figure in the Galt (1981) paper, and represents an earlier overflight. Figure $14 B$ depicts the (U3)(W3) spillet trajectory prediction and the mousse observations for this day. The observed trajectory is indicated to emanate from the spill site at right angles from the predicted trajectory, showing a greater divergence of observed from predicted initial trajectory than for Figure $14 \mathrm{~A}$.

\section{Discussion:}

The poor predictions of both Figures 14A and 14B can be attributed to deficencies in both the wind and the current fields. Inspection of Figure 5C, the (U1) wind field for July 1979 show a considerable counterclockwise rotation of the surface wind vector at 
21 degrees North, 92 degrees West (closer to the spill origin) from that of 27 degrees North, 95 degrees West (closer to Brownsville). This comparison indicates the spatial differentiation of the wind field which has been mentioned above as a weakness of the use of the Brownsville wind data. Additionally, the cyclonic feature termed the Campeche Gyre by Galt (1981) and described by de la Cerda (1975) would be likely to contribute to the southwesterly drift of the observed trajectory at the spill origin. Observations at the spill site (OSIR, 1981; Atwood (Ed.), 1980) indicate that rapid changes in the direction of the plume emanating from the well were commonplace, and there was little observed correlation between wind direction and the plume orfentation. Small excursions of a feature such as the Campeche Gyre would expla1n these local observations. It appears that the Ixtoc 1 well site lay at a location within the southwestern extreme of the cyclonic Campeche Gyre. At the time of the Galt overflight the plume extended West and South from the spill source. From 15 September to 20 September the Reseacher/Pierce Cruise participants observed the output plume moving to the Northeast at about 045 to 055 degrees true (Atwood (Ed.), 1980). On 21 September the output plume swung to a Southeasterly direction over about a 12 hour period, and when the Researcher departed the plume was flowing at about 135 degrees true (ibid). It is clear that none of the hydrodynamic fields used in this hindcast reflect the Campeche Gyre in its intensity or dynamic character. 
Observed Beaching of Ixtoc 0il:

Plots of URI/OSFM trajectory predictions using the (U3)(W3)

environmental data are overlayed with mousse sighting locations for the complete set of overflight information received from Shuhy (1979) in Figures $14 \mathrm{C}$ through 14H. Flightline boundaries have been Indicated by a graphic noted on the plots. Figures $14 \mathrm{E}$ and $14 \mathrm{H}$ have two days' overflight information superimposed. The model predicted shoreline beaching of oil is concentrated in a band from 24 to 26 degrees North for all days presented. Heavy ofling of the coast between 26 and 28 degrees North was reported (OSIR, 1980a) from Julian days 225 through 235 (see Figure 1). Heavy shoreline oiling was also reported by USCG overflight on Julian 235 between Latitudes 21 and 21.5 degrees North (Shuhy, 1979). These observed strandings of oil to elther side of the simulation predictions again show the predicted spill trajectory to be less than satisfactory in describing the surface advection of the spilled oll.

\section{Mass Balance Predictions:}

\section{Total Simulation Mass Balance Predictions:}

Figure 3 gives the time history of the estimate of oil escaping from Ixtoc 1 used for this hindcast. Estimation of the spill rate time history of oil from a blowout includes a good deal of subjective Judgement. The volume release rates presented are based upon field estimates from in OSIR $(1980 a-f)$ and the U.S. Coast Guard (Dept. of 
Iransportaion, 1980), and represent a best estimate based upon the range of estimates reported. Five percent of the oll is assumed to have burned in the fire which was ignited at spill inception and burned continuously until 11 March 1980.

Table 2 presents the model-predicted spilled o1l mass balance as a function of time in the environmental partitions: atmosphere, water surface, water column (top $10 \mathrm{~m}$ ), and shore. Column one is the continually increasing Jullan day reference (see Figure 1). Column 2 is the cumulative mass input to the model, based on the estimates of Figure 3. Model predictions of spilled oil in each of the environmental compartments are shown in columns 3-6 as a percentage of the cumulative mass spilled. Over half of the spilled oil is predicted to evaporate into the atmosphere. This large fraction is the consequence of the large fraction of 11 ght oll mass fractions in the Pemex Ixtoc 1 oll fractionation assay (Petroleos Mexicanos, 1980). Almost $30 \%$ of the derived mass fraction is made up of the paraffins and aromatics with molecules of twelve carbon atoms or less. The low molecular weight fractions have a high vapor pressure and w11l very rapidly evaporate when the oil spreads out on the sea surface. Evaporation can account for as much as $60 \%$ of the mass balance of a spill of a light crude (Huang and Monastero, 1982).

\section{Discussion: Beached 011 Entrapment:}

The routine used to entrap beached oil at the shoreline assumes a $100 \%$ loss of o11 from the sea surface to the shore. This is a 
table 2

URI/OSFM Mass Balance Predictions

for the Ixtoc 1 Blowout

Spill Parameters

$\begin{array}{ll}\text { Oil: } & \text { Ixtoc wellhead (PEMEX, 1980) } \\ \text { Sites } & 1924, H, 92 \text { 19. W } \\ \text { Anount: } & 140 \text { Milition callons } \\ \text { Start: } & 2 \text { June } 1979\end{array}$

\begin{tabular}{|c|c|c|c|c|c|c|}
\hline 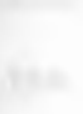 & $\begin{array}{l}\text { Julian } \\
\text { Day }\end{array}$ & $\begin{array}{c}\text { Cumulative } \\
\text { Mass } \\
\text { (MT) }\end{array}$ & $\begin{array}{c}\text { Atmos- } \\
\text { phere } \\
\text { ? }\end{array}$ & $\begin{array}{l}\text { Water } \\
\text { Sutface } \\
\text { ? }\end{array}$ & $\begin{array}{l}\text { Water } \\
\text { Column } \\
\text { s }\end{array}$ & $\begin{array}{c}\text { Shore } \\
\text { \% }\end{array}$ \\
\hline & $\begin{array}{l}154 \\
169 \\
184 \\
199 \\
214 \\
229 \\
244 \\
259 \\
274 \\
289 \\
304 \\
319 \\
334 \\
349 \\
364 \\
379 \\
394 \\
409 \\
424 \\
439 \\
446\end{array}$ & $\begin{array}{r}8970 \\
71050 \\
140240 \\
200020 \\
270190 \\
321110 \\
345350 \\
365100 \\
386500 \\
404300 \\
424660 \\
439050 \\
447002 \\
451062 \\
454650 \\
457341 \\
460929 \\
464517 \\
467204 \\
468574 \\
468591\end{array}$ & $\begin{array}{l}47.27 \\
47.74 \\
48.81 \\
49.68 \\
50.43 \\
50.96 \\
51.34 \\
51.58 \\
51.93 \\
52.09 \\
52.27 \\
52.39 \\
52.60 \\
52.90 \\
53.05 \\
53.14 \\
53.27 \\
53.40 \\
53.62 \\
53.81 \\
53.85\end{array}$ & $\begin{array}{r}52.73 \\
49.59 \\
48.33 \\
48.02 \\
45.90 \\
36.28 \\
26.56 \\
25.34 \\
19.74 \\
14.14 \\
14.47 \\
12.08 \\
11.98 \\
9.63 \\
6.68 \\
6.57 \\
6.73 \\
6.31 \\
5.77 \\
3.08 \\
2.64\end{array}$ & $\begin{array}{l}0.00 \\
2.67 \\
2.86 \\
2.30 \\
2.16 \\
1.84 \\
1.71 \\
1.62 \\
1.62 \\
1.55 \\
1.61 \\
1.62 \\
1.67 \\
1.66 \\
1.64 \\
1.63 \\
1.60 \\
1.63 \\
1.67 \\
1.68 \\
1.68\end{array}$ & $\begin{array}{l}0.00 \\
0.00 \\
0.00 \\
0.00 \\
1.50 \\
10.90 \\
20.37 \\
21.44 \\
26.69 \\
32.21 \\
31.62 \\
33.89 \\
33.73 \\
35.78 \\
38.58 \\
38.60 \\
38.30 \\
38.55 \\
38.83 \\
41.31 \\
41.71\end{array}$ \\
\hline
\end{tabular}


crude algorithm which will overestimate the oil mass lost to the shoreline (Gundlach et al., 1983). Of the 1.2 million gallons of Ixtoc 1 oil reported to have come ashore on Texas beaches, approximatedly 53 thousand gallons, or less than $5 \%$, was found to persist near the shore in the form of sub-tidal tar mats (Gundlach et al., 1981). The heaviest oiling of the south Texas coast occurred between 29 August and 1 September 1979. A tropical depression crossed the shoreline on 13 September 1979, causing a $60 \mathrm{~cm}$ elevation of the usually less than $1 \mathrm{~m}$ tides and generating 1 to $2 \mathrm{~m}$ waves. Within two days over 90 percent of the oil on the shoreline was removed by wave activity (Gundlach et al., 1981). Hard-packed, fine-grained sand beaches characterizing most of the barrier-1sland coastline resisted oil penetration and in general were cleansed rapidly. A small section of mixed sand and shell beach near the center of Padre Island retained significant amounts of oil. (Gundlach et al., 1981).

The Water Surface prediction of Table 2 is seen to be an underestimate, and the Shore prediction an overestimate for the later days in the spill hindcast because of the simplistic algorithm of stranded ofl discussed above.

\section{Discussion: Wind-Forced Water Column Entrainment:}

The Water column partition prediction is judged to be low, primarily because of the low windspeeds reflected in the Brownsville 
wind record. A significant increase in subsurface entrainment is to be expected with a wind record which reflects the more energetic windspeeds typical of offshore areas. Because no adequate over-ocean wind time series was avallable at the time of these simulations, it was not possible to obtain a precise estimate of the level of undervaluing of the Brownsville record. Comparison of monthly mean values of the (W1) and (W2) datasets to those of the (W3) set yielded factors of from two to three greater values. A less-than-100\% shoreline entrapment algorithm for beached ofl will also increase the Water Column fraction prediction, but the increase is not great because virtually all of the spillets which come ashore during the simulation are heavily weathered, and the exponential decay term within the entrainment routine (Chapter 2) quickly reduces the amount of oil entrained from a spillet. Previous simulations run without any shoreline entrapment ylelded Water Column partition fractions of between 2 and $3 \%$.

\section{Discussion; Subsurface Entrainment:}

The entrainment routine used in these simulations first Introduces the oil onto the water surface as a surface spillet. Subsurface entrainment and weathering of the released oil as it makes 1ts way from the release point at the wellhead to the surface is not addressed in these simulations, and some underestimate of the fraction of oil within the water column is expected because of this treatment. It is unclear, however, how great was the increase of 
stable subsurface entrained oil due to the turbulent mixing associated with the subsurface release of the Ixtoc oil. Topham (1975) reported on experiments with the subsurface discharge of gas and ofl mixtures. About $1 \%$ of the oil formed droplets of 50 microns or less in diameter, with a terminal rise velocity of $0.5 \mathrm{~mm} / \mathrm{sec}$ or less. This low percentage of small droplets could be further reduced by agglomeration of smaller droplets.

Flest and Boehm (1980) report on oll-in-water samples collected in the vicinity of the Ixtoc well blowout during the Researcher/Pierce cruise. Of samples which were passed through a 0.45 micron filter, two had fractions of filtered-to-unfiltered hydrocarbon concentrations of more than 0.21 , indicating a large amount of oil in an entrained form. The distribution of these high entrained-fraction samples was localized near the blowout source, however. It is not clear whether the entrained oil was in a stable "dissolved" form, and no conclusion about the stable subsurface-entrained fraction of Ixtoc ofl is presented (Fiest and Boehm, 1980).

Mass Balance Comparisons for 19 September 1979:

An environmental compartment mass balance estimate for 19 September 1979 based upon reports from the Researcher/Plerce Cruise has been reported previously (Spaulding et al., 1982). Only data collected during this cruise were comprehensive enough to allow an 
environmental partition mass balance estimate to be made on the basis of fleld-collected data. The values in Table 3 were generated on the basis of upper bound, lower boumd, and best estimates. Specific citations of all data sources used in the estimation procedure are included in Spaulding et al (1982).

Figure 15 shows a comparison of the model predicted mass balance in the partitions of atmosphere, water surface, and water column to the field-data-based estimate ranges for this day. Estimates of the amount of oll ashore were not possible with the field data available. Model estimation of oil entrained in offshore sediments was not possible given the entrainment scheme used, which first introduces oll into the environment as a surface slick (Chapter 2).

The model prediction for oil mass entrained in the water column is less than the lower bound estimate based on fleld observations. This result is to be expected, given the two reasons discussed above. The $5 \%$ of spilled oil mass estimated to be burned at the spill site was subtracted from the simulation spilled oil mass (Figure 3 ), and was an input, rather than a predicted variable in the simulation. The best estimate value for the field-data-derived atmosphere partition was the coumon subjective judgement of several observers at the blowout site. Upper and lower bound estimates were derived from observed n-alkane concentrations in the air above the affected area. The simulation prediction falls close to the upper bound of the fleld-derived estimate range. Questions of oil composition, subsurface entrainment, and oil weathering make these estimates 


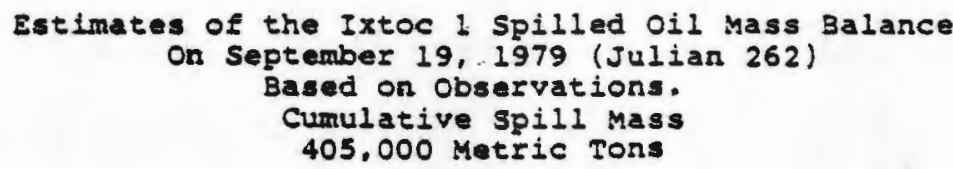

Lowar

Sound

Beat

Estimate

Upper

Bound

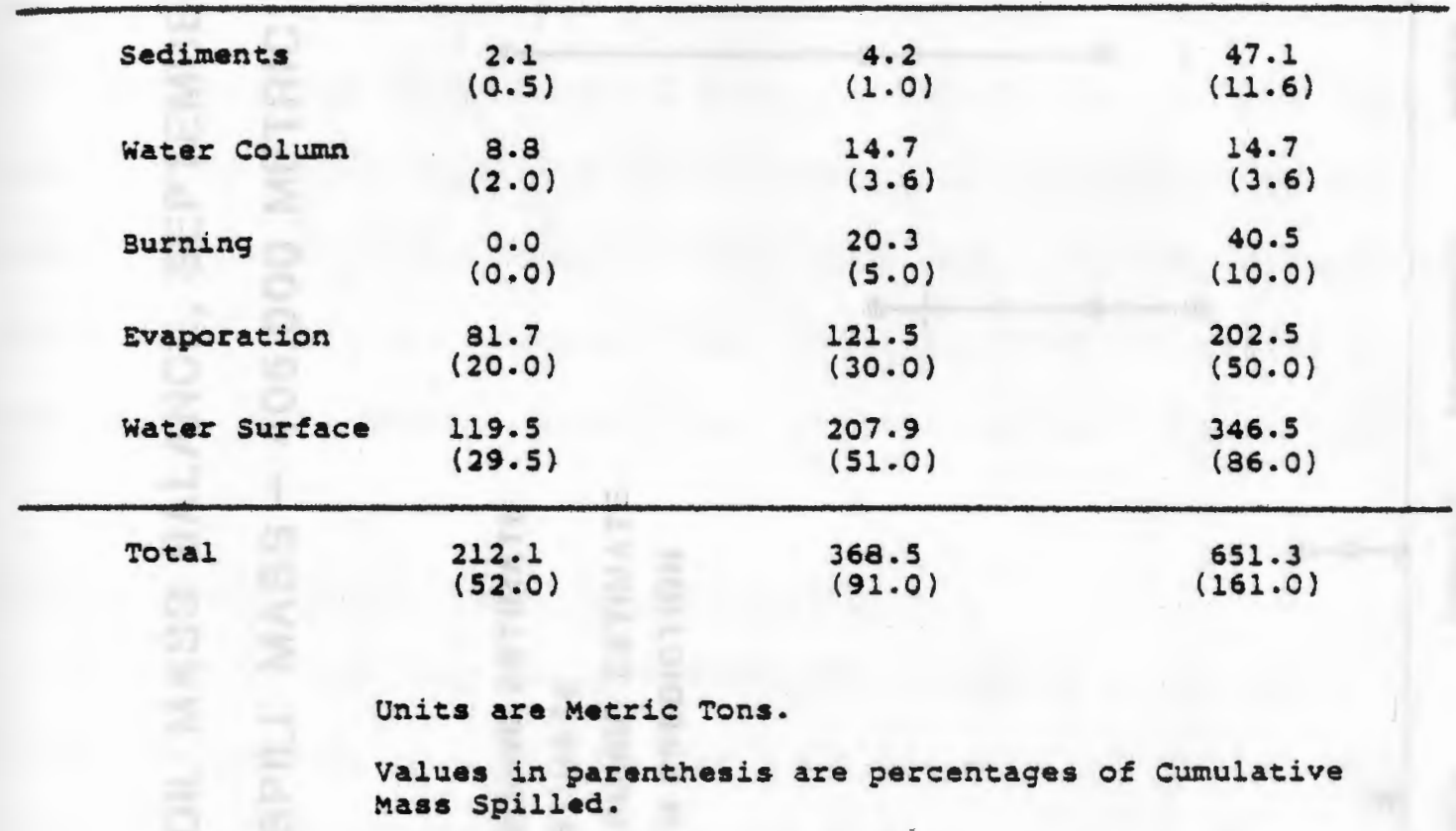


IXTOC I SPILLED OIL MASS BALANCE, SEPTEMBER 19, 1979 CUMULATIVE SPILL MASS - 405,000 METRIC TONS

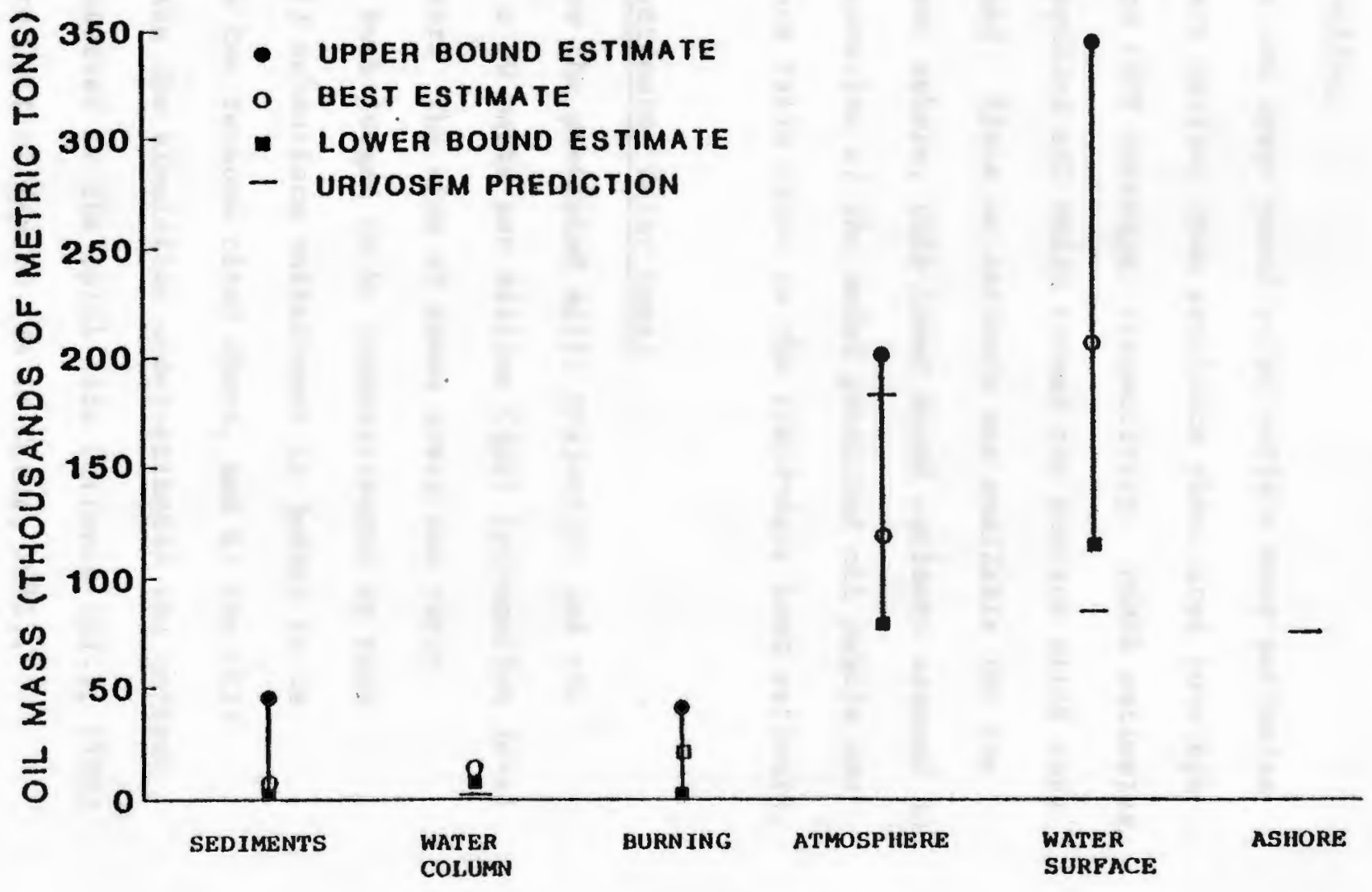


difficult to quantify. Boehm et al (1982) have presented a methodology which addresses the problem of the dissolution and evaporation of surface oll. Much work remains to be done in this aspect of oilspill modeling.

The best estimate and upper bound water surface mass estimates based on field data were derived from satellite photo area coverage estimates using $60 \%$ and $100 \%$ coverage, respectively. PEMEX estimates of the percentage of spilled oil which formed the surface slick were used for the lower bound. Since no estimate was available for the amount of oil which went ashore, this lower bound estimate assumed no beaching of o1l. A summation of the model predicted oil ashore and oil on the water surface falls close to the field-data best estimate.

Subsurface Elevated Hydrocabon Water Mass:

Figures 16A-E show the predicted spill trajectory and the predicted contours of a 50 parts per billion ( $\mathrm{ppb}$ ) hydrocarbon level in the top $10 \mathrm{~m}$ of water. The size of these areas and their geographic extent are both judged to be underestimated by this simulation because: 1) subsurface entrainment is judged to be underestimated for the two reasons cited above, and 2) the (U3) current field underlying the simulation underestimates the current speeds of the flows observed at the spill site (Attwood (Ed.), 1980) and in the southwestern Gulf of Mexico (de 1a Cerda, 1975). 


\section{3 (JUL IAN DAY)}

GROSE . C. BRWNS. W-3.5PC-5OPPB

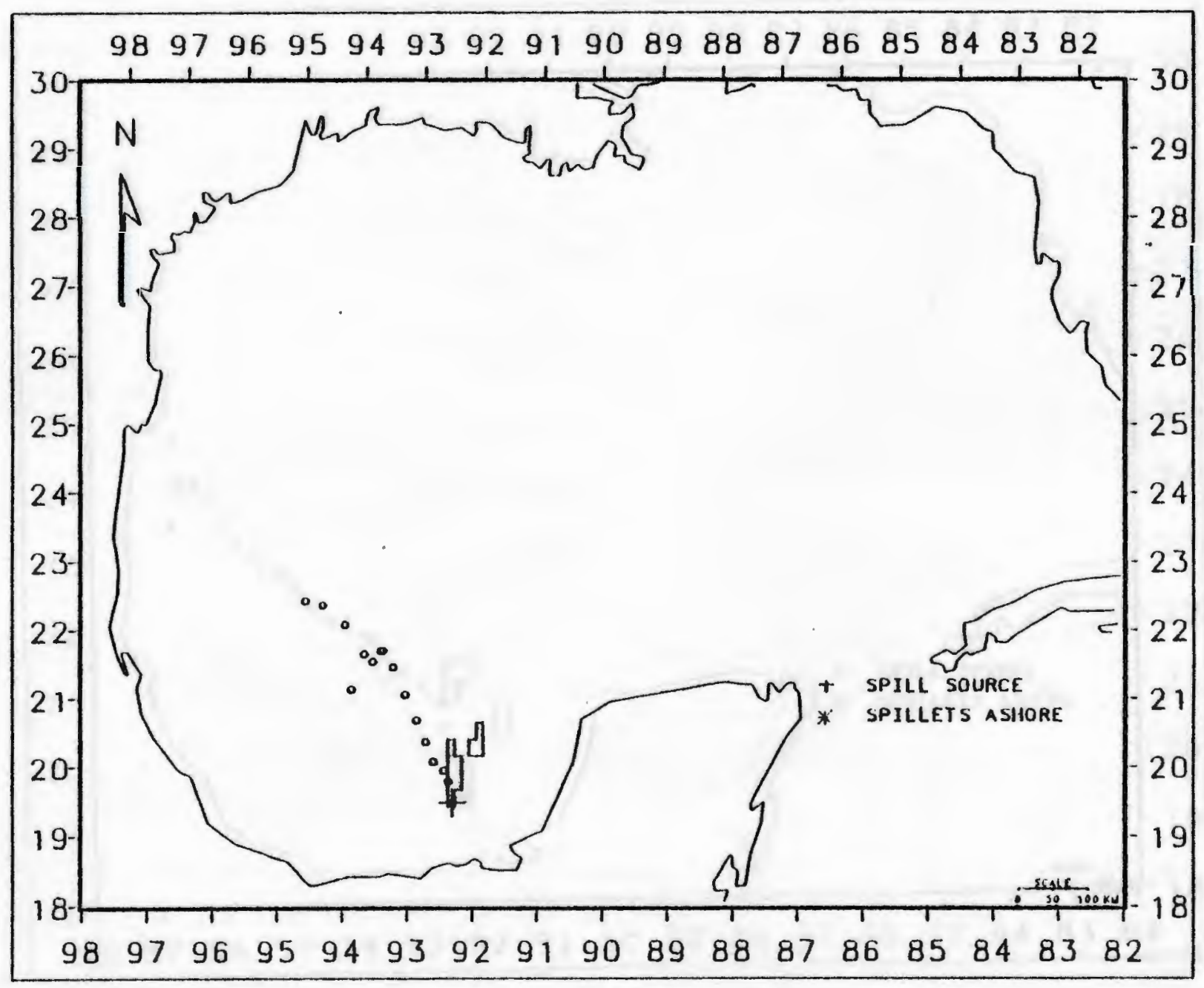




\section{3 (JULIAN DAY)}

GROSE . C. BRWNS W $W-3.5 P C-50 P P B$

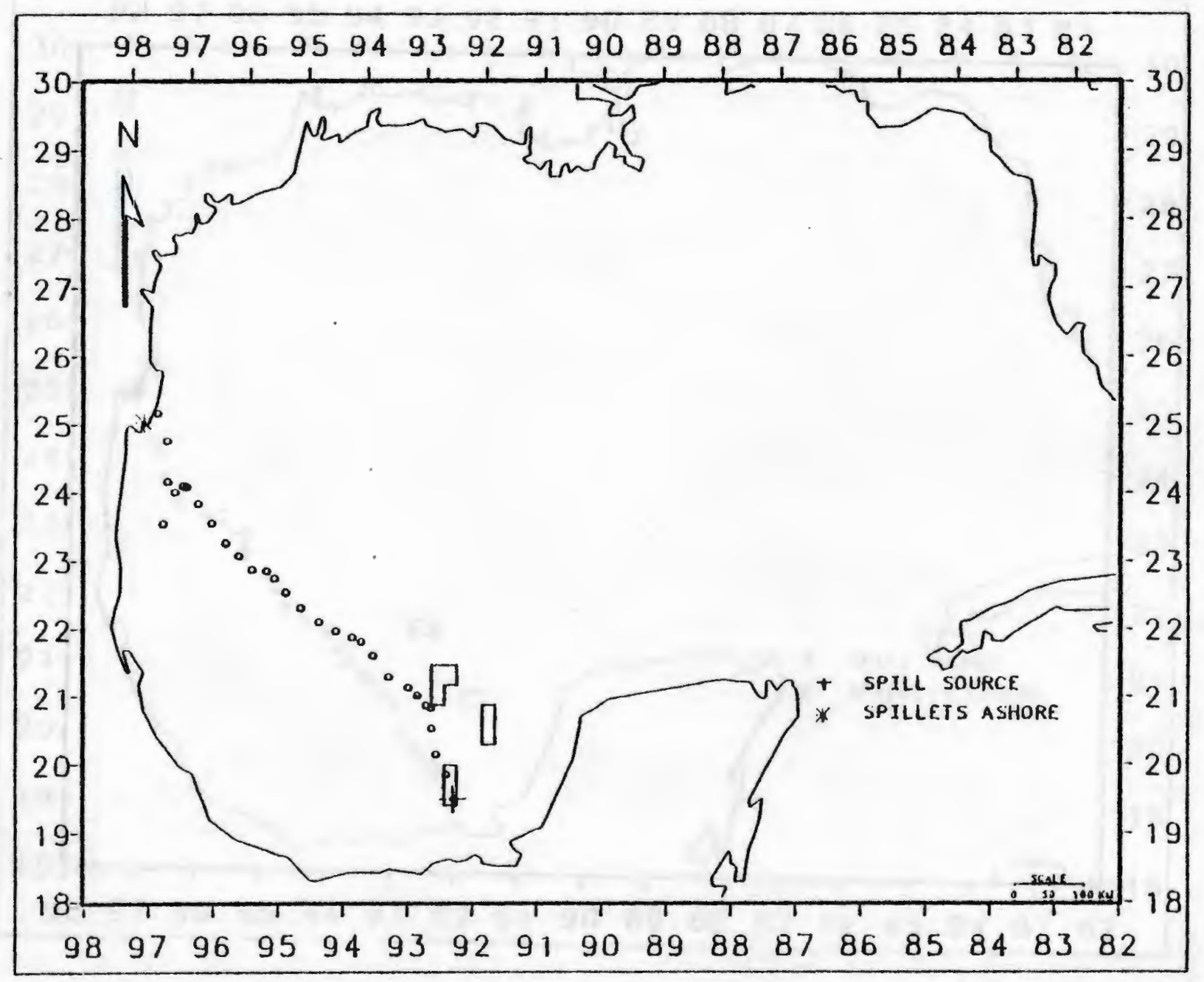

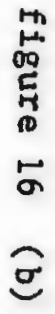




\section{3 (JULIAN DAY)}

GROSE . C. BRWNS. W-3. 5PC-5OPPB

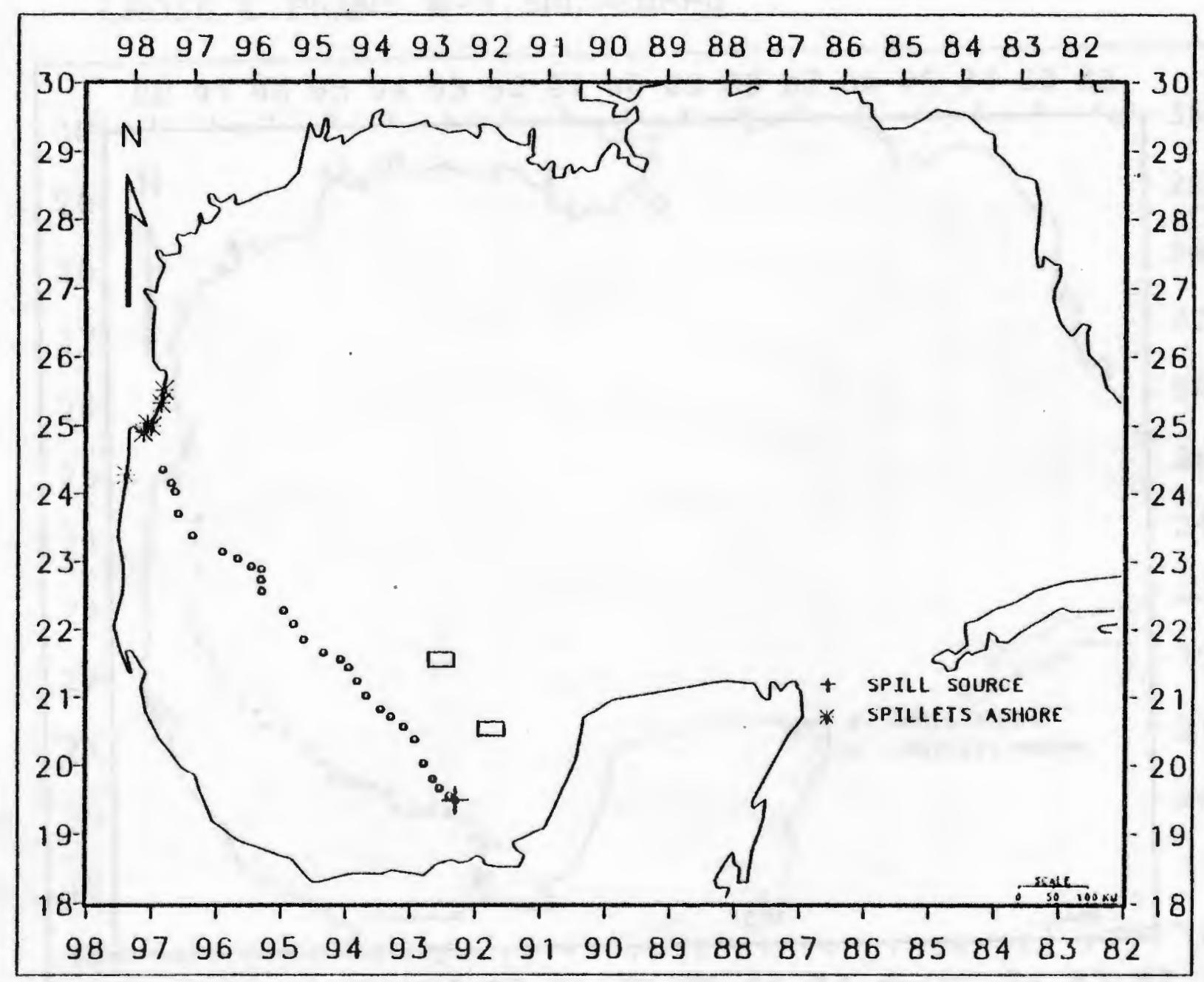




\section{3 (JULIAN DAY)}

GROSE . C. BRWNS. W-3. 5PC-5OPPB

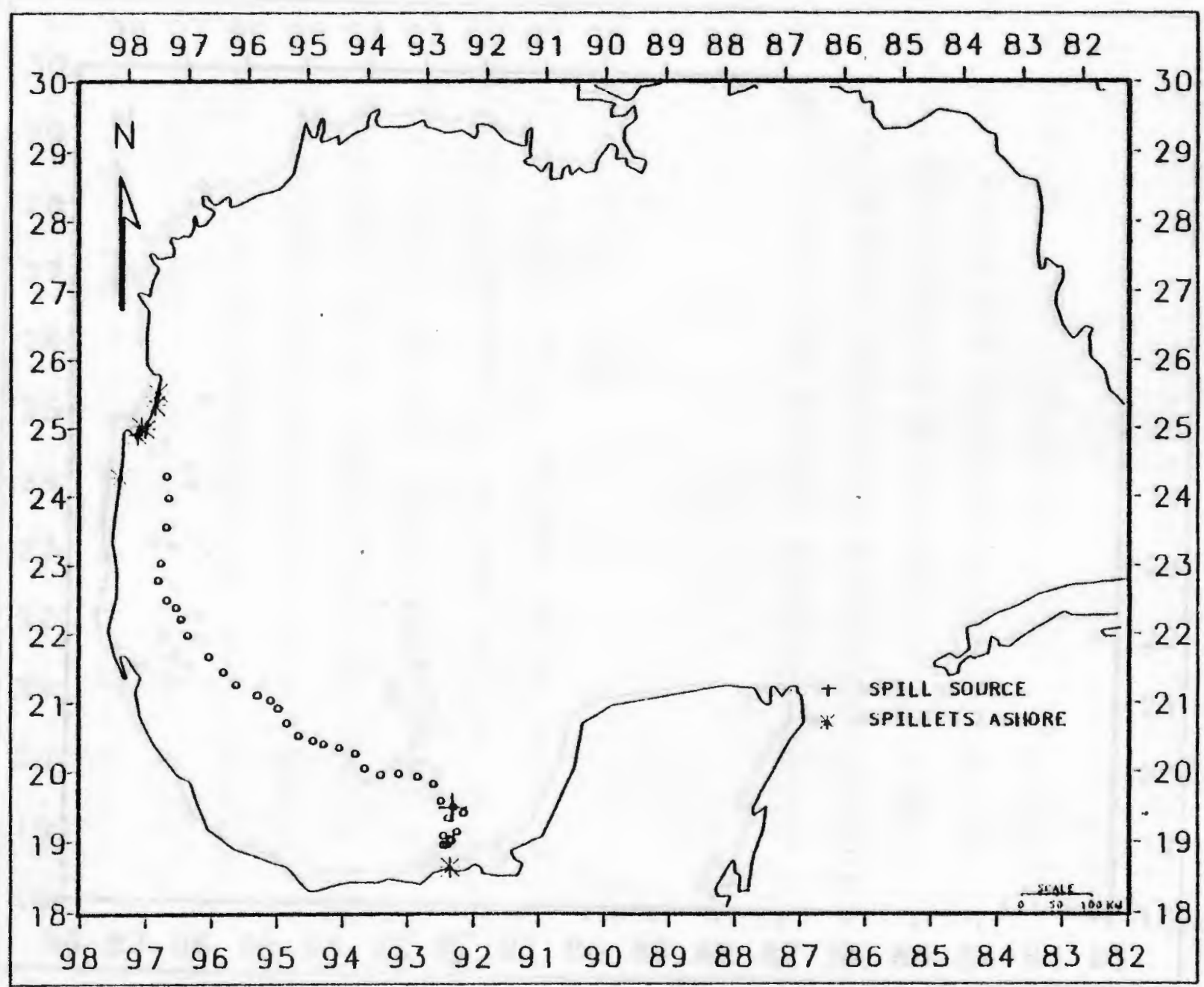




\section{1 (JULIAN DAY)}

GROSE C. BRWNS. W-3. 5PC $-50 P P B$

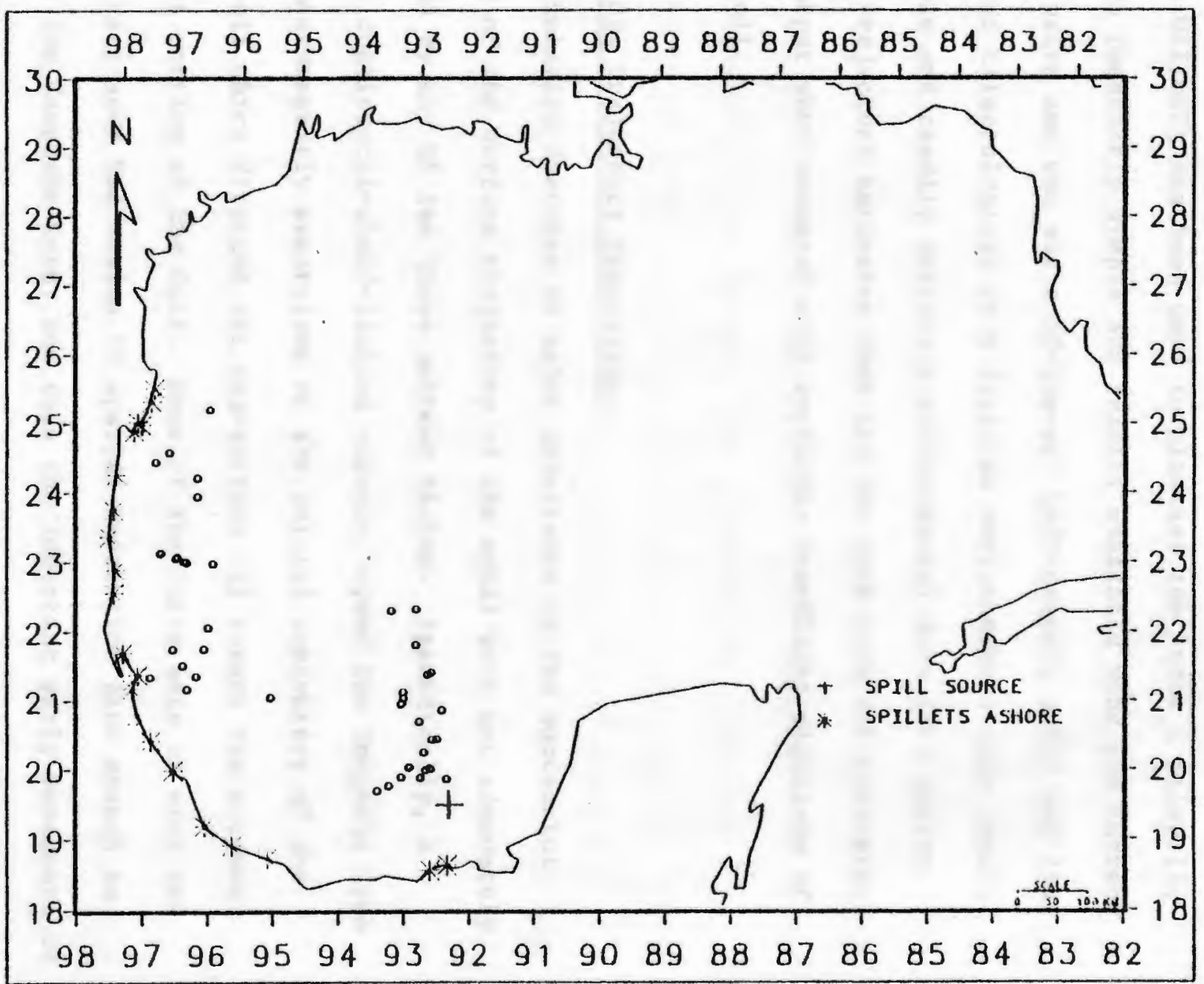


CHAPTER 6

Conclusions

The URI/OSFM has been used to hindcast the Ixtoc 1 oilspill, using two reasonably simple and readily available wind and current dataset pairs and one state-of-the-art hydrodynamic model and 1 ts associated climatological wind field as environmental data inputs. The simple and readily available environmental data gave better surface trajectory estimates than did the much more sophisticated model output when compared with avallable overflight sightings of surface oil.

Surface 011 Trajectory Simulation:

Circulation features of major importance to the successful modeling of the surface trajectory of the spill were not adequately described by any of the three current fields. Specifically, a cyclonic continental-shelf-limited current termed the Campeche Gyre caused southwesterly excursions of the initial trajectory of the spilled oil which directed the sea-surface oil toward the extreme southwest portion of the Gulf. None of the three sets of wind and current data used had scales of spatial resolution fine enough to describe the Campeche Gyre, and thus the important early movements of the spilled oil were incorrectly predicted. Because of the non-homogeneous spatial current field, small errors in the early stages of a trajectory simulation can lead to later errors of gross 
proportions.

The fact that the more simplistic environmental input datasets gave better trajectory simulations does not imply that the simpler approaches are better for use in equivalent ollspill trajectory simulations. Galt (1981) has demonstrated that successful trajectory modeling is achievable using a nested grid with a fine spatial mesh and coastal current observations taken in the field. The cost of the data-collection effort incorporated in the Galt (1981) modeling effort would be prohibitive for anything but a spill of the magnitude of the Ixtoc spill. The further development of coastal hydrodynamics modeling including finer spatial mesh grids and more complete specification of model boundary conditions with wind, density, and tidal forcing terms is the fundamental basis needed to improve ollspill trajectory formulations used in the modeling of coastal and continental shelf oil spills.

\section{Wind Data Collection:}

Underestimates of over-water wind speeds characterized the over-land collected wind data used in the simulations. An attempt to modify the land-collected wind data by the use of a statistical technique based on the monthly mean wind statistics of off-shore wind data gave reasonable wind speeds for only some of the months of the simulation. The monthly mean wind summaries for the Brownsville wind data were characteristically northerly and southerly for the winter months, while the buoy-collected wind data had a more equal 
distribution of wind directions around the compass.

Subsurface ofl:

Subsurface elevated hydrocarbon levels were predicted to exist near the spill source for the first two months of the spill. These predicitions were judged to be low estimates because: 1) low wind speeds from a land-collected wind record caused an underestimate in the wind-driven subsurface ofl entrainment; and 2) an overly simplistic ofl-ashore routine in the simulation trapped 100 percent of all ofl which touched shore onto the land, thus reducing the pool of oil on the sea surface available for sub-surface entrainment.

\section{Environmental Partitioning of 011 Mass Balance:}

Mass balance predictions for the model simulation were compared with estimates derived fom existing field data for a time 108 days after spill inception. Good agreement between the simulation atmosphere and water-surface predictions and field-data-based estimates was observed. 


\section{LITERATURE CITED}

Anonymous, 1975. TDF-14 Surface Observations, National Climatic Center, Asheville, NC 28801.

Anonymous, 1973. Atmospheric Program Descriptions, In: Navair 50-1G-522, pp. 4.1.1-4.1.8.

Atwood, D.K., J.A. Benjamin, and J.W. Farrington, 1980. The Mission of the September 1979 Research/Pierce Ixtoc-I Cruise and the Physical Situation Encountered. Proceedings of a Symposium on Preliminary Results from the September 1979 Researcher/Pierce IXTOC-1 Cruise.

Audunson, T., 1979. The Fate and Weathering of Surface 011 from the Bravo Blowout. Proceedings, 1979011 Spill Conference, Los Angelos, CA, March 19-22, 1979, sponsored by API, EPA, USCG.

Audunson, T., V. Dalen, and J.P. Mathisen. Slikforcast - A Simulation Program for 011 Spill Emergency Tracking and Long Term Contingency Planning.

Bakun, A., 1973. Coastal Upwelling Indices, West Coast of North America 1946-1971. NOAA Technical Report NMFS SSRF-671, Seattle, Washington, June 1973.

Beardsley, R.C. and W.C. Bolcourt, 1981. On Estuarine and Continental- Shelf Circulation in the Middle Atlantic Bight. Section 7, Warren and Wunsch (editors) 1981, pp.198-233.

Blumberg, A.F. and G.L. Mellor, 1981. A Numerical Calculation of the Circulation in the Gulf of Mexico. Report No. 66 prepared for the Division of Solar Technology, U.S. Dept. of Energy, by Dynalysis of Princeton, 159 p., January, 1981.

Boehm, P.D. and D.L. Fiest, 1980. Aspects of the Transport of Petroleum Hydrocarbons to the Offshore Benthos During the IXTOC-1 Blowout in the Bay of Campeche. Proceedings of a Symposium on Preliminary Results from the September 1979 Researcher/Pierce IXTOC-1 Cruise.

Boehm, P.D., D.L. Fiest, D. Mackay, S. Paterson, 1982.

Physical-chemical Weathering if Petroleum Hydrocarbons from the Ixtoc I Blowout: Chemical Measurements and a Weathering Model. Enviror. Sci. Technol. Vol. 16, No. 8, pp 498-504. August 1982 .

Brooks, J.M., D.A. Wiesenburg, R.A. Burke, Jr., M.C. Kennicutt 1981. Gaseous and Volatile Hydrocarbon Inputs from a Subsurface 011 Spill in the Gulf of Mexico. Environmental Science and Technology, Aug. 1981, Vol. 15, pp 951-959. 
Bumpus, D.F. and L.M. Lauzier, 1964. Surface Circulation on the Continental Shelf off Eastern North America Between Newfoundland and Florida. American Geophysic Soc., Serial Atlas of the Maine Environment, Folio 7, 4 p., 1965.

Capurro, L.R.A. and J.L. Reld (ed.) 1970. Contributions on the Physical Ocenography of the Gulf of Mexico. Gulf Publishing Co., Houston, Texas, 288 pp.

de la Cerda, A.M.V., 1975. Currents and Waters of the Upper 1200 Meters of the Southwestern Gulf of Mexico. M.S. Thesis, Texas A\&M University, Oceanography Department, August 1975.

Cornillon, F. and M. L. Spaulding. 1978. An $0 i 1$ Spill Fates Model. In: Environmental Assessment of Treated Versus Untreated $0 i 1$ Spills: Second Interim Progress Report, U.S.D.O.E. Contract No. E(11-1) 4047 .

Cornillon, P. and M. L. Spaulding. 1978. An 011 Spill Fates Model. Contract No. E(11-1) 4047, Department of Energy, Division of Environmental Control Technology.

Cornillon, P.C., M. L. Spaulding and K. Hansen. 1979. 011 Spill Treatment Strategy Modeling for Georges Bank. In: Proceedings of the 1979011 Spill Conference (API), pp. 685-692.

Fay, James, A., 1971. Physical Processes in the Spread of 0il on a Water Surface, In: Prevention and Control of 011 Spills, American Petroleum Institute, Washington, D.C., pp. 53-63.

Fiest, D.L. and P.D. Boehm, 1980. Subsurface Distributions of Petroleum from an Offshore Well Blowout - The IXTOC-1 Blowout, Bay of Campeche. Proceedings of a Symposium on Preliminary Results from the September 1979 Researcher/Pierce IXTOC-1 Cruise, December 1980.

Fischer, H.B., E.J. List, R.C.Y. Koh, J. Imberger, and N.H. Brooks, 1979. Mixing of Inland and Coastal Waters, Academic Press, $1979,483 \mathrm{p}$.

Garmon, L., 1980. Autopsy of an 011 Spill, Science News, Vol. 118, pp. 267-270, October 25, 1980 .

Galt, J.A., 1980. A Finite Element Solution Procedure for the Interpolation of Current Data in Complex Regions. J. of Phys. Oceanog., Bol 10, Dec. 1980, pp 1984-1997. 
Galt, J.A., 1981. Transport, D1stribution, and Physical

Characteristics of the 011. Section 2 of: The Ixtoc 1011

Sp111: The Federal Sclentific Response. National Oceanic and Atmospher1c Administration/Office of Marine Pollution

Assessment, December 1981.

Godshall, F.A. and R.G. Williams, J.M. Blshop, F. Everdale, S.W. Fehler, 1980. A Climatologic and Oceanographic Analysis of the Georges Bank Region of the Outer Continental Shelf. Final Report to the Bureau of Land Management, U.S. Department of the Interfor, 290 pp., September 1980.

Grose, P., F. Everdale, and L. Katz, 1982. Predicting the Surface Transport of 011 Pollutants in the Gulf of Mexico: First Results. Report prepared for: Office of Resource Coordination and Assessment, Offlce of Coastal Zone Management, National Oceanic and Atmospheric Administration, Washington, D.C. 20235, 18 pp., January 1982 .

Grose, P. and J. Mattson (ed1tors), 1977. The Argo Merchant 011 Sp111--A Preliminary Scientific Report. U.S. Department of Commerce, National Oceanic and Atmospheric Administration.

Gundlach, E.R., P.D. Boehm, M. Marchand, R.M. Atlas, D.M. Ward, D.A. Wolfe 1983. The Fate of Amoco Cadiz 0il. Science, Vol 221, 8 July 1983, pp 122-129.

Gundlach, E.R., K.J. Finkelstein, and J.L. Sadd 1981. Input and Persistence of Ixtoc $10 i 1$ on the South Texas Coast. Proceeaings, 1981011 Sp111 Conference, API, EPA, USCG, March, 1981, pp477-485.

Huang, J.C. F.C. Monastero 1982. Review of the Sate-of-the-Art of oil Spill Simulation Models. Final Report to the American Petroleum Institute, about 300 pp., June, 1982.

Kantha, L.H., A.F. Blanchard, H.J. Herring, G.L. Mellor 1981. The Physical Oceanongraph1c and Seasurface Flux Climatology of the South Atlantic Bight. An append1x to Dynalysis Report No. 70, as yet not released.

Ippen, A.T., 1966. Estuary and Coastline Hydrodynamics, McGraw-HilI, $1966,744 \mathrm{pp}$.

MaCaulay, M.C., K. Daly, and T.S. English, 1980. Acoust1c Observations of Biological Volume Scattering in the Vicinity of the IXTOC-1 Blowout, Proceedings of a Symposium on Preliminary Results from the Sept. 1979 Researcher/Pierce IXTOC-1 Cruise. 
Merrell, W.J., and J.M. Morrison, 1981. On th Circulation of the Western Gulf of Mexico with Observations from April 1978. J. of Geophysical Research, Vo1. 86 No. C5 pp. 4181-4185, May 20, 1981 .

Montgomery, R.B., 1954. Analysis of a Hugh M. Smith Oceanographic Section from Honolulu Southward Across the Equator. J. Marine Res. 13(1); 67-75.

Montgomery, R.B. and W.S. Wooster 1954. Thermosteric Anowaly and Analysis of Serial Oceanographic Data. Deep-Sea Res., 2; 63-70.

Mooers, C.N.K. 1978. Final Report, The Study of Atmospheric Forcing of Georges Bank, Appendix E of 8th Quarterly Progress Report, EG\&G Environmental Consultants, New England Outer Continental Shelf Physical Oeanography Program, October 1978.

Mooers, C.N.K., Fernandez-Partages, and J.F. Price, 1976. Meteorological Forcing Fields of the New York Bight (First Year's Progress Report). Technical Report, Rosensteil School of Miarine and Atmospheric Science, University of Miami, TR76-8, Miami, Florida, 15 pp.

Mooney, K.A., 1978. A Barotrophic Steady-State Numerical Model of the Circulation in the Gulf of Mexico. Ph.D. Thesis, University of Rhode Island, Graduate School of Oceanography.

Nath, J.H. and F.L. Ramsey, 1976. Probability Distributions of Breaking Wave Heights Emphasizing the Utilization of the JONSWAP Spectrum. Journal of Physical Oceanography (6) 316-323, May 1976.

National Data Buoy Center Monthly Wind Statsistc Summary Tables, 1979-1980. Mariners Weather Log, Vols 23(6) through 24(5), Nov. 1979 to Sept-Oct. 1980.

Neumann and Pierson, 1966. Principles of Physical Oceanography. Prentice-Hal1 Inc.

011 Spil1 Intelligence Report, 1979. Vo1. II, No. 23, 8 June. 1979.

011 Sp111 Intelligence Report, 1980a. Special Report: Ixtoc I, Vol. III, No. 1, 4 Jan. 1980.

Oil Spill Intelligence Report, 1980b. Vol. III, No. 5, 1 Feb. 1980.

Oil Spill Intelligence Report, 1980c. Vol. III, No. 7, 15 Feb. 1980. 
Oil Spil1 Intelligence Report, 1980d. Vol. III, No. 9, 29 Feb. 1980.

Oil Spill Intelligence Report, 1980e. Vol. III, No. 11, 14 March 1980.

Oil Spill Intelligence Report, 1980f. Vol. III, No. 12, 21 March 1980.

Oil Spill Intelligence Report, 1981. Vol. IV, No. 40, 16 Oct. 1981.

011 Spill Intelligence Report, 1983. Vol. VI, No. 22, 10 June 1983.

Okubo, A., 1971. Oceanic Diffusion Diagrams. Deep Sea Res. (8) 789-802.

Okubo, A., 1974. Some Speculations on Oceanic Diffusion Diagraris. Rapp. P.-v. Reun. Cons. int. Explot. Mer, 167: 77-85, pp 77-85. December, 1974.

Overton, Edward, 1981. Chemical Characterization of the 011. Section 3 from the National Oceanic and Atmospheric Administration Special Report. The Ixtoc 1 Spill: The Federal Scientific Response, 202 pp., December 1981.

Overton, E.B., J.R. DeLeon, and J.L. Laseter, 1982. Analysis of Polar Compounds in the Products of the Oxidative Weathering Process in IXTOC-I 011 and Selected Samples. Presented at the International Symposium IXTOC-1, Mexico City, June 1982.

Overton, E.B., L.V. NicCarthy, S.W. Mascare1la, M.A. Maberry, S.R. Antoine, J.L. Laseter, and J.W. Farrington, 1980. Detailed Chemical Analysis of Ixtoc 1 Crude 011 and Selected Environmental Samples from the Researcher and Pierce Cruises. Proceedings from Symposium on Preliminary Results from the September 1979 Researcher/Pierce Ixtoc 1 Cruise, p. 439-495, December 1980.

Pavish, D. 1977. A Three-Dimensional Numerical Model for Predicting Pollutant and Sediment Transport Using an Eulerian-Lagrangian Marker Particle Technique. MS Thesis, University of Rhode Island, Dept. of Ocean Engineering. 1977.

Petroleos Mexicanos, Gerencia de Desarrollo Petroquimico, 1980. Report on Work Performed to Control the Ixtoc-1 Well, to Control the $0 i 1$ Spill and to Determine Its Effects on the Marine Environment (translated by Ad-Ex for Exxon Production Research, Oct., 1980), Exxon P.0. No. 038585; Ad Ex job No. 56127. pp. 53-55d. 
Shuhy, Joseph 1979. U.S. Coast Guard officer attached to Campeche Oil Spill on Scene Coordinator, U.S. Coast Guard, P.O. Box 1621, Corpus Christi, TX. Supplied flight logs and charts from oilspill overflights for selected dates during the interval 13 August 1979 to 4 September 1979.

Spaulding, M.L., K.B. Jayko, and E.L. Anderson, 1982a. Hindcast of the Argo Merchant Spill Using the URI Oil Spill Fates Model. Accepted for publication.

Spaulding, M.L., S.B. Saila, C. Griscom, M. Reed, E. Lorda, H. Walker, C. Swanson, T. Isaji, E. Anderson, V. Pigoga, K. Marti, C. Jones, R. Glazman, F. White Assessing the Impact of Oil Spills on a Commercial Fishery, 1982b. Final Report to U.S. Department of Interior N.Y. Outer Continental Shelf office, July 1982; November 1982 .

Spill Technology Newsletter, 1979. Vol. 4(4), July - August 1979.

Stolzenbach, K.D., O.S. Madsen, E.E. Adams, A.M. Pollack, and C.K. Cooper, 1977. A Review and Evaluation of Basic Techniques for Predicting the Behavior of Surface Oil slicks. Massachusetts Institute of Technology Sea Grant Report No. 77-8.

Sturges, W. and J.P. Blaha, 1976. A Western Boundary Current in the Gulf of Mexico. Science, Vol 192, 23 April 1976, pp 367-369.

Tophan, D.R., 1975. Hydrodynamics of an Oil Well Blowout. Beaufort Sea Project Technnical Report 33, Dec., 1975. 52pp.

Topham, D.R., 1975. Hydrodynamics of an 01lwell Blowout, Beaufort Sea Technical Report \#33, Beaufort Sea Project, Dept. of the Enviromment, Canada.

Torgrimsen, Gary M., 1979. A Comprehensive Model for 011 Spill Simulation. Preprint. Address: Modeling and Simulation Studies, Special Projects, National Oceanic and Atmospheric Administration, Seattle, Washington, 98115.

U.S. Dept. of Commerce, NOAA, 1980. Proceedings of a Symposium on Preliminary Results from the September 1979 Researcher/Pierce Ixtoc-1 Cruise, December 1980. 591 pp.

U.S. Dept. of Transportation, United States Coast Guard 1980 . Report of Ixtoc I, Bay of Campeche Oil Spill. December 1980.

Warren, B.A. and C. Wunsch (editors), 1981. Evolution of Physical Oceanography, MIT press, $620 \mathrm{pp}$. 
Weisberg, R.H. and L.J. Pietrafesa, 1983. Kinematics and Correlation of the Surface Wind Field in the South Atlantic Bight. J. Geophys. Res., Vo1 88, No. C8, pp 4593-4610, May 30, 1983.

Wendell, L.L., 1972. Mesoscale Wind Fields and Transport Estimates Determined from a Network of Wind Towers. Monthly Weather Review 100(7): 565-578, 1972 .

Williams, R.G. and F.A. Godshall (editors), 1977. A Wind Estimation Proceedure, Appendix A of Sumarization of Interpretation of Historical Physical Oceanographic and Meterological Information for the Mid-Atlantic Region, Final Report to the Bureau of Land Management, U.S. Dept. of the Interior, by NOAA EDIS Center for Experimental Design and Data Analysis. Oct. 1977.

Wu, J. 1969. Wind Stress and Surface Roughness of the Air-Sea Interface. Journal of Geophysical Res. Vol. 74, No. 2, pp. 444-454.

Yalin, M.S., 1972. Mechanics of Sediment Transport. Chapter 6, Pergamon Press, Oxford.

Yang, W.C. and H. Wang, 1976. Modeling of 011 Evaporation in an Aqueous Environment. Ocean Englneering Report No. 7, Dept. of Civil Engineering, Univ. of Delaware, p. 38. June, 1976 